\title{
Comprehensive Management and Modeling of Water Quantities: Utilizing an Existing Watershed Model for Comprehensive Water Management and Planning, and Optimal Design of Outlet Control Structures for Ecological Detention Ponds
}

\begin{tabular}{c} 
A Dissertation \\
Presented to \\
the Faculty of the School of Engineering and Applied Sciences \\
University of Virginia \\
\hline
\end{tabular}

In Partial Fulfillment

of the Requirements for the Degree

Doctor of Philosophy

in

Civil Engineering

by

John Thomas Mobley Jr

May 2012 


\section{APPROVAL SHEET}

This dissertation is submitted in partial fulfillment of the requirements for the degree of

Doctor of Philosophy in Civil Engineering

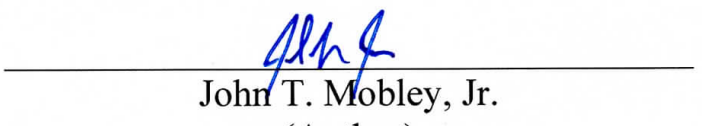

(Author)

This dissertation has been read and approved by the examining committee:

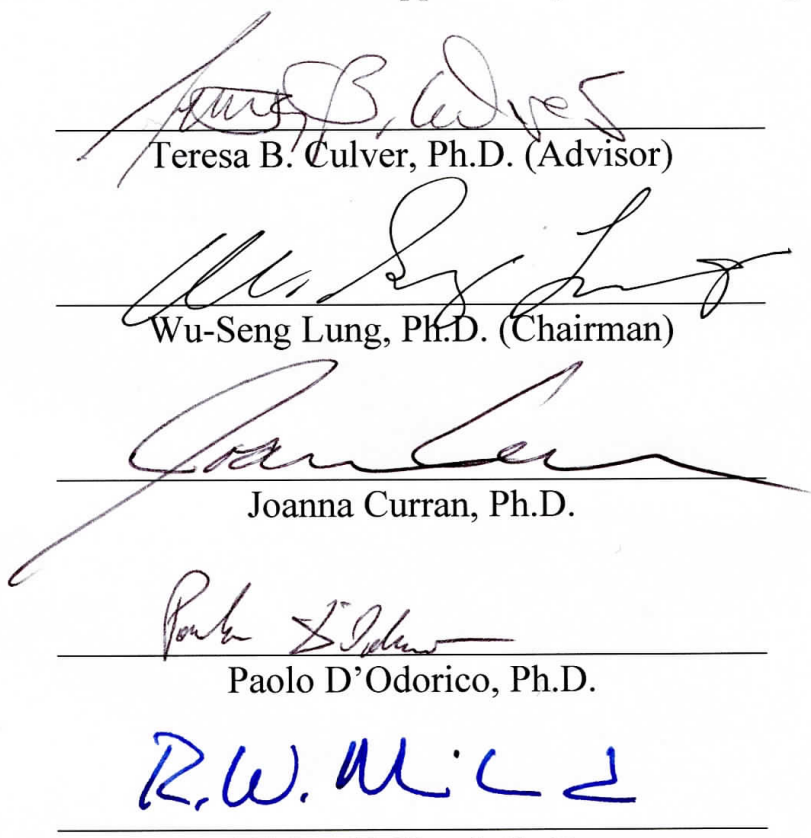

Richard Miksad, Sc.D.

Accepted for the School of Engineering and Applied Science

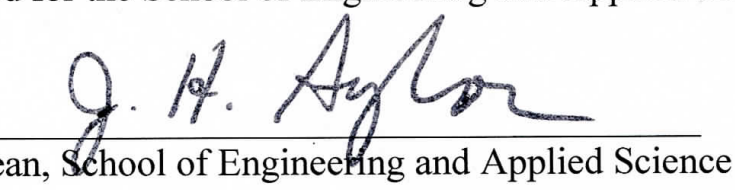

May 2012 


\begin{abstract}
This dissertation research has three primary objectives. Firstly, this work examines the use of a statistical flow methodology for characterizing ecologically important stream flows, the Indicators of Hydrologic Alteration (IHA), as a means to evaluate hydrologic model performance. Typically, IHA has been used to identify the extent of human impacts on a stream's hydrology and to set management goals to restore the stream ecology. In this work, the use of the seven "extreme low flow" statistics of IHA is extended to the evaluation of the performance of a hydrologic simulation model under low flow conditions. Specifically, this work uses the IHA framework to evaluate the accuracy of the Chesapeake Bay Program Phase 5 (CBP5) watershed model during low flow events on a regional scale that is relevant to many water supply planners and managers. Because the CBP5 model's primary focus is predicting the Bay's water quality, the measures used to calibrate the CBP5 model focused primarily on the calibration of the entire hydrological record and had only secondary emphasis on specific flow regimes, such as low flows and very low flows, although these flows are important for both stream ecologies and water supply planners. To provide a comparative performance benchmark, the performance of the simple Drainage Area Ratio (DAR) method relative to the IHA low flow statistics is also determined. This work demonstrates the use of IHA statistics for model evaluation in a case study, the Rivanna River watershed, a central Virginia subcatchment within the Chesapeake Bay drainage. For rivers with a large proportion of unregulated flow contributions, it is concluded that the computationally simple DAR model with appropriate surrogate watershed generally characterizes the extreme low flow conditions slightly more accurately than the CBP5 model. However, unlike the CBP5
\end{abstract}


model, the DAR model predicts future flows based solely on historical data, and thus the DAR model cannot predict flow impacts caused by hydrological alterations, thus limiting its use in water supply management. Nevertheless, this analysis suggests that incorporation of a low-flow-specific metric into the CBP5 calibration could improve its utility for water supply management and planning at a regional scale.

Secondly, this work develops and demonstrates a methodology to specifically assess the inter-relationships between estimated precipitation, observed stream flow, and hydrologic model performance. To satisfy this objective, this work introduces a new concept called 'precipitation fidelity,' which is the correspondence of stream outflow to the estimated precipitation used as input into a hydrologic model. Simple annual and daily precipitation fidelity indices are defined. The use of the precipitation fidelity indices is then demonstrated for the Rivanna Watershed as modeled using the CBP5 model and the associated precipitation input data set. The precipitation fidelity results are used in conjunction with model output to identify the effect of precipitation estimation accuracy on model performance at both long time scale and short time scales. Based on the daily precipitation fidelity measure, in the headwater watersheds, about a quarter of the days lack fidelity between the precipitation input and the observed stream flows. Days when the estimated input precipitation has runoff-generating rainfall, but the observed stream discharge does not increase, have the highest average relative daily modeling errors and high area-weighted daily modeling errors. These results indicate that precipitation needs to be better represented in the headwater subwatersheds. Regression analysis using the Analysis of Covariance method was used to determine statistical similarity between annual estimated precipitation and observed and modeled stream flows. Regression 
results suggested that direct hydrology calibration of the subwatershed of interest leads to both a higher level of correspondence between estimated precipitation and modeled flows and an acceptable 'goodness of fit' between the modeled and observed data.

Lastly, this work employs a novel simulation-optimization modeling approach to modify the design of detention ponds to preserve the natural ecological flows, while satisfying the requisite regulatory flow requirements. This work utilizes an innovative ecological flow paradigm: the eco-flow statistics. The eco-flow statistics consist of nine hydrological flow statistics that have been shown to be particularly relevant to ecological quality. The statistics include annual and seasonal ecodeficits and ecosurplus, calculated using median annual and seasonal functional duration curves, and the total seasonal ecochange. A new metric called the 'ecodifference' is defined as the weighted sum of the nine eco-flow statistics and represents the hydrologic alteration in the stream. The ecodifference in a receiving stream can be calculated using the outflow hydrograph from a detention pond hydrologic simulator. First, a design approach- using a hydrologic model, detention pond model, and the ecodifference metric- is used to design a series of flow controls in a detention pond outlet control structure that reduces the ecological impact to the stream caused by development, while meeting current design regulations. Then, a simulation-optimization strategy that incorporates a genetic algorithm with the design approach is introduced to design an outlet control structure that best minimizes the ecological impact to the stream. For a case study site, optimized designs have demonstrated that improvements in ecological flows can be achieved while meeting design regulations. By introducing this approach for eco-detention ponds, and then 
demonstrating its performance, this work has potential to impact stormwater management design practice. 
TABLE OF CONTENTS

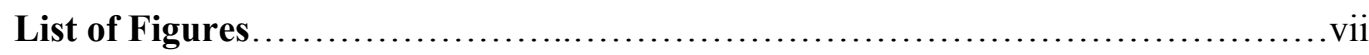

List of Tables ........................................................... vii

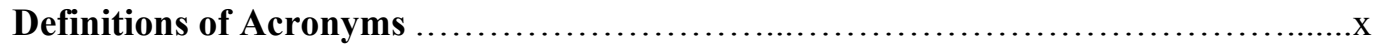

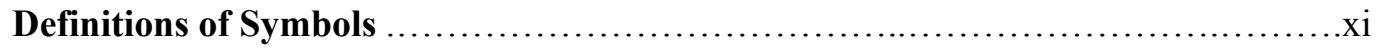

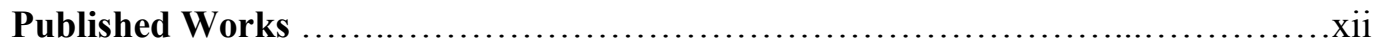

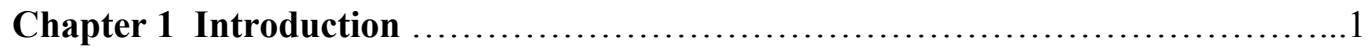

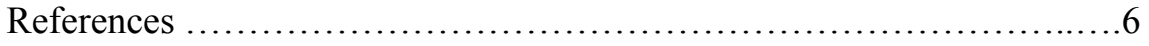

Chapter 2 Environmental flow components for measuring hydrologic model fit in

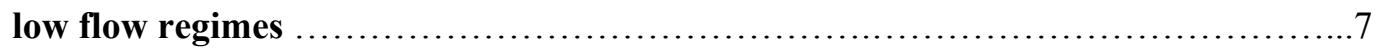

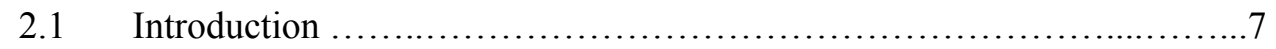

2.2 IHA Methodology and Environmental Flow Components ................10

2.3 Chesapeake Bay Program Phase 5 Model .............................12

$2.4 \quad$ Drainage Area Ratio Method .......................................14

$2.5 \quad$ Hydrologic Model Calibration ........................................15

2.6 CBP5 Watershed Model Calibration ................................18

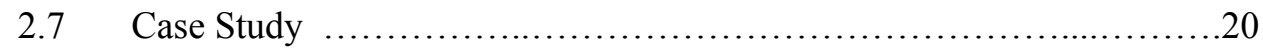

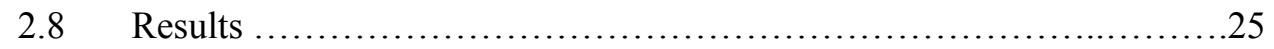

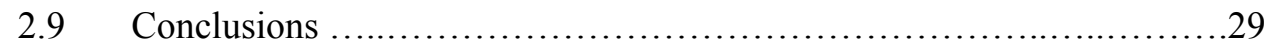

2.10 References .....................................................

Chapter 3 Understanding Precipitation Fidelity in Hydrological Modeling ...........37

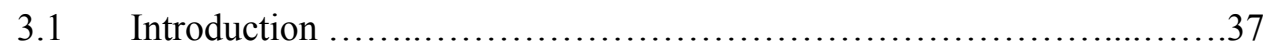

3.2 Precipitation in the CBP5 Watershed Model ..........................40

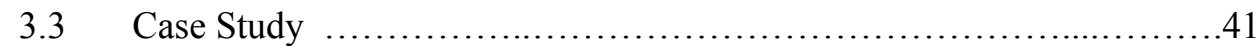

$3.4 \quad$ Precipitation Fidelity .............................................43

3.5 Daily Precipitation Fidelity .....................................44

3.5.1 Method ...............................................44

3.5.1.1 Time of Concentration ..............................47

3.5.1.2 Initial Abstraction ...................................47

3.5.2 Results ..............................................48

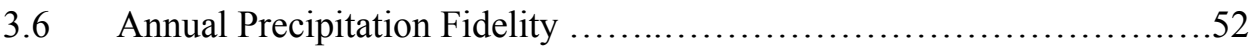




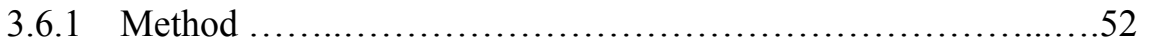

3.6.2 Results ...............................................53

3.7 Conclusions......................................................

$3.8 \quad$ References ..................................................61

Chapter 4 Design of Outlet Control Structures for Ecological Detention

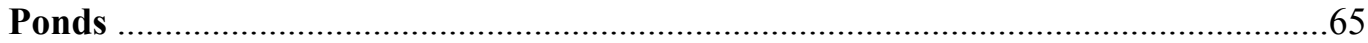

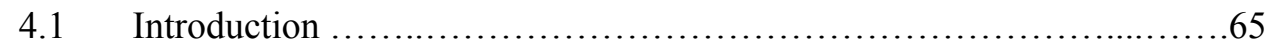

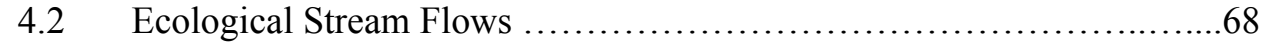

4.3 Flow Duration Curves, Eco-Flow Statistics, and Ecodifference Metric ...69

$4.4 \quad$ Ecological Detention Pond Design Approach .............................74

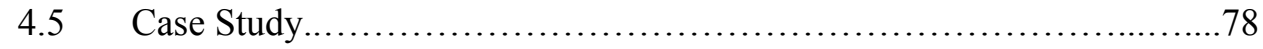

$4.6 \quad$ Method........................................................... 79

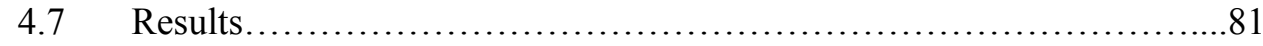

$4.8 \quad$ Conclusions...................................................... 85

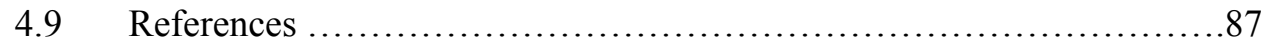

Chapter 5 Simulation-Optimization Approach for the Design of Outlet Control

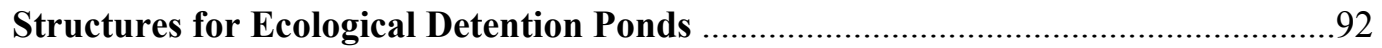

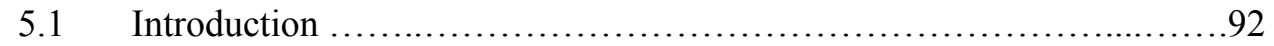

5.2 Simulation-Optimization Methodology for OCS Design ..................93

$5.3 \quad$ Illustrative Case Study .............................................

$5.4 \quad$ Results.......................................................... 100

$5.5 \quad$ Conclusions...................................................107

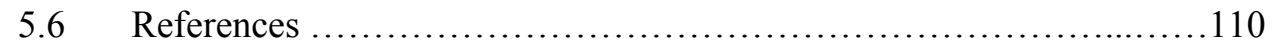

Chapter 6 General Conclusions and Recommendations for Future Work ..........111

$6.1 \quad$ Conclusions...................................................111

6.2 On-going and Future Research .....................................113

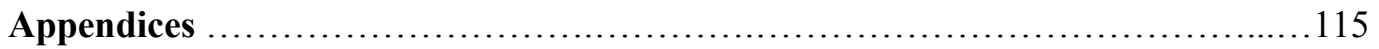




\section{LIST OF FIGURES}

Figure 2.1. Mechums, Moormans, North Fork Rivanna, and Rivanna subwatersheds in the CBP5 model, and USGS stream gages

Figure 2.2. Discharge values for four subwatersheds, (a) Mechums, (b) Moormans, (c) N.F. Rivanna, (d) Rivanna

Figure 2.3. ELF Duration values for four subwatersheds

Figure 2.4. ELF Frequency values for four subwatersheds

Figure 2.5. ELF Timing values for four subwatersheds

Figure 3.1. Determination of initial abstraction $\left(\mathrm{I}_{\mathrm{a}}\right)$ for four Rivanna subwatersheds

Figure 3.2. Annual Precipitation-Streamflow Regression data and trendlines for four Rivanna subwatersheds ((a) Mechums, (b) Moormans, (c) North Fork Rivanna, and (d) Rivanna)

Figure 3.3. Annual Precipitation Fidelity Index and model performance (MAAVE) for four Rivanna subwatersheds

Figure 4.1. Areas of ecodeficit and ecosurplus between pre-development and postdevelopment median flow duration curves of a receiving stream

Figure 4.2. Storm water detention pond and outlet control structure

Figure 4.3. Annual and Seasonal Functional Duration Curves for pre-development and post-development scenarios: (a) Annual; (b) Winter; (c) Spring; (d) Summer

Figure 5.1. Flowchart representing simulation-optimization methodology

Figure 5.2. Representative convergence of the genetic algorithm, showing the mean and best fitness value (ecodifference) identified per generation versus the number of generations. Results are for one trial with four openings and weighting combination A

Figure 5.3. Conventional OCS Design

Figure 5.4. Optimized Ecological OCS Design with two openings and under weighting combination A 


\section{LIST OF TABLES}

Table 2.1. Extreme Low Flow statistics and methods of comparison

Table 2.2. Calibration measures employed in CBP5 model internal calibration routine

Table 2.3. Available Stream Flow Data and Overlap with CBP5 model period

Table 2.4. Comparison of the mean volumetric errors of the CBP5 model for entire simulation period, 1986-2005, by Rivanna subwatershed

Table 3.1. CBP5 model performance (volumetric errors) for the simulation period 19862005, by Rivanna subwatershed

Table 3.2. Daily Precipitation Fidelity Combinations

Table 3.3. Percentage of days with each QP combination for overlap periods, by subwatershed

Table 3.4. Mean Daily Absolute Relative Volumetric Percentage Error (\%) corresponding to each QP combination in Table 4, by subwatershed

Table 3.5. Mean Daily Absolute Area-scaled Volumetric Error $\left(\mathrm{m}^{3} / \mathrm{hr} / \mathrm{km}^{2}\right)$ corresponding to each QP combination in Table 4, by subwatershed

Table 3.6. Regression equations and associated $\mathrm{r}^{2}$ values between estimated annual precipitation $(\mathrm{cm} / \mathrm{yr})$ and mean daily area-scaled streamflow $\left(\mathrm{Q}_{\mathrm{d}}, \mathrm{m}^{3} / \mathrm{hr} / \mathrm{km}^{2}\right)$, based on CBP5 (MOD) or observed USGS gage data (OBS)

Table 3.7. Two-tailed probability values (P-values) for four Rivanna subwatersheds. Statistical difference with a 95\%-confidence level requires P-value $\leq .05$

Table 4.1. Weighting coefficient assignments for four Weighting Coefficient Combinations

Table 4.2. Characteristics of the conventional detention pond's Outlet Control Structure

Table 4.3. Characteristics of the eco-detention pond's Outlet Control Structure

Table 4.4. Event Simulation Results

Table 4.5. Values of nine eco-flow statistics using continuous simulation results

Table 4.6. Values of ecodifference for four weighting combination

Table 5.1. Parameter Settings for Genetic Algorithm 
Table 5.2. Values of nine eco-flow statistics when optimized individually; four-opening OCS

Table 5.3. Minimum ecodifference and corresponding EPR values for four weighting combinations (A-D)

Table 5.4. Minimum ecodifference and corresponding EPR values for four weighting combinations under three violation conditions; four-opening OCS 


\section{DEFINITIONS OF ACRONYMS}

ALGA - Augmented Lagrangian Genetic Algorithm

ANCOVA - Analysis of Covariance method

Annual PFI - Annual Precipitation Fidelity Index

BMP - Best Management Practice

CBP - Chesapeake Bay Program

CBP5 - Chesapeake Bay Program Phase 5 watershed model

CWP - Center for Watershed Protection

Daily PFI - Daily Precipitation Fidelity Index

DAR - Drainage Area Ratio method

EFCs - Environmental Flow Components

ELF - extreme low flow

EPR - ecodifference Percent Reduction

FDC - flow duration curve

GA - Genetic Algorithm

HSPExp - HSPF Expert calibration software

HSPF - Hydrological Simulation Program-Fortran

IHA - Indicators of Hydrologic Alteration

MAAVE - mean annual absolute volumetric error

MDAAVE $E_{Q P}$ - mean daily absolute area-scaled volumetric error for combination QP

MDARVE - mean daily absolute relative volumetric error

MDARVE $E_{\mathrm{QP}}$ - mean daily absolute relative volumetric error for combination QP

MDE - Maryland Department of the Environment

MOD - estimated precipitation-to-model stream flow regression

NCDC - National Climatic Data Center

NWIS - National Water Information System

OBS - estimated precipitation-to-observed stream flow regression

OCS - outlet control structure

PEST - Parameter ESTimation software

PVE - Simulation period volumetric error

RRBC - Rivanna River Basin Commission

RVA - Range of Variability Approach

RWSA - Rivanna Water and Sewer Authority

STAC - Chesapeake Bay Program Scientific and Technical Advisory Committee

SWMM - United States Environmental Protection Agency Storm Water Management Model

TMDL - Total Maximum Daily Load

TNC - The Nature Conservancy

UDFCD - Denver Urban Drainage and Flood Control District

USBR - United States Bureau of Reclamation

USEPA - United States Environmental Protection Agency

USGS - United States Geological Survey

VADCR - Virginia Department of Conservation and Recreation

VADEQ - Virginia Department of Environmental Quality

WQCV - water quality capture volume 


\section{DEFINITIONS OF SYMBOLS}

1Q1 - 1-day annual minimum discharge, the lowest one-day discharge in a water year

3Q1 - the 3-day annual minimum discharge, the lowest 3-day mean daily discharge in a water year

7Q1 - the 7-day annual minimum discharge, the lowest 7-day mean daily discharge in a water year

7Q10 - the lowest 7-day-average flow that occurs, on average, once every ten years

$A$ - subwatershed area

$\mathrm{D}$ - vector of opening characteristics $\mathrm{D}_{\mathrm{k}}$ allocated to each rectangular outlet control device (k), consisting of height, width, and invert elevation

ecodifference $_{\text {conv }}$ - ecodifference for the conventional detention pond design

ecodifference $_{\text {eco }}$ - ecodifference for the ecological detention pond design

ecodifference(D) - ecodifference resulting from an OCS with openings described by D

$\mathrm{E}_{\mathrm{f}}$ - Nash-Sutcliffe efficiency index

$\mathrm{k}$ - single outlet control device

$\mathrm{I}_{\mathrm{a}}$ - initial abstraction

$\mathrm{j}$ - design criteria (peak flows of various return periods, etc.)

$\mathrm{L}_{\mathrm{k}}$ - lower bound on the on the height, width, and invert elevation that can serve for outlet control k

$\mathrm{m}$ - number of years in simulation period

$\mathrm{n}$ - number of days in simulation period

$n$ - sample size

$n_{Q P}$ - number of days in the analysis period with combination QP

$\mathrm{P}$ - daily precipitation indicator

$\mathrm{Q}$ - daily flow indicator

$\mathrm{Q}_{\mathrm{E}}$ - ELF minimum flow, the mean of all the ELF event minimum daily flows in a given water year

$\mathrm{Q}_{\mathrm{t}, \mathrm{mod}}$ - simulated mean stream flow on day $\mathrm{t}$

$\mathrm{Q}_{\mathrm{t}, \mathrm{obs}}$ - observed mean stream flow on day $\mathrm{t}$

$\mathrm{r}^{2}$ or $\mathrm{R}^{2}$ - coefficient of determination

$\mathrm{s}$ - number of days in simulation year

$\mathrm{S}_{\mathrm{i}}$ - value of one of the nine eco-flow statistics

$t_{c}$ - time of concentration

$\mathrm{T}_{\mathrm{R}}$ - return period

$\mathrm{T}_{\mathrm{WQ}}$ - water quality control volume release times

$\mathrm{U}_{\mathrm{k}}$ - upper bound on the height, width, and invert elevation that can serve for outlet control k

$\mathrm{w}_{\mathrm{j}}\left(\mathrm{V}_{\mathrm{j}}\right)$ - weighted violation of design criteria $\mathrm{j}$

$\mathrm{W}_{\mathrm{i}}$ - weighting coefficient of one of the nine eco-flow statistics

$\mathrm{x}$ - observed flow at the watershed with drainage area $A_{x}$

$\mathrm{y}$ - modeled flow at the target watershed with drainage area $\mathrm{A}_{\mathrm{y}}$

$Y_{i}$ - measured value of the criterion (dependent) variable $Y$

$\hat{Y}_{i}$ - predicted value of the criterion (dependent) variable $Y$

$\bar{Y}$ - mean of the measured values of $Y$ 


\section{PUBLISHED WORKS}

The following are refereed papers based on the work in this dissertation:

Mobley, J.T., Culver, T.B., and Burgholzer, R. (2012). "Environmental Flow

Components for Measuring Hydrologic Model Fit during Low Flow Events.” J. Hydrologic Engrg., doi:10.1061/(ASCE)HE.1943-5584.0000575.

Mobley, J.T., Culver, T.B., and Burgholzer, R. (2012). "Understanding Precipitation Fidelity in Hydrological Modeling." J. Hydrologic Engrg., doi:10.1061/(ASCE)HE.1943-5584.0000588.

Mobley, J.T., and Culver, T.B. (in review). "Design of Outlet Control Structures for Ecological Detention Ponds." J. Water Res. Plnng. Mngmt.

The following is a poster presentation based on the work in this dissertation:

Mobley, J.T., and Culver, T.B. (2012). "Design of Outlet Control Structures for Ecological Detention Ponds." Proceedings of the Environmental and Water Resources Institute Congress, May 20-24, ASCE, Albuquerque, NM.

The following is a conference paper partially based on the work in this dissertation:

Mobley, J.T., Culver, T.B., and Burgholzer, R. (2010). "Evaluation of the Importance of Reservoir Rule-based Modeling toward Improving the Accuracy of the Commonwealth of Virginia's Surface Water Model." Proceedings of the Environmental and Water Resources Institute Congress, May 16-20, ASCE, Providence, RI. 


\section{Chapter 1}

\section{Introduction}

Hydrologic scientists and engineers now recognize that natural systems (rivers, lakes, estuaries, landscapes, ecosystems, etc.), the built environment, water supply, and water quality are intrinsically connected. As this recognition grows, engineers and managers are being challenged to apply comprehensive planning strategies that sustain riverine species and maintain essential ecosystem processes while meeting human water supply needs (Mathews and Richter 2007). This "comprehensive" approach to water resources management and modeling must be applied at both regional/state scales and local/neighborhood scales for the most effective results.

At the regional/state scale, "community" watershed models - resulting from the collaboration between various public and private organizations working towards similar goals - are being used more frequently for both short-term and extended planning and permitting. Many community models also provide output that is relevant to the ecological health of the watersheds and streams. One example of such a comprehensive community watershed model is the Chesapeake Bay Program Phase 5 (CBP5) watershed model. The 
hydrologic simulation capabilities of the CBP5 watershed model present a robust platform with the potential to address water resources and Total Maximum Daily Load studies at the local scale in addition to its present function as a large-scale (multi-state) water quality model (STAC 2006). Given the potential benefits of the CBP5 model in water planning and permitting, the Virginia Department of Environmental Quality (VaDEQ) - which has oversight on water resource management throughout the state - is presently exploring the use of the CBP5 model for comprehensive water supply planning and management. However, before employing the model for these purposes, water managers (such as those at the $\mathrm{VaDEQ}$ ) must assess the quality of the simulation for each model application and, when possible, take steps to improve the accuracy of their simulations. This includes evaluation of model performance in different flow regimes (and specifically low flow regimes for water supply planning), as well as the assessment of input quality (primarily precipitation).

At the local/neighborhood scale, a comprehensive approach to water resources management can be achieved through the use of Best Management Practices (BMPs), techniques, measures, structural controls, or policies that are used to prevent or reduce the degradation of runoff water quantity and quality (USEPA 1991; Urbonas and Stahre 1993; USEPA 2004) and which are often used to mimic natural hydrological processes of a stream network (Villarreal et al. 2004). Site development designs often incorporate BMPs to meet various stormwater criteria, such as providing a water quality storage volume, a recharge volume, channel protection storage volumes, and flood protection; however, ecological protection is not an explicit criterion in most municipality BMP design methodologies. A comprehensive approach to water resources management at the 
neighborhood scale requires the incorporation of ecological sustainability measures into BMP design practice.

The goals of this thesis, while addressing three distinct water resources subjects, have the unified purpose of exploring the management and modeling of water quantities using a comprehensive water resources perspective.

The first goal of this thesis is to evaluate the potential advantages, limitations, and necessary adaptations of an existing community watershed model for use as a comprehensive state-wide water planning and management tool. Preliminary results for a case study watershed within the CBP5 model domain showed that calibrated subwatersheds exhibit high accuracy at the entire period scale, acceptable accuracy at the annual scale, yet relatively low accuracy at the daily scale (details of these results are presented and discussed in Chapters 2 and 3). These findings show an inverse relationship between volumetric error and time scale length, thus raising two prominent flags with regards to using CBP5 as a water management and planning tool:

First, the results question the usage of the CBP5 model for accurately modeling flows for short time scales, such as flow events. Water resource planning is often driven by relatively short and "extreme" low flow events (e.g. droughts), so event scale accuracy is of considerable importance to planners and managers. However, typical criteria for assessing model performance in low flow and extreme low flow regimes (such as the 7Q10 flow) only provides information about a single flow descriptor such as frequency, durations, timing, or a single statistic - such as mean or median - of low flow events, which alone offers a limited understanding of goodness of model fit for extreme low flow events. Chapter 2 introduces new approaches for exploring low flow-specific model fit in 
a simulation model, and in doing so, introduces a way to evaluate the appropriateness of the CBP5 watershed model for use as a comprehensive water planning and management tool.

Second, these preliminary results indicate that the differences between observed and CBP5 hydrographs are due to the timing of flows rather than the total volume of flows. Precipitation patterns and the routing of flows typically drive the timing of flows, and thus low model error can often be attributed to accurate precipitation estimation and proper simulation of flow routing. Since channel routing can be accurately simulated using general assumptions of the channel composition and geometries, specific emphasis must be directed towards precipitation estimation. In fact, precipitation estimation has been previously identified as having considerable influence on CBP5 model error (Apse et al. 2008). Chapter 3 introduces two new precipitation fidelity metrics to evaluate the extent of the impact of precipitation estimation on a hydrologic model and shows how these metrics can be applied to assess the appropriateness of the CBP5 model for use as a water planning and management tool.

The second goal of this thesis is to present a new simulation-optimization modeling approach to modify the design of detention ponds to preserve the natural ecological flows, while satisfying the requisite regulatory flow requirements. Chapter 4 introduces the 'ecodifference' metric, a weighted sum of the eco-flow statistics, and an integrated modeling approach - consisting of a hydrologic model, detention pond model, and the ecodifference metric - for designing an 'ecological' detention pond. The design approach is demonstrated for a case study watershed. Chapter 5 incorporates an optimization routine into the design approach presented in Chapter 4, thereby assisting a 
modeler to identify the BMP design that minimizes the ecological impairment to the receiving stream. The simulation-optimization approach is also demonstrated for the case study. General conclusions and recommendations for future research are given in Chapter 6. 


\section{References}

Apse, C., DePhilip, M., Zimmerman, J. and Smith, M.P. (2008). 'Case Study 1: A model for water supply planning in Virginia', in "Developing instream flow criteria to support ecologically sustainable water resource planning and management", Final report to the Pennsylvania Instream Flow Technical Advisory Committee. 196 p., available at

http://www.depweb.state.pa.us/watershedmgmt/lib/watershedmgmt/water_allocati on/pa instream flow_report-_tnc growing greener-_final.pdf.

Mathews, R., and Richter, B.D. (2007). "Application of the Indicators of Hydrologic Alteration Software in Environmental Flow Setting." J. Am. Water Resour. Assoc., 43(6), 1400-1413.

Scientific and Technical Advisory Committee (STAC). (2006). "Final report of the Chesapeake Bay Scientific and Technical Advisory Committee's workshop: 'Modeling in the Chesapeake Bay Program: 2010 and Beyond"'. STAC Publication 06-001. Annapolis, Maryland, January, 2006.

United States Environmental Protection Agency (USEPA). (1991). "Construction site stormwater discharge control: an inventory of current practices." Rep. No. EPA/883/R-91/100. . (2004). "The Use of Best Management Practices (BMPs) in Urban Watersheds." Rep. No. EPA/600/R-04/184.

Urbonas, B., and Stahre, P. (1993). "Storm Water Best Management Practices and Detention for Water Quality, Drainage and CSO Management." PTR Prentice Hall, New Jersey.

Villarreal, E.L., Semadeni-Davies, A., and Bengtsson, L. (2004). "Inner city stormwater control using a combination of best management practices." Ecological Engineering, 22(4-5), 279-298. 


\section{Chapter 2}

\section{Environmental flow components for measuring hydrologic model fit in low flow regimes}

\subsection{Introduction}

Water supply managers must consider both long time scales for extended management decisions and short times scales in preparation for extreme stream flow events. In addition, water managers in many areas are responsible for allocating water flows to support riverine species and maintain essential ecosystem processes (Mathews and Richter 2007). For example, the Code of Virginia was amended in 2003 to ensure the availability of adequate and safe drinking water, as well as to encourage and protect all other beneficial uses of the water resource, such as ecological services (Virginia Acts of Assembly 2003). To accommodate both human and riverine ecosystem water needs, water managers require a watershed model that can provide accurate estimates of stream flow in flood and drought periods, which tend to be short and intense, as well as normal long-term conditions. 
The 7Q10, the lowest 7-day-average flow that occurs, on average, once every ten years, is commonly used to define the critical low flow period for water supply planning and wasteload allocations (USEPA 2009). However, a single statistic fails to provide information on low flow timing, duration, frequency, or flows of various period lengths, all of which may have significant impacts on riverine systems (Poff 1996; Puckridge et al. 1998; Bragg et al. 2005).

Poff and Allan (1995) reported the significance of hydrological factors on environmental variables and first proposed the synthesis of flow parameters and associated ecological conditions into one methodology. This developed into the original Indicators of Hydrologic Alteration (IHA) (Richter et al. 1996; Richter el al. 1997; Poff et al. 1997). IHA utilizes 33 significant flow parameters to quantitatively link hydraulic conditions to ecological impacts based on a natural flow regime. IHA was followed by the Range of Variability Approach (RVA), which was incorporated into the IHA software program (Richter et al. 1997). The RVA uses a range of natural variability about a measure of central tendency to measure the acceptable variability for a long-term flow regime. However, the complexity of the RVA and difficulties in attaining flow targets has limited the utility of the RVA in real water management situations (Mathews and Richter 2007).

In response, a new set of flow parameters called Environmental Flow Components (EFCs) was developed to supplement the original IHA statistical parameters and better characterize the hydrograph in a manner that is representative of key flowecology relationships (Mathews and Richter 2007). In the updated IHA approach, EFCs are defined as broad groupings of events in a flow regime; the groupings include extreme 
low flows, low flows (the most common flows), high flow pulses (up to bankfull condition), small floods (bankfull condition up to the 10-year flow), and large floods (greater than the 10-year flow) (TNC 2007). Mathews and Richter (2007) note that a practical advantage of EFCs is that environmental flow recommendations based upon them can be readily implemented in most water management settings.

The IHA approach has been implemented into a variety of ecological and engineering applications, including reservoir optimization (Shiau and Wu 2010), BMP placement (Edgerly 2006), optimized watershed development (Reichold et al. 2010), altered flow ecological assessments (Kirby 2003; Shaw 2001), and ecological flow policy recommendations (Mathews and Richter 2007; Richter et al. 2006). However, this author has not found any studies that use the IHA methodology as a measure of hydrological model fit.

The IHA methodology is based on calculating a set of statistical measures for two flow series and then evaluating the differences between the two statistical sets. Traditionally, the statistics are used to compare an altered flow regime to the original natural state for a given river. For example, a dam constructed on a river would cause an altered flow regime. This work uses the IHA methodology in a slightly different way, utilizing the comparison of statistical sets as a way of assessing model fit rather than the degree of alteration. Instead of comparing the altered flow regime to the original flow regime, this analysis uses the IHA methodology to evaluate the differences between a modeled flow regime and an observed flow regime for a given river.

Specifically, this work uses the seven "extreme low flow" statistics of IHA to evaluate the accuracy of an existing hydrologic model, the Chesapeake Bay Program 
Phase 5 (CBP5) watershed model (USEPA 2010), during low flow events on a regional scale relevant to many water supply planners and managers. To provide a comparative performance benchmark, the performance of the simple Drainage Area Ratio (DAR) method (Hirsch 1979) relative to the IHA low flow statistics is also determined. A case study to demonstrate the use of IHA statistics for model evaluation is developed using the Rivanna River watershed in Virginia, a subcatchment within the Chesapeake Bay drainage.

\subsection{IHA Methodology and Environmental Flow Components}

Environmental flows can be seen as a compromise between river basin development on the one hand and maintenance of river ecology on the other (Smakhtin 2007). The amount of research and empirical evidence used to develop appropriate statistical parameters for each of the EFCs in the IHA methodology presents an opportunity to leverage the statistics for combined ecosystem and water supply management. In particular, the extreme low flow (ELF) grouping is fundamentally important in water supply management and planning, as droughts consist of series of continuous days classified in the ELF grouping. The IHA methodology default classifies daily flows that are below the $50^{\text {th }}$ percentile of all daily flows in the simulation period as low flows, and daily flow values that are the lowest $10 \%$ of low flows in the period as composing the ELF set (TNC 2007). Members of the ELF set can be referred to as 'ELF days'. One or more continuous ELF days can be referred to as an 'ELF event'.

Seven statistical measures in the IHA methodology focus on very low flow event characteristics. Four statistics are specifically used to analyze days classified in the ELF 
grouping. These include: the ELF minimum flow, which is the mean of all the ELF event minimum daily flows in a given water year; the ELF duration, which is the mean duration of ELF events in a water year; the ELF timing, which is the mean Julian day of the ELF days in water year, reported as a single Julian day value; and the ELF frequency, which is number of ELF events in a water year (TNC 2007). These four statistics have important ecological implications, such as enabling the recruitment of certain floodplain plant species, purging invasive, introduced species from aquatic and riparian communities, and concentrating prey into limited areas to benefit predators (TNC 2007). In addition, the IHA methodology also calculates three other very low flow statistics that are frequently used in civil engineering low flow analyses. These three statistical measures include: the 1-day annual minimum discharge (1Q1), the lowest one-day discharge in a water year; the 3-day annual minimum discharge (3Q1), the lowest 3-day mean daily discharge in a water year; and the 7-day annual minimum discharge (7Q1), the lowest 7-day mean daily discharge in a water year.

The seven statistical measures can be used to compare observed values to modeled values through various methods, such as percentage differences and absolute value differences. The seven statistical measures and the associated comparison formulas are shown in Table 2.1, where the subscript "mod" refers to the modeled output value and "obs" refers to the observed record value. 
Table 2.1. Extreme Low Flow statistics and methods of comparison

\begin{tabular}{|c|c|}
\hline Statistical Measure & Comparison Formula \\
\hline 1-day annual minimum discharge (1Q1) & $\left(\left(1 Q 1_{\text {mod }^{-}} 1 Q 1_{\text {obs }}\right) /\left(1 Q 1_{\text {obs }}\right)\right) * 100$ \\
\hline 3-day annual minimum discharge (3Q1) & $\left(\left(3 Q 1_{\text {mod }^{-}} 3 Q 1_{\text {obs }}\right) /\left(3 Q 1_{\text {obs }}\right)\right) * 100$ \\
\hline 7-day annual minimum discharge (7Q1) & $\left(\left(7 Q 1_{\text {mod }^{-}} 7 Q 1_{\text {obs }}\right) /\left(7 Q 1_{\text {obs }}\right)\right) * 100$ \\
\hline ELF discharge $\left(Q_{E}\right)$ & $\left(\left(\left(Q_{E, \text { mod }}-Q_{E, o b s}\right) /\left(Q_{E, o b s}\right)\right) * 100\right.$ \\
\hline ELF duration & $\mid\left(\right.$ Duration $_{\bmod }-$ Duration $\left._{\text {obs }}\right) \mid$ \\
\hline ELF timing & $\mid\left(\right.$ Julian Date mod - Julian Date $\left._{\text {obs }}\right) \mid$ \\
\hline ELF frequency & $\mid\left(\right.$ Events $_{\bmod }-$ Events $\left._{\text {obs }}\right) \mid$ \\
\hline
\end{tabular}

\subsection{Chesapeake Bay Program Phase 5 Model}

The Chesapeake Bay Program Phase 5 (CBP5) model is a continuous watershed simulation model, with capabilities of performing coupled hydrologic and water quality analyses for long simulation periods. The CBP5 model is one of a suite of models related to the Bay that are the result of nearly 30 years of collaborative development by federal, state, academic and private partners (Chesapeake Bay Program 2010). The modeling approaches are peer-reviewed via technical advisory committees composed of government and academic experts who meet quarterly and periodically release review guidance. The primary function of the CBP5 model has been to support development of management actions to protect the water quality and restore the living resources in the Chesapeake Bay, as well as in the tributary watersheds that discharge to the Bay (USEPA 2010). The model employs the watershed code Hydrological Simulation Program-Fortran (HSPF) as the simulation engine (Bicknell et al. 1997) and was calibrated to reproduce important hydrologic processes and pollutant loads contributing to water quality impairments within the Chesapeake Bay over a twenty-year simulation period (19862005). The large scope of the CBP5 model and standardized calibration provides 
consistency for Total Maximum Daily Loads (TMDLs) across subregions, as well as for statewide TMDL development (USEPA 2010).

The hydrologic simulation capabilities of the CBP5 watershed model present a robust platform for a range of hydrologic analyses in addition to its primary purpose as a regional water quality model. This is consistent with the Scientific and Technical Advisory Committee (STAC) for the Chesapeake Bay Program modeling, who noted the critical need for greater support of the 'community of modelers' that would benefit from being able to utilize the Chesapeake Bay model to address water resources and TMDL studies on a more local scale (STAC 2006). One water management organization currently exploring the use of the CBP5 model for water supply planning and management is the Virginia Department of Environmental Quality (VaDEQ), which has oversight on water resource management throughout the state. The VaDEQ has traditionally used simplified conceptualizations of a hydrological system, such as the Drainage Area Ratio (DAR) method (Hirsch 1979), for making decisions related to the impacts of surface water withdrawal and discharge permits. A steady increase in state population and the associated development and expansion of water resource facilities has obliged the VaDEQ to move from simple correlation or regression-based approaches such as DAR to more sophisticated, established mechanistic watershed models, such as the CBP5 model, for surface water supply management in Virginia (Apse et al. 2008). Built from HSPF, the CBP5 model can predict the mechanistic response to many future scenarios, including changes in land use, climate, and water resources management. 


\subsection{Drainage Area Ratio Method}

The DAR method supposes for two watersheds with similar physical characteristics, such as slope and land cover, that the ratio of flows at the outlets of the two watersheds is equal to the ratio of the drainage areas of the two watersheds (Hirsch 1979). DAR is given by (2.1):

$$
y=\frac{A_{y}}{A_{x}} x
$$

where $\mathrm{x}$ the observed flow at the watershed with drainage area $A_{x}$ and $y$ is the modeled flow at the target watershed with drainage area $\mathrm{A}_{\mathrm{y}}$. For flow prediction in ungaged basins, this simple correlation method can generate a synthetic flow series without flow observations at the target watershed. For watershed modeling purposes, the method can generate a flow series for a watershed of any size, whether upstream or downstream of an existing stream gage or even in a separate watershed with similar characteristics.

Despite the DAR method's simplicity and widespread applicability, there are some major limitations associated with the DAR method. DAR assumes that observed and modeled watersheds have the same physical characteristics in order to estimate flows on an area-weighted basis. Although this assumption may be reasonable in the absence of flow measurements at the watershed of interest, it is often difficult to find a nearby gaged watershed similar enough to justify this strong assumption (Jia and Culver 2006). Also, DAR is particularly limited in the presence of significant hydraulic modifications, such diversions, withdrawals, weirs, dams, and reservoirs. Similarly, as a purely data driven method, DAR can only predict a flow series extrapolated from historical observations; it 
is not an appropriate tool to predict resultant flows under modified future management, demands or weather patterns.

\subsection{Hydrologic Model Calibration}

For site-specific hydrological modeling, appropriate values of the model parameters must be determined to reasonably simulate the system. Some parameter values may be defined by field data and measurement, but with lack of information on the scales of model conceptualization, spatial and temporally variability and measurement error, one should expect calibration of parameter values will be required (Gupta et al. 1998). An extensive body of literature exists relative to this process of calibrating hydrological models. As models increase in complexity and the number of parameter values increases, the calibration challenge can explode, and automated calibration tools can assist in parameter value determination. A wide range of mathematical algorithms have been utilized to identify the 'best' set of parameter values, including derivativebased models, such as the widely used Parameter ESTimation software or PEST (Doherty 2004), and efficient search algorithms, such as Latin Hypercube Sampling (Jia and Culver 2008) and Dynamically Dimensioned Search (Tolson and Shoemaker 2007).

However, regardless of the search algorithm, the mathematical definition of fit is critical, especially for automated calibration. Legates and McCabe (1999) demonstrated that commonly used fit measures that are familiar from statistics (such as the coefficient of determination, $\mathrm{R}^{2}$ ) have inherent mathematical biases toward fitting high flows. The Nash-Sutcliffe efficiency (1970) has been suggested as an alternative metric for hydrologic models (Legates and McCabe, 1999; McCuen et al, 2006), but it can be 
difficult to interpret and may, at times, lead to acceptance of poor fits (Legates and McCabe, 1999). The Nash-Sutcliffe efficiency is given by (2):

$$
E_{f}=1-\left(\frac{\sum^{n}\left(\hat{Y}_{i}-Y_{i}\right)^{2}}{\sum\left(Y_{i}-\bar{Y}\right)^{2}}\right)
$$

where $\hat{Y}_{i}$ and $Y_{i}$ are the predicted and measured values of the criterion (dependent) variable $Y$, respectively; $\bar{Y}$ is the mean of the measured values of $Y$; and $n$ is the sample size. If the predictions of the model are unbiased, the $E_{f}$ value is positive. $E_{f}$ is equal to one if model is a perfect representation of the observed system.

Even when the Nash-Sutcliffe efficiency is used as a calibration metric, use of multiple measures of fit are recommended for hydrologic models (Legates and McCabe 1999). In fact, HSPExp, which provides guidance for manual calibration of HSPF, recommends using a hierarchal approach to fit a suite of hydrological calibration criteria, including total volume errors, volume errors for the $50 \%$ lowest flows, volume errors for the highest $10 \%$ of flows, seasonal volume errors, and fits for selected individual storms (Lumb et al. 1994). However, incorporating multiple calibration criteria into an automatic hydrological calibrator requires multi-objective optimization (Gupta et al. 1998) and may introduce a new challenge of how to appropriately weigh the various calibration criteria (Kim et al. 2007).

Within the spectrum of possible calibration criteria, water supply managers are particularly interested in the goodness of model fit and the flexibility of the model to accurately simulate a range of low flow regimes, yet methodological aspects of model calibration with specific regard to low flows are currently not well developed (Smakhtin 
2001). Common goodness-of-fit criteria for hydrologic models, such as the accuracy of simulated hydrograph shape, flood peaks and flow volumes, provide relatively little information about the quality of low-flow simulations, and it is necessary to consider other criteria which reflect the model performance in the low-flow domain of a continuous daily stream flow hydrograph (Smakhtin 2001). A variety of existing lowflow measures and indices have been used as performance criteria; these include singleday flow duration curves, frequencies and durations of low-flow periods below certain reference discharges, baseflow volumes, and recession rates (Smakhtin 2001; Smakhtin et al. 1998; Gustard and Wesselink 1993). However, each of these criteria only provides information about a single flow descriptor such as frequency, durations, timing, or the mean/median value of low flow events, which alone offers a limited understanding of goodness of model fit for extreme low flow events.

In addition, to efficiently perform a calibration, one must understand the sensitivities of the calibration criteria to the parameter values. For instance, sensitivity analyses of the HSPF model has determined that hydrologic predictions are particularly sensitive to the values of five parameters per pervious land segment; these parameters are the lower and upper zone nominal water storage capacities, initial water storage (for event-based simulations), soil infiltration capacity, and slope of the overland surface (Linsley et al. 1986; Al-Abed and Whiteley 2002). Information on the sensitivities of the calibration criteria has been incorporated into HSPExp (Lumb et al. 1994) so that it can provide calibration feedback as to which parameters to adjust and whether to increase or decrease the values. In addition, multiple EPA resources (USEPA 1999, 2000) provide additional guidance on parameterizing HSPF. 


\subsection{CBP5 Watershed Model Calibration}

Our work utilizes hydrologic simulation results from the CBP5 as calibrated by the Chesapeake Bay Program. Since the methodology by which the CBP5 model was calibrated may impact the appropriateness of using the CBP5 model for regional scale water resources analysis, the calibration of the CBP5 model is briefly described here. More complete calibration information can be found in the CBP5 model documentation (USEPA 2010).

By utilizing rules from HSPExp (Lumb et al. 1994), as well as through calibration experience, the Chesapeake Bay Program found sensitivities between six calibration metrics and six established HSPF parameters (USEPA 2010). The CBP5 calibration measures include: (1) Overall Bias, (2) Winter/Summer Balance, (3) Baseflow/Stormflow Balance, (4) Quickflow Recession Index, (5) Baseflow Recession Index, and (6) Peak Bias (USEPA 2010). The links between the sensitive parameters and the calibration metrics are shown in Table 2.2. A simplified Levenberg-Marquardt algorithm with fixed derivative forms, representing the change in each criterion with respect the single applicable calibration parameter, was used to identify appropriate parameter values. A similar approach of fixing derivatives was taken by Santhi et al. (2008). The other parameter values in the CBP5 were determined from a geographical information system database (USEPA 2010), or did not show sensitivity and thus were given default values primarily based on USEPA BASINS software parameterization (USEPA 2000), or the parameter values were correlated to the values of one of the six sensitive parameters. The CBP5 model was then calibrated to the observed stream flow data from U.S. Geological 
Survey (USGS) gaging stations at 287 stations in the Phase 5 model domain (USEPA 2010).

Table 2.2. Calibration measures employed in CBP5 model internal calibration routine

\begin{tabular}{|l|c|l|}
\hline $\begin{array}{l}\text { CBP5 Calibration } \\
\text { Measure }\end{array}$ & $\begin{array}{l}\text { HSPF } \\
\text { Parameter }\end{array}$ & Parameter Definition \\
\hline Overall Bias & land evap & Evaporation from interception \\
\hline $\begin{array}{l}\text { Winter / Summer } \\
\text { Balance }\end{array}$ & LZSN & Lower zone nominal soil moisture storage \\
\hline $\begin{array}{l}\text { Baseflow / } \\
\text { Stormflow Balance }\end{array}$ & INFILT & Index to the infiltration capacity of the soil \\
\hline $\begin{array}{l}\text { Quickflow } \\
\text { Recession Index }\end{array}$ & IRC & Interflow recession parameter \\
\hline $\begin{array}{l}\text { Baseflow } \\
\text { Recession Index }\end{array}$ & AGWR & Basic groundwater recession parameter \\
\hline Peak Bias & INTFW & Interflow inflow parameter \\
\hline
\end{tabular}

A post-audit of the resulting quality of the calibration calculated the NashSutcliffe efficiency for various predictions of the CBP5 model. Note that maximizing the efficiency was not a specified goal of the automatic calibration. The median efficiency for predicting the monthly flows at the gages was almost 0.85 , and the median efficiency for predicting daily flows and the $\log$ of the daily flows were about 0.625 and 0.7 , respectively (USEPA 2010). Another study of the CBP5 model performance at the subwatershed-scale calculated the mean annual absolute volumetric error (MAAVE). The MAAVE is defined as follows:

$$
M A A V E=\frac{100}{m} \sum_{1}^{m}\left(\left|\left(\sum_{1}^{s} Q_{t, \text { mod }}-\sum_{1}^{s} Q_{t, o b s}\right) /\left(\sum_{1}^{s} Q_{t, o b s}\right)\right|\right)
$$

where $\mathrm{Q}_{\mathrm{t}, \text { mod }}$ is the simulated stream flow on day $\mathrm{t}\left[\mathrm{m}^{3} / \mathrm{s}\right]$; $\mathrm{Q}_{\mathrm{t}, \mathrm{obs}}$ is the observed stream flow on day $\mathrm{t}\left[\mathrm{m}^{3} / \mathrm{s}\right]$; $\mathrm{s}$ is the number of days in simulation year; and $\mathrm{m}$ is the number of 
years in simulation period. When compared to 141 USGS stream gauges in subwatersheds located throughout Virginia, Apse et al. (2008) found that the resulting MAAVE for the CBP5 model over the 16 years calibration/validation period was less than $15 \%$ for $82.9 \%$ of the subwatersheds and less than $20 \%$ for $92.2 \%$ of the subwatersheds.

The six calibration measures used in the CBP5 hydrologic model are primarily oriented towards the calibration of the long-term hydrological record and only secondarily emphasize specific flow regimes, such as low flows and "extreme" low flows. Extreme low flows- the lowest $10 \%$ of low flows in a period- are the primary contributor to drought conditions. Since low flows typically occur during the summer, the summer bias (used in the Winter/Summer Balance calibration measure) gives broad insights on low flow periods from June to August. However, in the mid-Atlantic region, many low flows also occur in September and October, so this calibration measure does not provide a complete picture with regards to low flow periods. Also, the baseflow/stormflow partitioning (used in Baseflow/Stormflow Balance calibration measure) generally separates low flows (extreme low flow and low flows) from high flows (high flow pulses and floods), but does not separate extreme low flows from low flows. The CBP5 model does not utilize a calibration measure specific to extreme low flow events.

\subsection{Case Study}

The case study catchment, the Rivanna watershed, is a tributary of the Chesapeake Watershed, and the majority of the watershed area consists of four nested 
sub-basins: the Rivanna subwatershed above Palmyra, Virginia, and three tributary watersheds of the Rivanna: the Mechums, the Moormans, and the North Fork Rivanna subwatersheds. The Rivanna subwatershed, located in central Virginia, begins in the Blue Ridge Mountains (including portions of Shenandoah National Park), crosses the ridge and valley region east of mountains, and then traverses the piedmont to discharge into the James River, a direct tributary of the Chesapeake Bay. The Rivanna watershed encompasses an area of $1984 \mathrm{~km}^{2}$ (Rivanna River Basin Roundtable 1998), includes parts of five Virginia counties, as well as the city of Charlottesville, and is home to approximately 140,000 people (RRBC 2009). The three tributary subwatersheds are headwater sub-basins located in the mixed piedmont and mountainous terrain of the Rivanna watershed. The Rivanna subwatershed drains the three tributary subwatersheds, as well as a mixture of rolling hills and piedmont areas downstream of the tributary subwatersheds. The four subwatersheds are shown in Figure 2.1. 


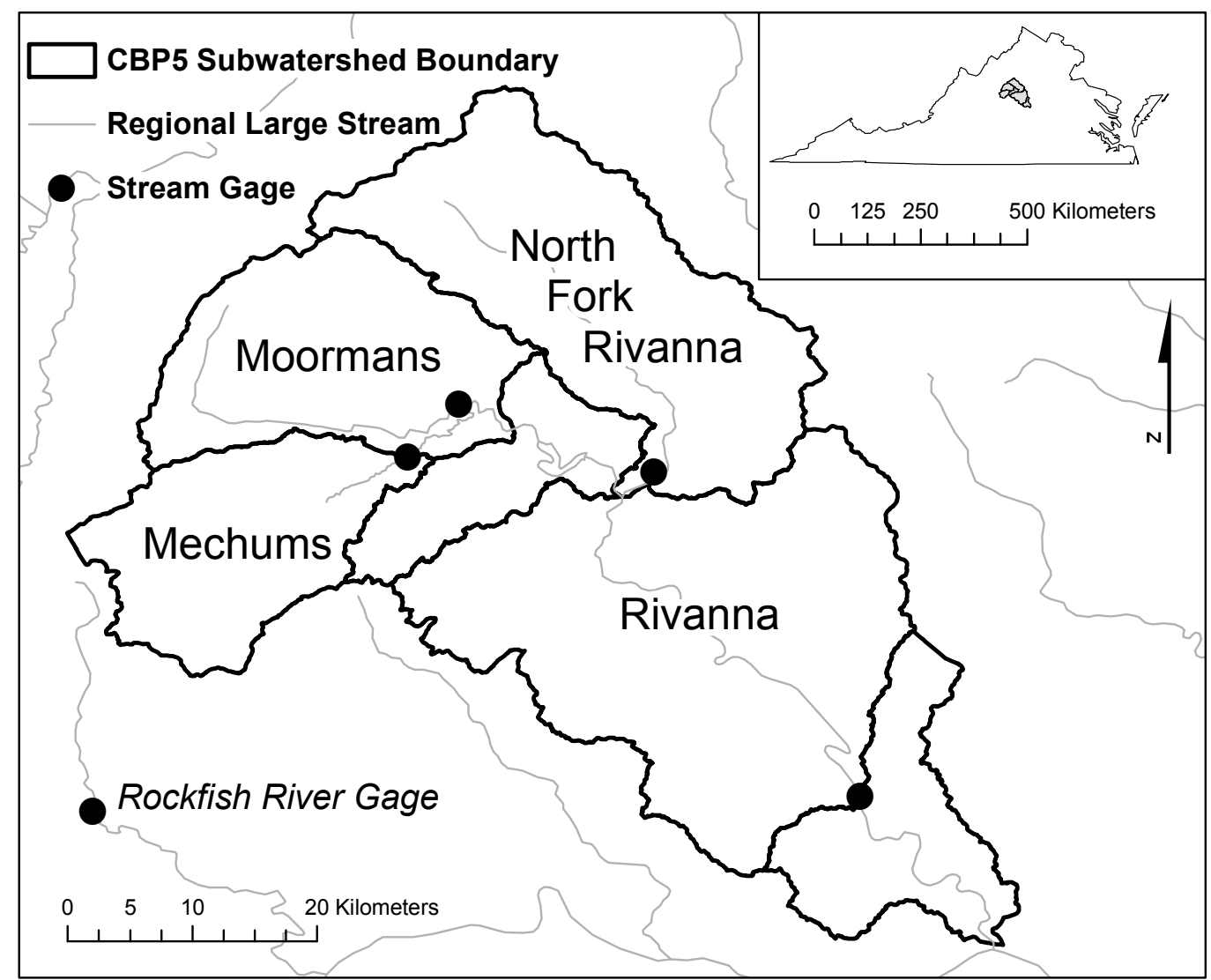

Fig. 2.1. Mechums, Moormans, North Fork Rivanna, and Rivanna subwatersheds in the CBP5 model, and USGS stream gages

Daily stream flow data is available from a USGS stream flow gage located in each of the four subwatersheds and the CBP5 model provided a simulated daily flow series for each of the subwatersheds for the twenty-year model simulation period (1986-2005). As shown in Table 2.3, an "overlap period" was established for the time range when both USGS daily stream flow measurements and simulated subwatershed outflow were available for each subwatershed. As displayed in Figure 2.1, the active USGS stream gages on the Mechums and Rivanna Rivers are located at CBP5 model segment outlets, and thus the observed and modeled outflows can be directly compared. The USGS stream gages on the Moormans and the North Fork Rivanna Rivers are not located at a CBP5 
model segment outlet. The drainage area contributing to the Moormans River stream gage is $64 \%$ of the total Moormans CBP5 model segment area, and the drainage area contributing to the North Fork Rivanna River stream gage is $98 \%$ of the total CBP5 model segment area for that subwatershed. For both subwatersheds, a simple areaweighting approach was used to relate the observed flow and modeled flow at two different locations.

Table 2.3. Available Stream Flow Data and Overlap with CBP5 model period

\begin{tabular}{|l|r|l|l|l|}
\hline & $\begin{array}{l}\text { Drainage } \\
\text { Area } \\
\text { (sq km) }\end{array}$ & $\begin{array}{l}\text { Available } \\
\text { USGS Data }\end{array}$ & $\begin{array}{l}\text { Data } \\
\text { Overlap } \\
\text { Period }\end{array}$ & $\begin{array}{l}\text { Duration of } \\
\text { Overlap } \\
\text { (yrs) }\end{array}$ \\
\hline Mechums & 247.1 & $1943-2010$ & $1986-2005$ & 20 \\
\hline Moormans & 199.4 & $1980-2010$ & $1986-1997$ & 12 \\
\hline North Fork Rivanna & 448.1 & $1970-1993$ & $1986-1992$ & 7 \\
\hline Rivanna & 1727.5 & $1935-2010$ & $1986-2005$ & 20 \\
\hline
\end{tabular}

Table 2.4 shows MAAVE and the mean daily absolute relative volumetric error (MDARVE) for outflows from four CBP5 simulated subwatersheds in the Rivanna watershed. MDARVE is calculated as follows:

$$
\text { MDARVE }=\frac{100}{n} \sum_{1}^{n}\left(\left|\left(Q_{t, \bmod }-Q_{t, o b s}\right) /\left(Q_{t, o b s}\right)\right|\right)
$$

where $\mathrm{n}$ is the number of days in simulation period. The USGS stream gages located in three of the subwatersheds (Mechums, North Fork Rivanna, and Rivanna) were used for the CBP5 model calibration, and calibration fit was measured at the three gage locations. The USGS stream gage station located in the Moormans subwatershed was active during the simulation period but was not one of the stations used in the CBP5 model calibration. The Moormans subwatershed includes a reservoir that was not modeled in the CBP5 
model; subwatersheds with reservoirs were often excluded from direct calibration and their parameter values were set by calibration of neighboring subwatersheds (USEPA 2010). The results for the calibrated subwatersheds show that although the CBP5 model simulates volumetric flows within the $15-20 \%$ annual error ranges that define a majority of the Virginia subwatersheds in the CBP5 model (Apse et al. 2008), the model does not appear to produce accurate results with respect to very short time scales (MDARVE) for those subwatersheds (Table 2.4). Since daily model performance has often been linked to low flow indices (Gustard and Wesselink 1993; Smakhtin et al. 1998), the large daily errors shown in Table 2.4 question the use of the CBP5 model for planning and management purposes in a low flow context.

Table 2.4. Comparison of the mean volumetric errors of the CBP5 model for entire simulation period, 1986-2005, by Rivanna subwatershed

\begin{tabular}{|l|r|r|}
\hline Subwatershed & MAAVE (\%) & MDARVE (\%) \\
\hline Mechums & 15.36 & 54.40 \\
\hline Moormans & 48.90 & 69.36 \\
\hline NF Rivanna & 12.39 & 53.47 \\
\hline Rivanna & 13.35 & 60.02 \\
\hline
\end{tabular}

For implementation of the DAR method in the Rivanna drainage, an appropriate gaged watershed must be chosen for creating the DAR modeled stream flow time series. For this analysis, the flow series recorded at the USGS stream gage on the Rockfish River near Greenfield, Virginia (Figure 2.1), was selected for use in the DAR method. The Rockfish River drains a watershed of 245.5 square kilometers, has a long period of recorded daily stream flows (1943-2010), and is composed of a mixture of mountainous and hilly terrain directly adjacent to the Rivanna watershed. The proximity, terrain similarities, and approximate closeness in size to the headwater subwatersheds make this 
subwatershed an appropriate surrogate for the Rivanna subwatersheds. Also, the Rockfish River has been used as a surrogate for the Rivanna watershed in past permitting studies of the watershed by the Rivanna Water and Sewer Authority (RWSA) and the VaDEQ (e.g. VaDEQ 2007).

\section{$2.8 \quad$ Results}

Using the CBP5 and DAR models, time series of the outflow discharges were generated for the respective overlap periods for each of the four case study subwatersheds. Overlap periods were chosen since consistent data ranges are necessary for making accurate comparisons between the observed and modeled results. It should be noted that model results were gathered for the full data ranges and were compared to the overlap data range results, yet little difference in the statistical results was seen between the full data range and the overlap data range.

The seven extreme low flow statistical measures were calculated using the IHA methodology. Mean annual values were then calculated for each of seven statistics. The results of the four mean annual discharge values $\left(1 \mathrm{Q} 1,3 \mathrm{Q} 1,7 \mathrm{Q} 1\right.$, and $\left.\mathrm{Q}_{\mathrm{E}}\right)$ for the four subwatersheds are shown in Figure 2.2. Note that the x-axis scale (discharge) is four times larger for the Rivanna subwatershed than the three headwater subwatersheds. The CBP5 model underestimates extreme low flows, to varying degrees, in all four subwatersheds. The ability of the model to statistically reproduce extreme low flow events appears to be poor for the headwater subwatersheds (Mechums, Moormans, and North Fork Rivanna) where percentage errors for flows range from $-37.7 \%$ to $-77.3 \%$, but 
relatively good for the larger Rivanna subwatershed, where percentage errors for flows only range from $-4.9 \%$ to $-11.2 \%$.
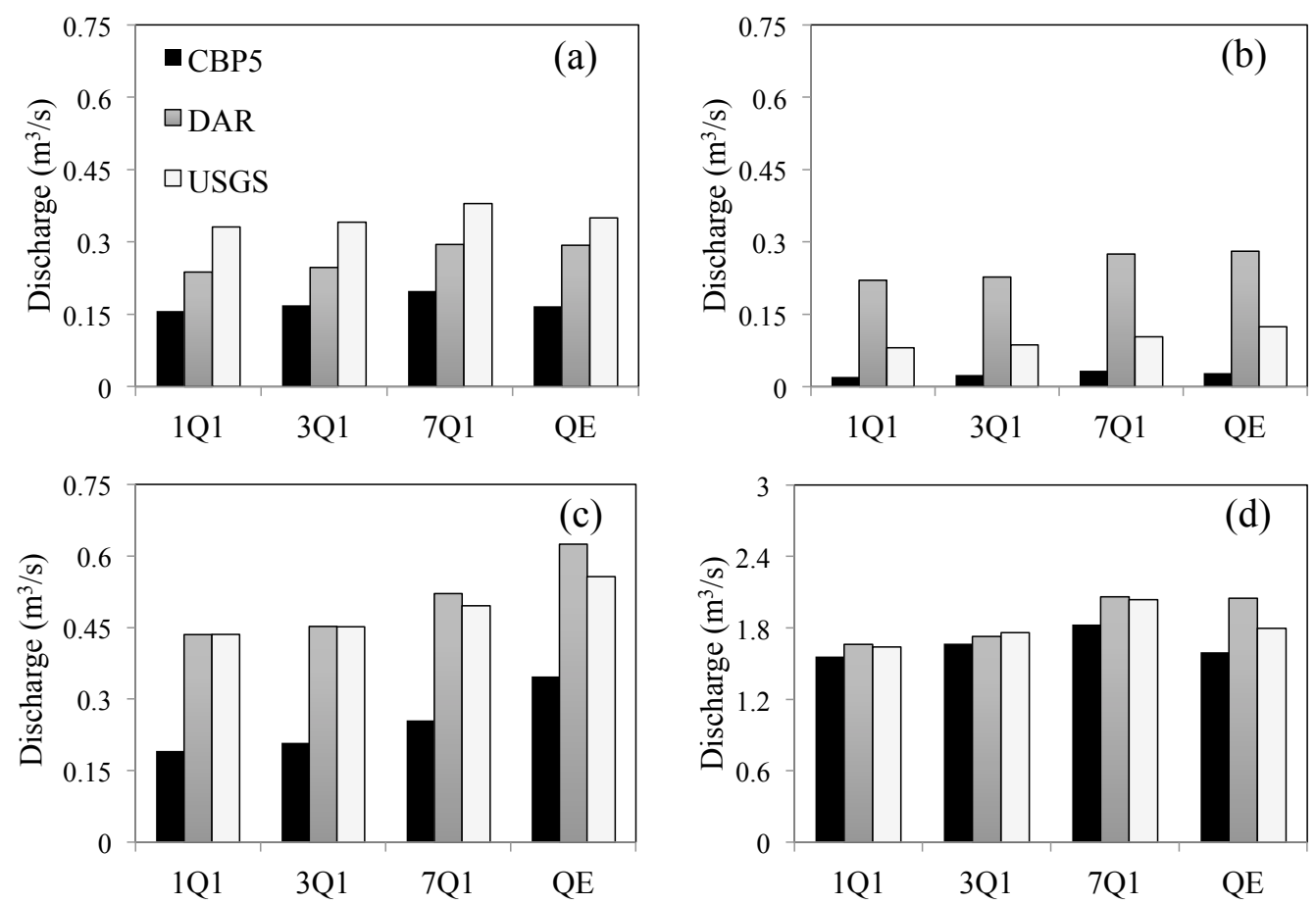

Fig. 2.2. Discharge values for four subwatersheds, (a) Mechums, (b) Moormans, (c) N.F. Rivanna, (d) Rivanna

For three of the four subwatersheds, the DAR model predicts the magnitudes of the extreme low flows as well or better than the CBP5 model; for the Mechums, North Fork, and Rivanna subwatersheds, the percentage errors in the magnitudes of low flows range from $-28.1 \%$ to $14 \%$. In the fourth subwatershed, the Moormans subwatershed, outflow is highly regulated by an upstream reservoir, and flow release is very limited during drought periods. Since DAR does not incorporate storage and release from reservoirs, DAR significantly overestimates the stream flow during extreme low flow events in this subwatershed, with errors ranging from $125.3 \%$ to $173.2 \%$. This serves as 
an example of the limitations of DAR with respect to in-stream diversions and impoundments.

Figures 2.3, 2.4, and 2.5 display ELF duration, ELF frequency, and ELF timing results, respectively. The CBP5 model provides a very accurate description of the ELF durations (Figure 2.3) and frequencies (Figure 2.4) in the Mechums and Moormans subwatersheds. For the North Fork Rivanna and Rivanna subwatersheds, the mean duration of ELF events is over-estimated by CBP5 by less than three days (Figure 2.3). Correspondingly, for these two subwatersheds, the mean number of annual ELF events was under-estimated: CBP5 estimated just over three events, compared to the observed value of approximately five events, as shown in Figure 2.4. For the four subwatersheds, the observed mean timing of ELF events ranged from the end of the fourth week in August until the end of the third week in September, and the CBP5 estimated average timings were different than the observed values by 6 to 23 days (Figure 2.5). 


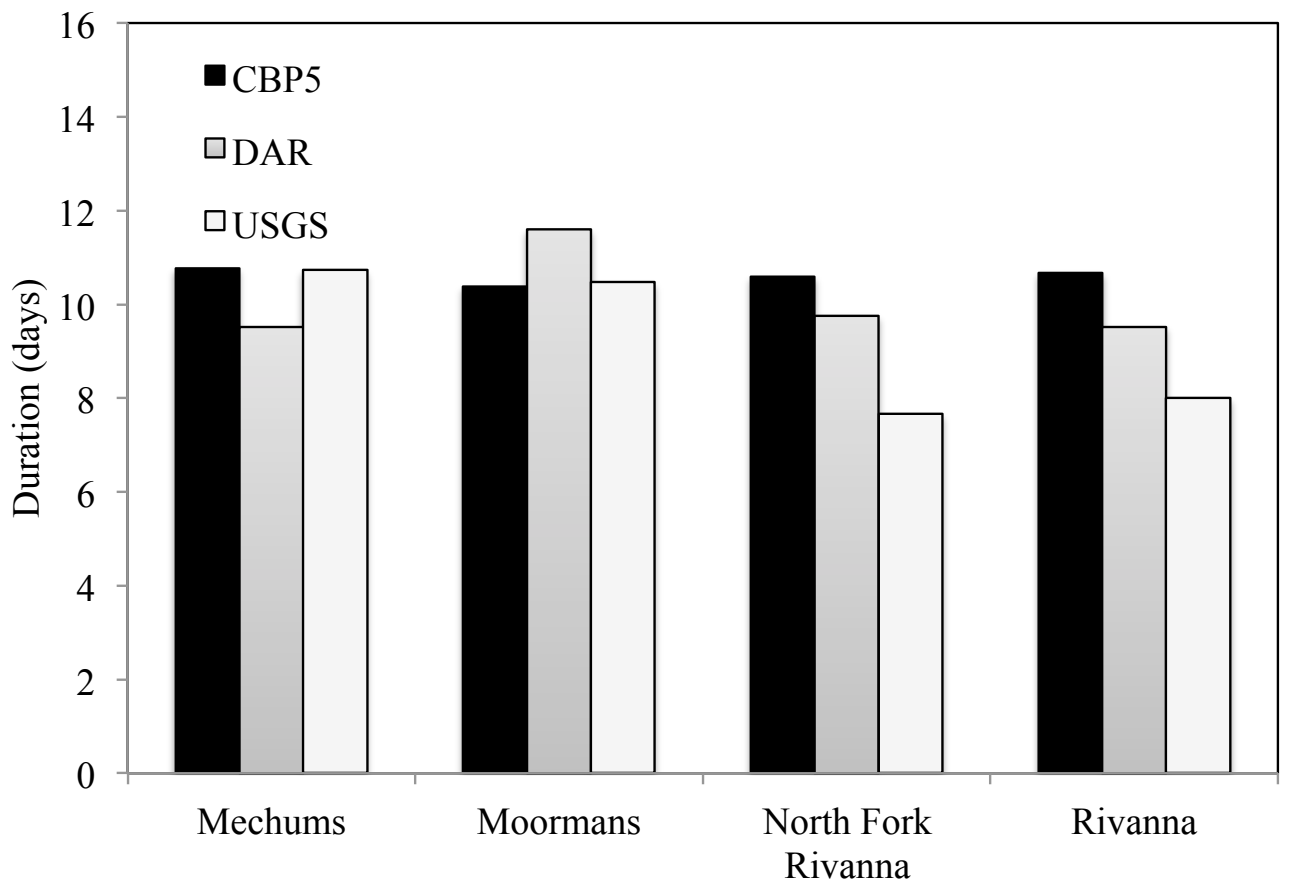

Fig. 2.3. ELF Duration values for four subwatersheds

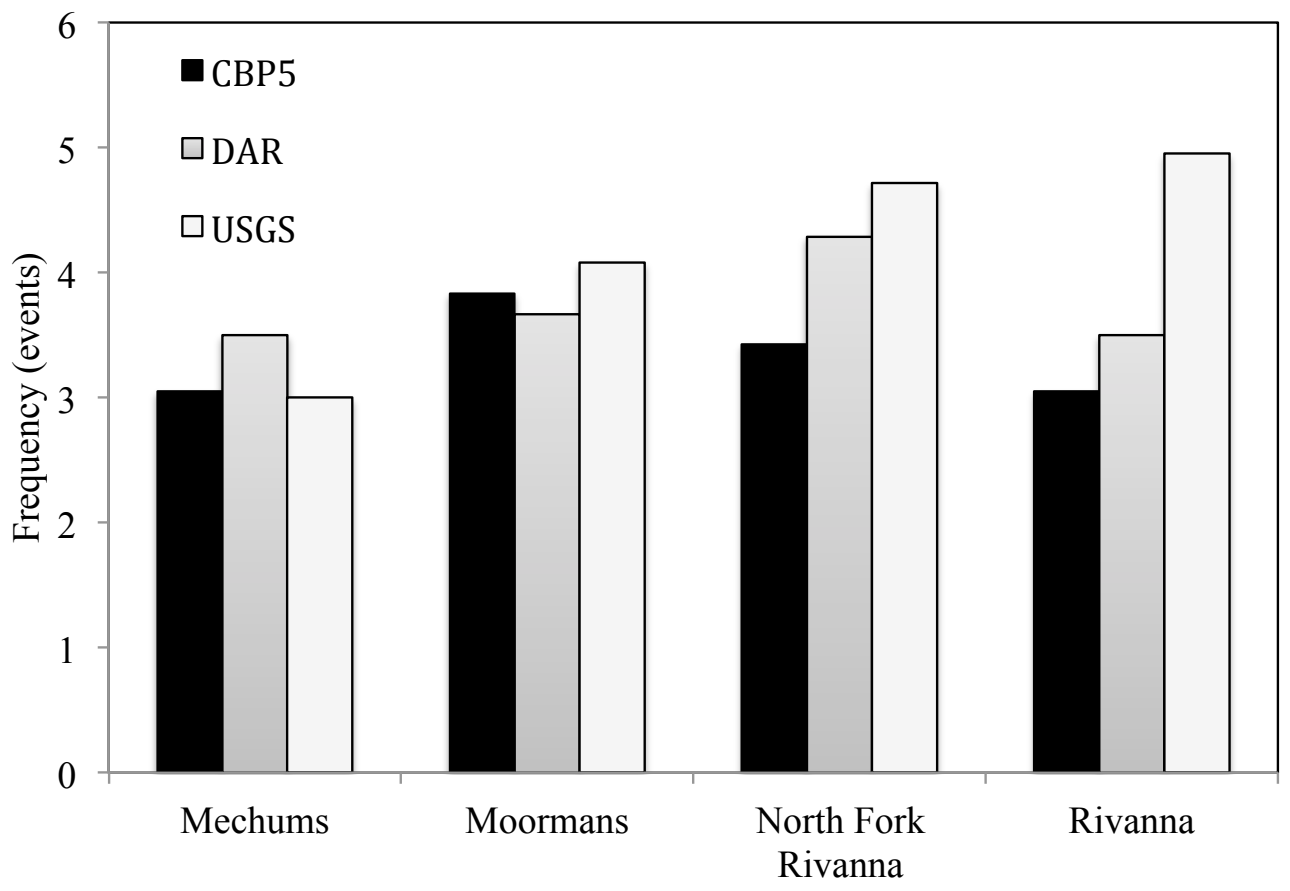

Fig. 2.4. ELF Frequency values for four subwatersheds 


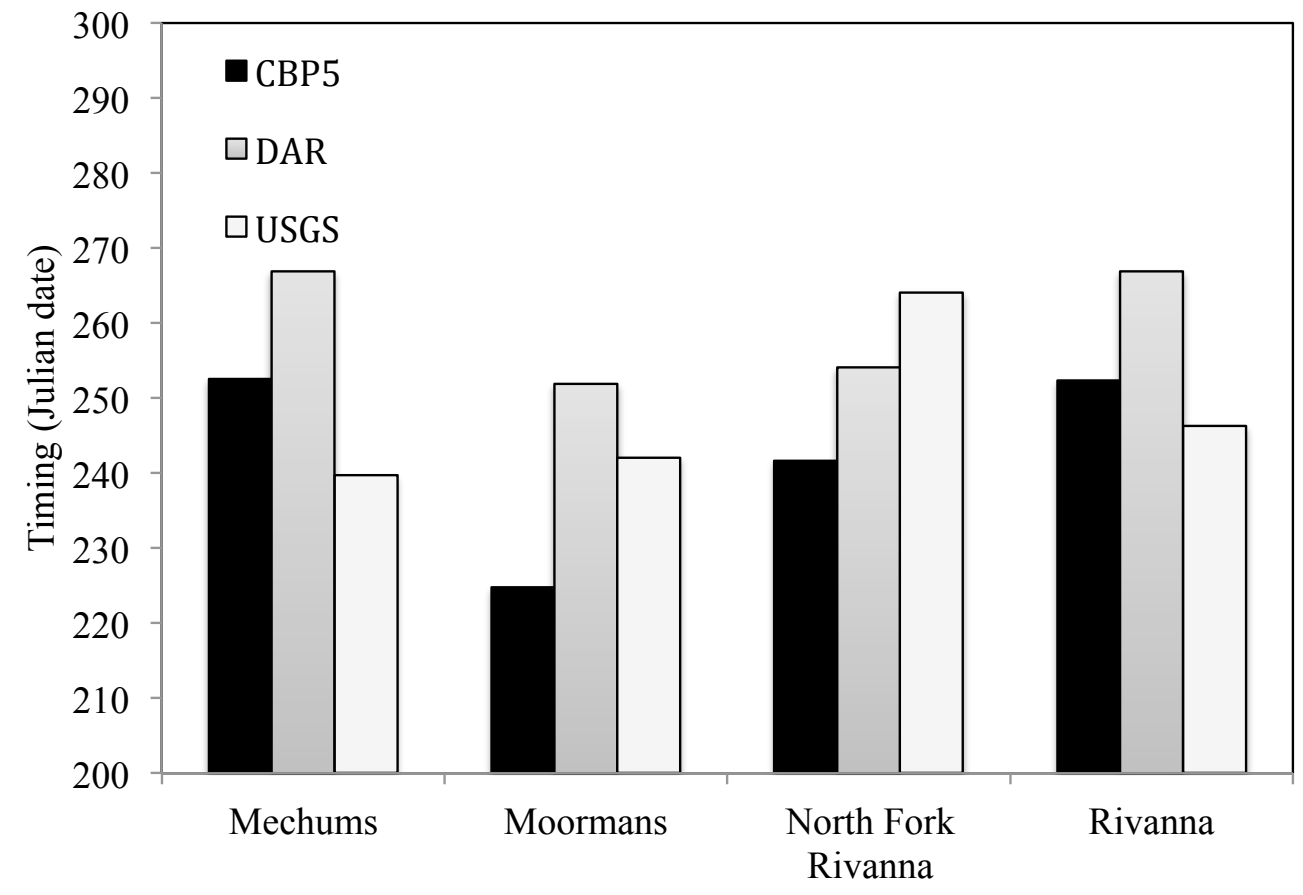

Fig. 2.5. ELF Timing values for four subwatersheds

Overall, with respect to predicting ELF duration, frequency, and timing characteristics for these subwatersheds, the DAR and CBP5 models exhibit similar accuracies. For the four subwatersheds, the mean absolute error in the ELF duration is 1.4 days for CBP5 and 1.5 days for DAR. The mean absolute error in the number of annual ELF events is 0.9 and 0.7 events for CBP5 and DAR, respectively, and the mean absolute error in the timing of ELF events was 15 days and 17 days for CBP5 and DAR, respectively.

\subsection{Conclusions}

In this work, the updated IHA methodology was successfully used as a tool to assess hydrologic model fit for extreme low events. The seven statistical measures chosen 
for fit assessment incorporate the hydrologic requirements of both the human and ecological users of a watershed and provide a more telling and robust picture of model fit for these extreme events than a single statistic such as a 7Q10 flow. Leveraging the IHA methodology in this fashion presents an opportunity to evaluate any model for water supply management with improved assurance that the chosen model will satisfy both human and ecosystem needs.

In this study, for rivers with a large proportion of unregulated flow contributions, the computationally simple DAR model with an appropriate surrogate watershed generally characterizes the extreme low flow conditions more accurately than the CBP5 model. This is similar to the findings of Jia and Culver (2006) who concluded that DAR was a suitable synthetic flow generation approach when the computational resources are limited and when a neighboring gage with a good correlation to the target flows is available. However, three critical issues can undermine the successful use of DAR for some water management scenarios: DAR can only predict future flows given conditions similar to the past; DAR cannot predict impacts of alternative management decisions; and the availability of data from an appropriate surrogate watershed could limit the success of the DAR approach.

For the three subwatersheds with stream gages that were utilized in the CBP5 calibration, the non-volume ELF statistics (ELF duration, frequency, and timing), show little difference between the CBP5 and DAR statistical results. However, for these three subwatersheds, CBP5's average absolute model error with respect to the ELF statistics related to volumetric flows $\left(1 \mathrm{Q} 1,3 \mathrm{Q} 1,7 \mathrm{Q} 1\right.$, and $\left.\mathrm{Q}_{\mathrm{E}}\right)$ are approximately three times higher than the model's average annual volumetric error (MAAVE in Table 2.4). The 
errors for the subwatershed without direct calibration are even higher. These results indicate that although the CBP5 model is better suited for exploring various watershed management alternatives than DAR, the CBP5 model does not currently accurately characterize the low flow episodes that can be critical for both water supply management and aquatic ecosystems.

These low flow errors may be attributed to one or more of the following three key factors: errors in precipitation on the subwatershed-scale, omission of hydraulically relevant local structures, or insufficient emphasis on low flows in the current calibration. For the CBP5 model, the largest percentage errors in daily flow occurred on days when the precipitation input showed rainfall, but the stream gage showed no increase in flow (Mobley et al., 2012); this mismatch between the precipitation input and the target flow shows a lack of precipitation fidelity. Similarly, the Chesapeake Bay Program advisory committee (STAC 2006) noted potential benefits of leveraging the expertise of the National Weather Service to improve weather input into the model and also the need to develop a 'nested' modeling capability that would allow a community modeler to run a subwatershed of the Chesapeake Bay independently with locally updated information. Local information could include the extensive array of instream hydraulic structures found on many rivers and streams in Virginia. Specifically, both the CBP5 and DAR models are limited in their ability to replicate the full suite of reservoir operation rules, inter-basin transfers, and outlet types. For instance, impacts of reservoir operations and/or incomplete or inaccurate data on water transfers may be contributing to the generally higher magnitude errors seen in the Moorman's subwatershed in which there is a reservoir that is not simulated by the CBP5 model and where inter-subbasin water 
transfers may occur. In water supply planning, management, and permitting, these water management structures and operations must be simulated. For this purpose, the VADEQ has constructed a separate flow routing model to interface with the surface runoff portion of the Phase 5 model (Burgholzer 2008). This flow routing model is integrated with the decision support system, and possesses robust and flexible discharge, transfer, and withdrawal rules to be used in conjunction with the rainfall, runoff, and potentially a separate groundwater model (Apse et al. 2008). Finally, this work suggests that the CBP5 model should be recalibrated using a combination of statistics that would preserve predictions of contaminant loads to the Chesapeake Bay while also reproducing low flow events accurately. Such a calibration would corroborate the use of the CBP5 model for both water quality and water supply analyses. 


\subsection{References}

Al-Abed, N.A., and Whiteley, H.R. "Calibration of the Hydrological Simulation Program Fortran (HSPF) model using automatic calibration and geographical information systems." Hydrol. Process., 16, 3169-3188.

Apse, C., DePhilip, M., Zimmerman, J. and Smith, M.P. (2008). 'Case Study 1: A model for water supply planning in Virginia', in "Developing instream flow criteria to support ecologically sustainable water resource planning and management", Final report to the Pennsylvania Instream Flow Technical Advisory Committee. 196 p., available at http://www.depweb.state.pa.us/watershedmgmt/lib/watershedmgmt/water_allocation/ pa_instream_flow_report__tnc_growing_greener-_final.pdf.

Bicknell, B.R., Imhoff, J.C., Kittle, J.L., Jr., Donigian, A.S., Jr., and Johanson, R.C. (1997). "Hydrological Simulation Program--Fortran, User's manual for version 11." U.S. Environmental Protection Agency, National Exposure Research Laboratory, Athens, Ga., EPA/600/R-97/080, 755 p., available at http://water.usgs.gov/software/HSPF/.

Bragg, D.M., Black, A.R., Duck, R.W., and Rowan, J.S. (2005). “Approaching the physical-biological interface in rivers: A review of methods for ecological evaluation of flow regimes." Prog. Phys. Geogr., 29, 506-531.

Burgholzer, R. (2008). Web Online Object-Oriented Meta-Modeling (WOOOMM) Platform, unpublished software, Virginia Department of Environmental Quality.

Chesapeake Bay Program. (2010). "Modeling" http://www.chesapeakebay.net/modeling.aspx, last modified 11/2/2010.

Doherty, J. (2004). "PEST: Model-independent parameter estimation, User manual: $5^{\text {th }}$ ed., Watermark Numer. Comput., Brisbane, Australia.

Doherty, J. and J.M. Johnston. (2003). "Methodologies for calibration and predictive analysis of a watershed model." J. Am. Water Resour. Assoc., 39(2): 251-265.

Edgerly, J. L. (2006). "Quantifying urban-induced flow regime alteration using mathematical models and hydrologic metrics.” MS thesis, Colorado State University.

Gupta, H. V., Sorooshian, S., and Yapo, P.O. (1998). "Toward improved calibration of hydrologic models: Multiple and noncommensurable measures of information." Water Resour. Res., 34(4), 751-763.

Gustard, A., and Wesselink, A. (1993). "Impact of land use change on water resources: Balquidder catchments.” J. Hydrol., 145, 389- 401.

Hirsch, R.M. (1979). “An evaluation of some record reconstruction techniques.” Water Resour. Res., 15(12), 1781-1790. 
Jia, Y., and T.B. Culver (2006). "Bootstrapped artificial neural networks for synthetic flow generation with a small data sample." J. Hydrol., 331, 580- 590.

Jia, Y. and T.B. Culver (2008) "Uncertainty analysis for watershed modeling using generalized likelihood uncertainty estimation with multiple calibration measures", $J$. Water Res. Plnng. Mngmt., 134(2), 97-106, 2008. doi: 10.1061/(ASCE)07339496(2008)134:2(97).

Kim, S.M, B.L. Benham, K.M. Brannan, R.W. Zeckoski, and J. Doherty. (2007). "Comparison of hydrologic calibration of HSPF using automatic and manual methods, Water Resour. Res., 43, W01402, doi:10.1029/2006WR004883.

Kirby, C.W. (2003). "Benthic macroinvertebrate response to post-development stream hydrology and hydraulics.” Ph.D. thesis, George Mason University.

Legates, D. R., and McCabe, G. J. (1999). "Evaluating the use of 'goodness-of-fit' measures in hydrologic and hydroclimatic model validation." Water Resour. Res., $35(1), 233-241$.

Linsley RK, Kohler MA, and J.L.H. Paulhus. (1986). Hydrology for Engineers. McGrawHill: New York; 339-356.

Lumb, A.M., McCammon, R.B., and Kittle, Jr., J.L. (1994). “Users manual for an expert system (HSPexp) for calibration of the Hydrologic Simulation Program-Fortran." U.S. Geological Survey Water-Resources Investigations Report 94-4168, 102 p.

Mathews, R., and Richter, B.D. (2007). "Application of the Indicators of Hydrologic Alteration Software in Environmental Flow Setting." J. Am. Water Resour. Assoc., 43(6), 1400-1413.

McCuen, R.H., Knight, Z., and Cutter, A.G. (2006). "Evaluation of the Nash-Sutcliffe Efficiency Index.” J. Hydrologic Engrg., 11(6), 597-602.

Mobley, J.T., Culver, T.B., and Burgholzer, R. (2012). "Understanding Precipitation Fidelity in Hydrological Modeling." J. Hydrologic Engrg., doi:10.1061/(ASCE)HE.1943-5584.0000588.

Nash, J.E., and Sutcliffe, J.V. (1970). "River flow forecasting through conceptual models. Part 1: A discussion of principles." J. Hydrol., 10(3), 282-290.

Poff, N. L., and Allan, J. D. (1995). "Functional organization of stream fish assemblages in relation to hydrological variability." Ecology, 76, 606-627.

Poff, N.L. (1996). "A hydrogeography of unregulated streams in the United States and an examination of scale-dependence in some hydrological descriptors." Freshwater Biology, 36, 71-91. 
Poff, N. L., Allan, J. D., Bain, M. B., Karr, J. R., Prestegaard, K. L., Richter, B. D., Sparks, R. E., and Stromberg, J. C. (1997). "The natural flow regime." BioScience, 47(11), 769-784.

Puckridge, J.T., Sheldon, F., Walker, K.F. and Boulton, A.J. (1998). "Flow variability and the ecology of large rivers." Marine and Freshwater Research, 49, 55-72.

Reichold, L., Zechman, E.M., Brill, E.D., and Holmes, H. (2010). "SimulationOptimization Methodology to Support Sustainable Watershed Development by Mimicking the Predevelopment Flow Regime." J. Water Resour. Plann. Manage., 136(3), 366-375.

Richter, B.D., Baumgartner, J., Powell, J., and Braun, D. (1996). "A method for assessing hydrologic alteration within ecosystems.' Conserv. Biol., 10, 1163-1174.

Richter, B.D., Baumgartner, J.V., Wigington, R., and Braun, D.P. (1997). "How much water does a river need?" Freshwater Biol., 37(1), 231-249.

Richter, B.D., Warner, A.T., Meyer, J.L., and Lutz, K. (2006). “A collaborative and adaptive process for developing environmental flow recommendations." River. Res. Appl., 22, 297-318.

Rivanna River Basin Commission (RRBC). (2009). "About the Rivanna Watershed," http://www.rivannariverbasin.org/watershed-info.php.

Rivanna River Basin Roundtable. (1998). "Rivanna River Basin Project - State of the Basin”, available at http://www.tjpdc.org/environment/rivBasin.asp

Santhi, C., N. Kannan, J.G. Arnold, and M. DiLuzio. (2008). "Spatial calibration and temporal validation of flow for regional scale hydrological modeling," J. Amer. Wat. Resour. Asso., 44(4), 829-846.

Scientific and Technical Advisory Committee (STAC). (2006). "Final report of the Chesapeake Bay Scientific and Technical Advisory Committee's workshop: 'Modeling in the Chesapeake Bay Program: 2010 and Beyond'". STAC Publication 06-001. Annapolis, Maryland, January, 2006.

Shaw, D.T. (2001). "Internal Report on the Impacts of Upstream Dams, Groundwater Withdrawals and Climate Variability on Baseflows of Altamaha River, Georgia", The Nature Conservancy, Altamaha River Bioreserve, Darian, Ga.

Shiau, J., and Wu, F. (2010). “A dual active-restrictive approach to incorporating environmental flow targets into existing reservoir operation rules." Water Resour. Res., 46.

Smakhtin, V.Y., Sami, K., Hughes, D.A. (1998). "Evaluating the performance of a deterministic daily rainfall-runoff model in a low-flow context." Hydrol. Process., $12,797-811$. 
Smakhtin, V.U. (2001). Low flow hydrology: a review. J. Hydrol., 240, 147-186. 703. (2007). "Environmental flows: a call for hydrology." Hydrol. Process., 21, 701-

The Nature Conservancy (TNC). (2007). "User's Manual for the Indicators of Hydrologic Alteration (IHA) Software.” The Nature Conservancy, Charlottesville, Virginia. http://www.nature.org/ initiatives/freshwater/conservationtools/art17004.html, accessed October 2010.

Tolson, B. A. and C. A. Shoemaker (2007). Dynamically Dimensioned Search Algorithm for Computationally Efficient Watershed Model Calibration, Water Resources Research, Vol. 43, W01413.

United States Environmental Protection Agency (USEPA). (1999). "HSPFParm: An Interactive Database of HSPF Model Parameters, version 1.0" EPA-823-R-99-004. U.S. Environmental Protection Agency, Office of Water, Washington, DC.

. (2000). "BASINS Technical Note 6: Estimating Hydrology and Hydraulic Parameters for HSPF." EPA-823-R-00-012. U.S. Environmental Protection Agency, Office of Water, Washington, DC.

. (2009). "Design Flows: Definitions and Methods", as accessed on October 15, 2010, at http://water.epa.gov/scitech/datait/models/dflow/flow101.cfm.

. (2010). "Chesapeake Bay Phase 5.3 Community Watershed Model.” EPA 903S10002 - CBP/TRS-303-10. U.S. Environmental Protection Agency, Chesapeake Bay Program Office, Annapolis MD. December 2010.

Virginia Acts of Assembly. (2003). Amendment to Senate Bill 1221: Addition of Section 62.1-44.38:1.

Virginia Department of Environmental Quality (VaDEQ). (2007). Part I - Special Conditions. VWP Individual Permit No. 06-1574. Richmond, VA 


\section{Chapter 3}

\section{Understanding Precipitation Fidelity in Hydrological Modeling}

\subsection{Introduction}

Hydrologic modeling has become a critical tool for water resource managers for both short-term and extended planning and permitting. Before using a hydrologic model, managers must assess the quality of the simulation for each model application and, when possible, take steps to improve the accuracy of their simulations. Some parameter values may be defined by field data and measurement, but with lack of information on the scales of model conceptualization, spatial and temporal variability and measurement error, one should expect calibration of model parameter values will be required (Gupta et al. 1998). An extensive body of literature exists relative to this process of calibrating hydrological models, and multiple hydrologic model calibration tools are available to water resource managers (e.g. Lumb et al. 1994; Doherty 2004).

In addition to the values of the model parameters, the accuracy of the precipitation input has been found to be critical in hydrologic modeling. Using a simple deterministic, distributed rainfall-runoff model, Beven and Hornberger (1982) found that the most 
important factor affecting the reproduction of the hydrograph is the total depth of precipitation. Specifically, Beven and Hornberger say that the timing of peak flow was the model prediction most sensitive to different rainfall patterns and that an accurate estimate of the total depth of precipitation in a storm event is essential for accurate runoff simulation. Obled et al. (1994) and Pessoa et al. (1993) also make similar arguments.

The combination of the high spatial and temporal variability of rainfall and the limited number of specific rainfall measurements at discrete raingage locations has driven the development of various methods to estimate rainfall at unsampled locations and at the scale of the hydrologic model conceptualization. Traditional techniques used for precipitation estimation include the Thiessen method (Thiessen 1911) and kriging (Tabios and Salas 1985; Seo et al. 1990). Most contemporary work in precipitation estimation can be classified into one of two general categories. The first research category is primarily oriented towards the improvement of rainfall estimation, including assessing the merits and deficiencies of raingage, radar, and coupled raingage-radar (e.g. Kalinga and Thian 2006; Cole and Moore 2008), as well as determining rainfall-related uncertainty based on creating a "true" rainfall pattern through the use of multiple gage readings and an interpolation method, and then comparing single gage readings or combinations of gage readings to the "true" readings (Bastin et al. 1984; Tabios and Salas 1985; Ball and Luk 1998; Chaubey et al. 1999; Andreassian et al. 2001; Segond et al. 2007; Ruelland et al. 2008). The second category consists of topics in precipitation-based uncertainty as it relates to rainfall-runoff modeling. Of particular interest in this field of contemporary literature is the space-time representation of rainfall in hydrologic models (e.g. Wilson et al. 1979; Jakeman and Hornberger 1993), the spatial variability of rainfall 
(e.g. Obled et al. 1994; Smith et al. 2004; Segond et al. 2007; Nicotina et al 2008; Fu et al. 2011), uncertainty in calibrated hydrologic model parameters due to rainfall spatial variability (e.g. Troutman 1983; Chaubey et al. 1999; Chang et al. 2006), and the influence of estimated rainfall on goodness of fit for rainfall-runoff models (e.g. Lopes 1996). The investigation in this paper is restricted to the last topic: developing a method for isolating hydrologic model errors driven by the quality of the estimation of the precipitation input.

A variety of statistics have been used to quantify the effect of different rainfall estimations on rainfall-runoff model performance. The Nash-Sutcliffe efficiency index, the final value reported as a result of the Nash-Sutcliffe Model efficiency test (Nash and Sutcliffe 1970), is a widely used statistic for this purpose (Oudin et al. 2006; Bardossy and Das 2008; Kim and Kaluarachchi 2009; van der Heijden and Haberlandt 2010). Modified versions of the Nash-Sutcliffe efficiency index such as the modified Nash objective function (e.g. Servat and Dezetter 1991) have also been employed to evaluate the influence of precipitation estimates on model fit in hydrologic models (Paturel et al. 1995). Although they are not unique to assessing impact of precipitation input on hydrologic model output, other statistical criteria have been used to measure variations between observed and simulated flows given different rainfall models; these include the relative bias and the Root Mean Squared Error (Bardossy and Das 2008), as well as Mean Square Error, Mean Absolute Error, Variance, Bias and Absolute Errors (Umakhanthan and Ball 2003). Each of these criteria calculates model fit using only observed and simulated outflow, while neglecting the relative effects of any particular input, such as precipitation. To quantify precipitation impacts, previous researchers evaluated model 
performance by comparing the values of the criteria, given different precipitation estimation approaches. However, in practice, water resources managers often do not have the luxury of performing modeling with a range of precipitation inputs.

The objective of this research is to develop and demonstrate a methodology to specifically assess the inter-relationships between estimated precipitation, observed stream flow, and hydrologic model performance. To satisfy this objective, this work introduces a new concept called 'precipitation fidelity,' which is the correspondence of stream outflow to the estimated precipitation used as input into a hydrologic model. Annual and Daily Precipitation Fidelity Indices are defined. The use of the Precipitation Fidelity Indices is then demonstrated for the Rivanna Watershed in central Virginia as modeled using the CBP5 watershed model (USEPA 2010) and associated precipitation input data set. The precipitation fidelity results are used in conjunction with model output to identify the effect of precipitation estimation accuracy on model performance at both long time scale and short time scales. The following sections will present an overview of the precipitation data set used in the CBP5 model and additional pertinent notes on the case study watershed, followed by the sequential development and demonstration of the daily and annual precipitation fidelity measures with respect to this model-precipitation input-watershed system, with the final section summarizing and discussing the results.

\subsection{Precipitation in the CBP5 Watershed Model}

HSPF, the hydrology simulation engine used by the CBP5 model, represents heterogeneity by defining subwatersheds, but within a subwatershed lumped parameter values are utilized. The domain for the CBP5 model is resolved into about 1000 model 
segments that average $171 \mathrm{~km}^{2}$ (USEPA 2010). A multi-linear regression model, which is a kriging model created specifically for the CBP watershed model (Hay et al. 1991; Hay et al. 2000a; Hay et al. 2000b; Hay et al. 2006), was used to estimate the daily precipitation across the domain, and then the daily values were disaggregated into hourly values (USEPA 2010). Full details on the CBP5 model development, input data (including the estimated precipitation), and calibration can be found in USEPA Report 903S10002 (USEPA 2010).

The Virginia Department of Environmental Quality, which has oversight on water resource management throughout the commonwealth of Virginia, would like to assess the potential and limitations of utilizing the CBP5 model for surface water supply planning and permitting at a regional scale. This work uses, without modification, the precipitation input and the results from the USEPA-calibrated CBP5 model for the case study watershed as an example of assessment of precipitation-induced errors in a precipitation-hydrologic model-watershed system.

\subsection{Case Study}

The case study watershed for this research is the Rivanna Watershed. This is the same study area explored in Chapter 2. The subwatersheds composing the Rivanna Watershed are shown in Figure 2.1. The Mechums and Moormans subwatersheds are primarily a mixture of mountainous and rolling terrain (approximately 25-30\% mountainous), the North Fork Rivanna subwatershed is a mixture of mountains, hills, and

piedmont (approximately 10-15\% mountainous), and the Rivanna subwatershed is 
composed mostly of piedmont areas downstream of the three headwater subwatersheds. Further details on the four subwatersheds are given in Chapter 2.

Several volumetric error measures for the CBP5 model with respect the four case study subwatersheds were calculated. In addition to an annual error measure (the MAAVE), the mean daily absolute relative volumetric error (MDARVE) was also determined to give a general indication of accuracy during short time scales. Volumetric error for the entire simulation period (PVE) was used for volumetric accuracy over a long time scale. PVE, MAAVE, and MDARVE are calculated using variations on the equation for mean absolute percent error, a measure of accuracy frequently used to evaluate crosssectional forecasts (Ahlburg 1995; Hyndman and Koehler 2006; Rayer 2007). The three metrics are defined as percentage values. MAAVE and MDARVE are defined in Chapter 2 by equations (2.3) and (2.4), respectively. PVE is given by:

$$
P V E=100\left(\left|\left(\sum_{1}^{n} Q_{t, \mathrm{mod}}-\sum_{1}^{n} Q_{t, o b s}\right) /\left(\sum_{1}^{n} Q_{t, o b s}\right)\right|\right)
$$

where $\mathrm{Q}_{\mathrm{t}, \text { mod }}$ is the simulated mean stream flow on day $\mathrm{t}\left[\mathrm{m}^{3} / \mathrm{hr}\right]$; $\mathrm{Q}_{\mathrm{t}, \mathrm{obs}}$ is the observed mean stream flow on day $\mathrm{t}\left[\mathrm{m}^{3} / \mathrm{hr}\right]$; and $\mathrm{n}$ is the number of days in simulation period. Table 3.1 shows CBP5 model volumetric errors for the four case study subwatersheds at each of these time scales. For the three directly-calibrated subwatersheds, the results in Table 3.1 show high accuracy at the entire period scale, acceptable accuracy at the annual scale (within the 15-20\% acceptability ranges reported by Apse et al. 2008), yet relatively low accuracy at the daily scale. 
Table 3.1. CBP5 model performance (volumetric errors) for the simulation period 1986-2005, by Rivanna subwatershed

\begin{tabular}{|l|c|r|r|r|}
\hline Subwatershed & $\begin{array}{c}\text { CBP5 Calibration } \\
\text { Target }\end{array}$ & \multicolumn{1}{c|}{$\begin{array}{c}\text { PVE } \\
\text { (\%) }\end{array}$} & \multicolumn{1}{c|}{$\begin{array}{c}\text { MAAVE } \\
\text { (\%) }\end{array}$} & $\begin{array}{c}\text { MDARVE } \\
\text { (\%) }\end{array}$ \\
\hline Mechums & Yes & 0.19 & 15.36 & 56.45 \\
\hline Moormans & No & 25.33 & 48.90 & 73.40 \\
\hline NF Rivanna & Yes & 1.62 & 12.39 & 57.05 \\
\hline Rivanna & Yes & 8.52 & 13.35 & 58.68 \\
\hline
\end{tabular}

These results display an inverse relationship between volumetric error and time scale length, and indicate that the differences between observed and CBP5 modeled outflow hydrographs are the result of the timing of flows as well as the volume of flows. Given the direct correlation between input and output of a modeled system, these results also suggest the possibility that the precipitation input to the hydrology model might be problematic with respect to both timing of precipitation events and precipitation depths. Evaluations of precipitation fidelity in different flow circumstances and comparison with model performance are necessary to evaluate this possibility.

\subsection{Precipitation Fidelity}

A number of potentially useful measures were considered for quantitatively measuring precipitation fidelity. Since the amount of available data varies amongst locations, an emphasis was placed on employing as little data as possible while maximizing useful results. Also, the measures were judged for their ability to assess the usability of the CBP5 model for a long time period if only a short period of the USGS stream flow record is available, and to make conclusions about the effect of precipitation estimation accuracy on model performance for short and long time scales. 
Two measures were developed that met these needs: a Daily Precipitation Fidelity Index and an Annual Precipitation Fidelity Index. The Daily Precipitation Fidelity Index evaluates the correspondence between model precipitation input and observed output at the daily scale. The Daily Precipitation Fidelity Index can be used to understand daily model error model performance as a function of rainfall and stream flow events. The Annual Precipitation Fidelity Index is used to evaluate the accuracy of the modeled stream flow volumes at the annual scale, the trends in annual precipitation-based stream flow response during a simulation period, and along with a goodness of fit analysis, how deviations from the trends indicate potential problems with the precipitation data.

\subsection{Daily Precipitation Fidelity}

\subsubsection{Method}

Hourly precipitation values were compiled from the CBP5 HSPF Phase 5 Data Library Data (Chesapeake Community Modeling Program 2010) and were summed into daily precipitation totals for each subwatershed. The daily mean stream flow values for each of the USGS gages in the Rivanna subwatershed were obtained from the USGS National Water Information System (USGS 2011) with a typical resolution of $0.028 \mathrm{~m}^{3} / \mathrm{s}$;

thus, an increase in daily stream flow was defined as an increase of $0.028 \mathrm{~m}^{3} / \mathrm{s}$ or more. A simple logical measure was then used to indicate a correspondence between the estimated daily precipitation in a subwatershed and an increase in observed daily stream flow. The logic is straightforward: the daily flow indicator, $Q$, is assigned a value of 1 if the observed stream flow is recorded as increasing, and Q is 0 otherwise; and the daily precipitation indicator, $\mathrm{P}$, is assigned a value of 1 if the estimated precipitation is greater 
than the initial abstraction $\left(\mathrm{I}_{\mathrm{a}}\right)$, which is the minimum rainfall depth needed to generate runoff. If the estimated precipitation is less than $\mathrm{I}_{a}$, then $\mathrm{P}=0$. Each day can fall into one of four possible ' $\mathrm{QP}$ ' combinations $\left(\mathrm{QP}_{10}, \mathrm{QP}_{01}, \mathrm{QP}_{00}\right.$, and $\left.\mathrm{QP}_{11}\right)$ depending on the value of the indicators $\mathrm{Q}$ and $\mathrm{P}$, as defined in Table 3.2. Days having $\mathrm{QP}_{00}$ and $\mathrm{QP}_{11}$ combinations constitute the "agreement" category, and the percentage of days that compose the "agreement" category indicates the fidelity of the estimated precipitation and is termed the Daily Precipitation Fidelity Index (Daily PFI). Days having $\mathrm{QP}_{10}$ and $\mathrm{QP}_{01}$ combinations compose the 'non-matching' days. Isolating non-matching days will help to identify days when model error may be driven by precipitation input error as opposed to other sources, such as parameter calibration errors. From the modeler's perspective, some non-matching days $\left(\mathrm{QP}_{10}\right)$ will have "phantom storms" with increases in observed stream flow that the hydrologic model will not be able to explain without precipitation input. Conversely, on $\mathrm{QP}_{01}$ days, the hydrologic model will simulate stream rise due to input precipitation above $I_{a}$, even though no increase in stream flow was observed on those days.

Table 3.2. Daily Precipitation Fidelity Combinations

\begin{tabular}{|l|c|c|}
\hline \multicolumn{1}{|c|}{ Description } & Combination & Category \\
\hline $\begin{array}{l}\text { The observed stream record (USGS) indicates a rainfall } \\
\text { event and the estimated precipitation does not }\end{array}$ & $\mathrm{QP}_{10}$ & Non- \\
\cline { 1 - 2 } $\begin{array}{l}\text { The estimated precipitation indicates a rainfall event } \\
\text { and the observed stream record does not }\end{array}$ & $\mathrm{QP}_{01}$ & \multirow{2}{*}{ Agreement } \\
\cline { 1 - 2 } $\begin{array}{l}\text { NEITHER the observed stream record NOR the } \\
\text { estimated precipitation indicate a rainfall event }\end{array}$ & $\mathrm{QP}_{00}$ & \\
\cline { 1 - 2 } $\begin{array}{l}\text { BOTH the observed stream record AND the estimated } \\
\text { precipitation indicate a rainfall event }\end{array}$ & $\mathrm{QP}_{11}$ & \\
\hline
\end{tabular}


Once the number of days within each QP category is determined, the short term performance of the hydrologic model for each of the four QP combinations is quantified by the mean daily absolute relative volumetric error (\%) or $\mathrm{MDARVE}_{\mathrm{QP}}$, as shown in equation (3.2):

$$
\operatorname{MDARVE}_{Q P}=\frac{100}{n_{Q P}} \sum_{1}^{n_{Q P}}\left(\left|\left(Q_{t, \bmod }-Q_{t, o b s}\right) /\left(Q_{t, o b s}\right)\right|\right)
$$

where $n_{Q P}$ is the number of days in the analysis period with combination QP. In addition to the relative error, the mean daily absolute area-scaled volumetric error (MDAAVE $\mathrm{QP}_{\mathrm{Q}}$ ) between the modeled and observed flows is determined as follows:

$$
M D A A V E_{Q P}=\frac{1}{A n_{Q P}}\left(\sum_{1}^{n_{Q P}}\left(\left|Q_{t, \mathrm{mod}}-Q_{t, o b s}\right|\right)\right)
$$

where $A$ is the area of the subwatershed of interest $\left(\mathrm{km}^{2}\right)$. Using two measures of daily performance is useful, since these measures of daily model error (Eq. 3.2 and 3.3) have different biases; Equation (3.2) may exaggerate errors during low flows, while Equation (3.3) tends to emphasize errors during high flows when absolute errors tend to be the largest.

Determination of the Daily PFI requires two primary data sets: the observed daily stream flow record and the estimated daily precipitation time series. However, a proper hydrology analysis of a basin also requires estimation of certain hydrologic parameters; two necessary parameters include the time of concentration and the initial abstraction of the subwatershed. Therefore, the method for determining the Daily PFI has imbedded within it the calculation of the time of concentration and the initial abstraction value to allow the determination of days within each daily QP combination and the agreement category. 


\subsubsection{Time of Concentration}

To identify an increase in observed daily stream flow related to a particular precipitation event, one must determine the time of concentration $\left(t_{c}\right)$ required for runoff generated by the precipitation to reach the stream gage. An increase in observed stream flow is recorded if the observed stream flow in a watershed increases from day $t$ to day $t$ $+t_{c}$. For the case study, calculations indicated that $t_{c}$ values were slightly less than one day for the three headwater subwatersheds and approximately two days for the downstream Rivanna subwatershed. Therefore, for calculating the Daily PFI, $t_{c}$ values are equal to one day for the Mechums, Moormans, and North Fork Rivanna subwatersheds, and two days for the Rivanna subwatershed.

\subsubsection{Initial Abstraction}

A sensitivity analysis was used to test the impact of $I_{a}$ values on the Daily PFI. As shown in Figure 3.1, for all four subwatersheds, the rate of change in precipitation fidelity values is drastic between $\mathrm{I}_{\mathrm{a}}=0$ and $\mathrm{I}_{\mathrm{a}}=0.125 \mathrm{~cm} /$ day, yet the rate of change becomes much smaller as the value of $I_{a}$ increases beyond that value. An estimation of initial abstraction was deemed satisfactory when the rate of change in the Daily PFI per unit of initial abstraction dropped below one percent. Using this criterion, the initial abstraction was approximated as $0.125 \mathrm{~cm} /$ day for all four subwatersheds. This value is consistent with literature (Steenhuis et al. 1995). For each of the four subwatersheds, approximately half of the daily precipitation totals were below the initial abstraction value of $0.125 \mathrm{~cm} /$ day. Note that the Rivanna precipitation fidelity values, as shown in Figure 3.1, tend to be slightly higher than the three headwater subwatersheds. This is in 
part due to the 2-day time of concentration value, which offers a longer amount of time for potential precipitation-stream flow correspondence.

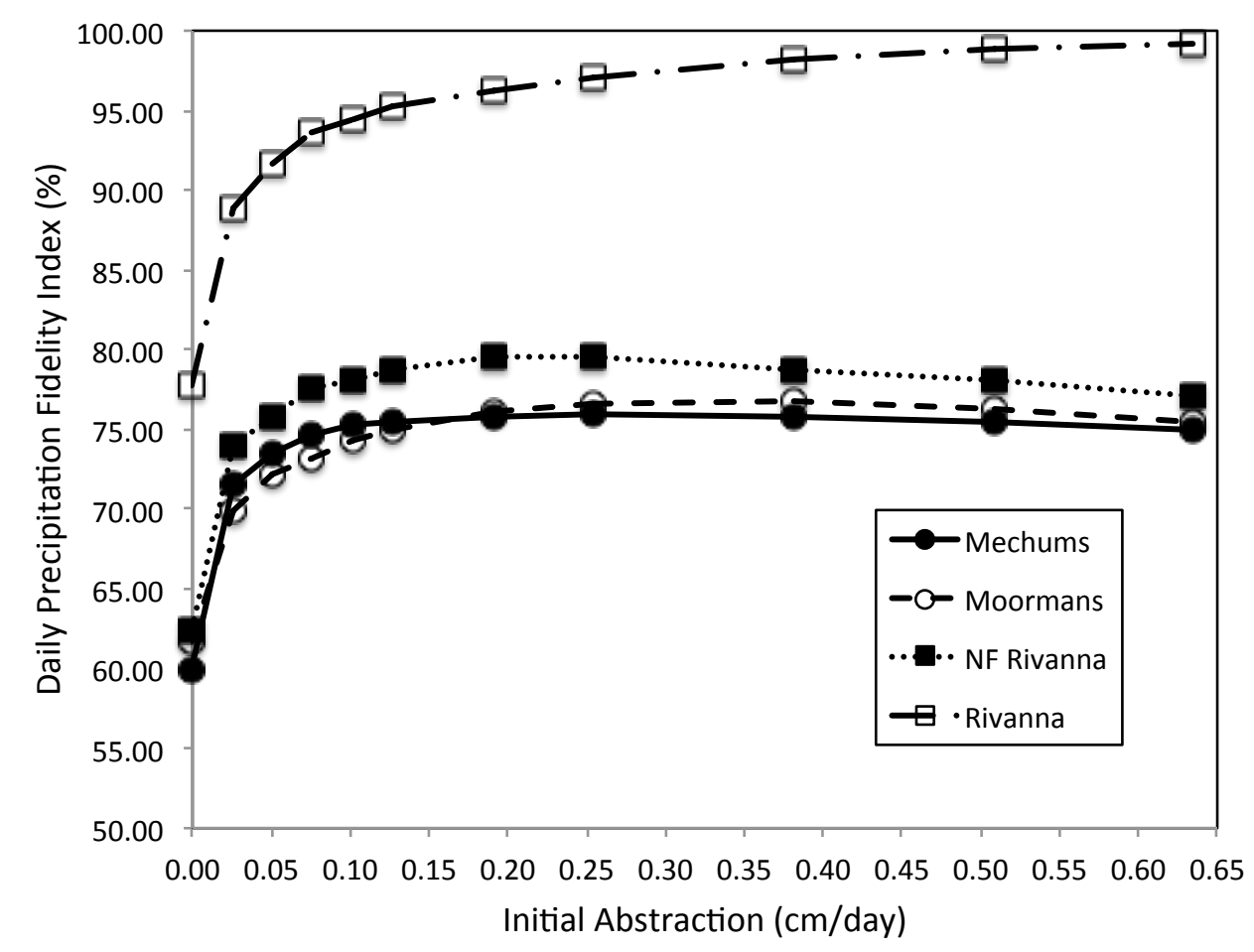

Fig. 3.1. Determination of initial abstraction $\left(I_{a}\right)$ for four Rivanna subwatersheds

\subsubsection{Results}

Using a $t_{c}$ value of one day for the three headwater subwatersheds and two days for the Rivanna subwatershed and an initial abstraction value of $0.125 \mathrm{~cm} /$ day for all four subwatersheds, the QP category was determined for each day in the analysis period. Then for each of the four subwatersheds, the percentages of days that comprise each QP category are shown in Table 3.3. The last column of Table 3.3 is the Daily PFI. 
Table 3.3. Percentage of days with each QP combination for overlap periods, by subwatershed

\begin{tabular}{|l|c|c|c|c|c|c|}
\hline Subwatershed & $\begin{array}{c}\mathbf{Q P}_{\mathbf{1 0}} \\
\mathbf{( \% )}\end{array}$ & $\begin{array}{c}\mathbf{Q P}_{\mathbf{0 1}} \\
\mathbf{( \% )}\end{array}$ & $\begin{array}{c}\mathbf{Q P}_{\mathbf{0 0}} \\
\mathbf{( \% )}\end{array}$ & $\begin{array}{c}\mathbf{Q P}_{\mathbf{1 1}} \\
\mathbf{( \% )}\end{array}$ & $\begin{array}{c}\text { \% Non- } \\
\text { matching }\end{array}$ & $\begin{array}{c}\text { \% agree } \\
\text { (Daily } \\
\text { PFI) }\end{array}$ \\
\hline Mechums & 14.59 & 9.96 & 55.57 & 19.89 & 24.54 & 75.46 \\
\hline Moormans & 14.08 & 11.00 & 55.42 & 19.51 & 25.07 & 74.93 \\
\hline NF Rivanna & 12.05 & 9.19 & 58.58 & 20.18 & 21.24 & 78.76 \\
\hline Rivanna & 0.00 & 4.81 & 69.59 & 25.59 & 4.81 & 95.19 \\
\hline
\end{tabular}

The daily model performance in each subwatershed was then determined relative to each precipitation fidelity category. $\mathrm{MDARVE}_{\mathrm{QP}}$ and $\mathrm{MDAAVE} \mathrm{QP}_{\mathrm{QP}}$ were calculated for each of the four subwatersheds (Table 3.4 and Table 3.5, respectively). Since the percentage of days in the Rivanna subwatershed $\mathrm{QP}_{10}$ category is zero, the MDARVE 10 and MDAAVE 10 is not applicable (NA) for the Rivanna subwatershed in Tables 3.4 and 3.5. The mean daily errors across all QP categories are shown in Table 3.1 (MDARVE) and the last column of Table 3.5 (MDAAVE).

Table 3.4. Mean Daily Absolute Relative Volumetric Percentage Error (\%) corresponding to each QP combination in Table 3.3, by subwatershed

\begin{tabular}{|l|r|r|r|r|}
\hline Subwatershed & MDARVE $_{10}$ & MDARVE $_{01}$ & MDARVE $_{00}$ & MDARVE $_{11}$ \\
\hline Mechums & 44.91 & 72.00 & 59.35 & 49.03 \\
\hline Moormans & 69.18 & 81.43 & 75.85 & 64.96 \\
\hline NF Rivanna & 44.35 & 62.50 & 61.63 & 48.87 \\
\hline Rivanna & NA & 69.26 & 61.00 & 50.38 \\
\hline Average & 39.61 & 71.30 & 64.46 & 53.31 \\
\hline
\end{tabular}

Table 3.5. Mean Daily Absolute Area-scaled Volumetric Error $\left(\mathrm{m}^{3} / \mathrm{hr} / \mathrm{km}^{2}\right)$ corresponding to each QP combination in Table 3.3, by subwatershed

\begin{tabular}{|l|r|r|r|r|r|}
\hline Subwatershed & MDAAVE $_{10}$ & \multicolumn{1}{c|}{ MDAAVE $_{01}$} & MDAAVE $_{00}$ & MDAAVE $_{11}$ & MDAAVE \\
\hline Mechums & 8.36 & 50.05 & 22.69 & 53.72 & 29.49 \\
\hline Moormans & 11.49 & 50.57 & 26.48 & 92.53 & 39.90 \\
\hline NF Rivanna & 7.73 & 47.20 & 22.73 & 59.35 & 30.56 \\
\hline Rivanna & $\mathrm{NA}$ & 49.66 & 22.43 & 46.49 & 29.89 \\
\hline Average & 6.89 & 49.37 & 23.58 & 63.02 & \multicolumn{1}{|c}{} \\
\cline { 1 - 5 } & & &
\end{tabular}


The results from Tables 3.3, 3.4, and 3.5 give insights on the effect of errors in precipitation estimation on model performance for short time scales. In general, the three directly calibrated subwatersheds - Mechums, North Fork Rivanna, and Rivanna subwatersheds - all exhibit very similar overall daily error values, both in terms of relative errors (56.45-58.68\%) and area-scaled errors $\left(29.49-30.56 \mathrm{~m}^{3} / \mathrm{hr}^{\prime} / \mathrm{km}^{2}\right)$. The Moormans subwatershed is the outlier in both Tables 3.4 and 3.5, exhibiting an overall relative error of $73.40 \%$ and area-scaled error of $39.90 \mathrm{~m} / \mathrm{hr} / \mathrm{km}^{2}$. These high error values may be attributed to the fact that the Moormans subwatershed was the only one of the four case study subwatersheds that was not directly calibrated in the CBP5 hydrologic calibration.

A closer look at the precipitation fidelity sub-categories shows that, on average, the larger magnitude errors occur on days when the estimated precipitation is greater than $\mathrm{I}_{\mathrm{a}}\left(\mathrm{QP}_{01}\right.$ and $\left.\mathrm{QP}_{11}\right)$ and smaller error magnitudes occur on days when estimated precipitation is below the $\mathrm{I}_{\mathrm{a}}\left(\mathrm{QP}_{10}\right.$ and $\left.\mathrm{Q}_{00}\right)$. Non-matching days $\left(\mathrm{QP}_{01}\right.$ and $\left.\mathrm{QP}_{10}\right)$ account for up to a quarter of the daily occurrences, indicating that the estimated precipitation is not accurately depicting the observed stream flow on these days. For the case study, the number of days with combination $\mathrm{QP}_{10}$ is higher than combination $\mathrm{QP}_{01}$ for three of the four subwatersheds, yet days with combination $\mathrm{QP}_{01}$ exhibit a relative volumetric error that is almost twice as high as days with combination $\mathrm{QP}_{10}$. The difference in the areascaled error is more drastic; Table 3.5 shows that the area-scaled error for days with combination $\mathrm{QP}_{01}$ is more than seven times as high as days with combination $\mathrm{QP}_{10}$. For this case study, these results indicate that combination $\mathrm{QP}_{01}$ has a particularly important impact on model performance. 
The results also give insight into the attenuation of precipitation estimation error from upstream to downstream subwatersheds. Table 3.3 shows that each of the three headwater subwatersheds has a relatively large number of days with combination $\mathrm{QP}_{01}$, and that model performance on those days is poor. The Rivanna subwatershed, with its two-day time of concentration, has a much higher daily PFI than the headwater subwatersheds. Although the percentage of days with $\mathrm{QP}_{01}$ non-agreement category is much lower than in the three headwater subwatersheds, $\mathrm{QP}_{01}$ category does exhibit higher relative and area-scaled errors than the days in the agreement category. Furthermore, despite the high daily PFI, the overall MDARVE (Table 3.1) and MDAAVE (Table 3.5) for the Rivanna subwatershed are similar to those of the headwater subwatersheds. This suggests that much of the error in the downstream Rivanna subwatershed is actually due to the attenuation of error from upstream subwatersheds. These results also indicate that low model performance in downstream subwatersheds, which might otherwise be attributed to problematic precipitation estimations in the subwatershed itself, might actually be attributable to precipitation problems at the scale of the headwater subwatersheds.

Several hydrological simplifications are incorporated into the daily PFI methodology. In the Daily PFI methodology, precipitation events are assumed to be the only driver of measurable increases in stream flow. While stream flow may change from day to day during dry periods due to changes in base flow, one would anticipate that a stream would likely be in recession during these periods. It would be an exceptional case where non-precipitation-related base flow changes cause increases in stream flow. Such an exceptional situation would be an area with highly regulated groundwater with 
episodic withdrawals. Although base flows are included within the USGS stream flow measurements and simulated within the CBP5 HSPF model, complex subsurface flows and withdrawals are beyond the scope of the model and the Daily PFI methodology. In addition, while the CBP5 HSPF model does consider the impacts of antecedent dry days and soil moisture on the initial abstraction, the Daily PFI methodology assumes a constant initial abstraction for each subwatershed. This assumption was made to maintain a simple Daily PFI methodology. Storm events with precipitation depths near the constant $I_{a}$ and/or with very long or short antecedent dry periods may contribute to the relatively high rate of daily discharge disagreement, as seen in the results in Tables 3.4 and 3.5 .

\subsection{Annual Precipitation Fidelity}

\subsubsection{Method}

A precipitation fidelity analysis for a longer time scale can provide additional insight into precipitation-based model error. An annual precipitation fidelity analysis can provide information about trends in annual precipitation-based stream flow response during a simulation period, while variation from these trends will identify subwatersheds with potentially problematic precipitation estimates. Using observed daily stream flow values from USGS gages and estimated precipitation values from the CBP5 HSPF Phase 5 Data Library, the regression of annual mean observed daily discharge against the mean annual estimated precipitation for each subwatershed for each year of record shows the trend in the annual stream flow response. The resulting coefficient of determination $\left(\mathrm{r}^{2}\right)$ of estimated annual precipitation input to observed annual stream flow indicates the 
fidelity of the estimated precipitation at an annual time step and is termed the Annual Precipitation Fidelity Index (Annual PFI).

In addition to the determination of Annual PFI, regression analysis is used to evaluate the goodness-of-fit of the model by comparing the regression of the modeled stream flow versus precipitation to the regression of the observed stream flow versus precipitation. For a high performing model with good quality precipitation input, one would anticipate a close match of the regressions for precipitation-to-model output and precipitation-to-observed flow. Alternatively, a distinctive difference between the two regressions would suggest that precipitation input and/or the model calibration are problematic. The similarity of two linear regressions can be measured using the Analysis of Covariance (ANCOVA) method. The estimated precipitation-to-observed stream flow regression is the same regression used to determine the value of Annual PFI and is termed the "OBS" regression in the following results. The estimated precipitation-tomodel stream flow regression is termed the "MOD" regression in the results. The ANCOVA method tests whether the slopes and intercepts of the OBS and MOD regressions are significantly different.

\subsubsection{Results}

In Figure 3.2, the two regression lines for each of the four subwatersheds are shown. The abscissa is the estimated annual precipitation and the ordinate is the annual mean daily outflow scaled by subwatershed area; both the modeled stream flow (hollow circles labeled as "MOD”) and the observed stream flow (filled circles labeled as "OBS")

are shown for each subwatershed. The OBS and MOD regression formulas and $\mathrm{r}^{2}$ values for the four subwatersheds are provided numerically in Table 3.6. 

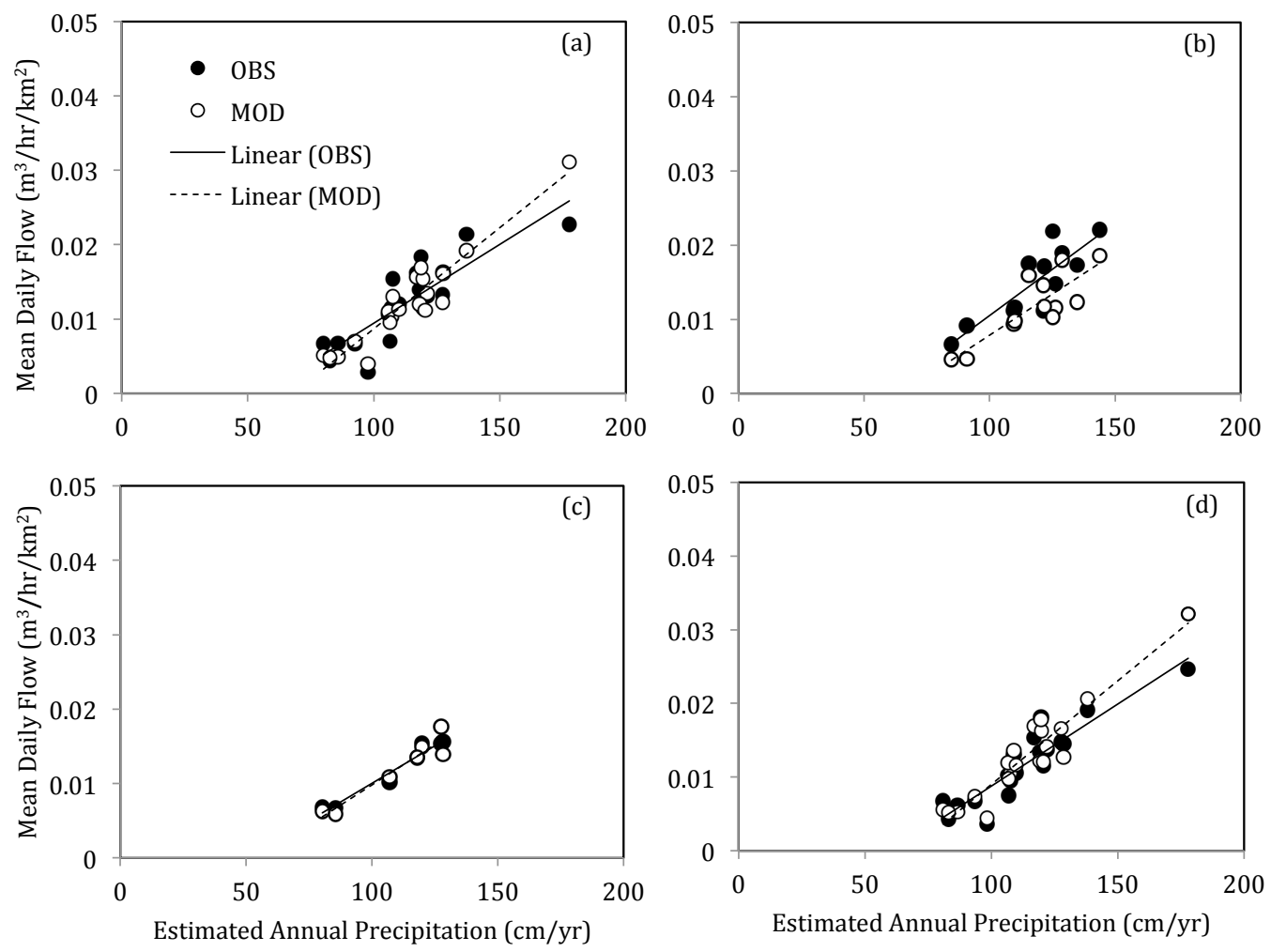

Fig. 3.2. Annual Precipitation-Streamflow Regression data and trendlines for four Rivanna subwatersheds ((a) Mechums, (b) Moormans, (c) North Fork Rivanna, and (d) Rivanna 
Table 3.6. Regression equations and associated $r^{2}$ values between estimated annual precipitation $(\mathrm{cm} / \mathrm{yr})$ and mean daily area-scaled streamflow $\left(Q_{d}, \mathrm{~m}^{3} / \mathrm{hr} / \mathrm{km}^{2}\right)$, based on CBP5 (MOD) or observed USGS gage data (OBS)

\begin{tabular}{|c|c|c|c|}
\hline Subwatershed & Simulation & Regression Equation & $r^{2}$ \\
\hline Mechums & \multirow{4}{*}{ MOD } & $Q_{d}=0.0003 p-0.0185$ & 0.90 \\
\hline Moormans & & $Q_{d}=0.0002 p-0.0142$ & 0.70 \\
\hline North Fork Rivanna & & $Q_{d}=0.0002 p-0.0119$ & 0.92 \\
\hline Rivanna & & $Q_{d}=0.0003 p-0.0191$ & 0.90 \\
\hline Mechums & \multirow{4}{*}{ OBS } & $Q_{d}=0.0002 p-0.0118$ & 0.73 \\
\hline Moormans & & $Q_{d}=0.0002 p-0.0144$ & 0.73 \\
\hline North Fork Rivanna & & $Q_{d}=0.0002 p-0.0101$ & 0.96 \\
\hline Rivanna & & $Q_{d}=0.0523 p-0.0135$ & 0.84 \\
\hline
\end{tabular}

The results show that for the three directly calibrated subwatersheds, the Mechums, North Fork Rivanna, and Rivanna subwatersheds, the MOD $r^{2}$ values are equal to or greater than 0.90 , indicating that there is a high level of correspondence between estimated precipitation and modeled flows. This should be expected since the estimated precipitation is the primary data driving the output of the mechanistic CBP5 model. The Mechums and Rivanna subwatersheds show a much clearer trend between estimated precipitation and modeled flows than between estimated precipitation and observed flows, while the North Fork Rivanna subwatershed shows high $\mathrm{r}^{2}$ values for both regressions. The MOD $\mathrm{r}^{2}$ value for the Moormans subwatershed was only 0.70 , significantly lower than the other subwatersheds. The USGS gage in the Moormans subwatershed was not utilized during the CBP5 calibration, and the poor annual regression results highlight the impact of direct hydrology calibration on model consistency at the subwatershed scale.

The Annual PFI, which compares estimated precipitation to observed outflows, is not quantifying a direct input-output connection like the MOD regression. It is a measure of the correspondence, and thus quality, of the input data. The OBS regressions show a 
broad range of values for the Annual PFI, with $\mathrm{r}^{2}$ values ranging from 0.73 to 0.96 . Although the precipitation estimates appear to be relatively accurate for some subwatersheds, such as the North Fork Rivanna, the $r^{2}$ values show that the estimates are less accurate for others, such as the Mechums subwatershed. It is also of interest to note that mountainous subwatersheds exhibit a lower Annual PFI than subwatersheds located primarily in the piedmont. Specifically, the Mechums and Moormans subwatersheds, which have a greater percentage of mountainous terrain than the North Fork Rivanna and Rivanna subwatersheds, exhibit lower fidelity values.

The ANCOVA method was used to compare the regressions for each of the four subwatersheds. The OBS and MOD slopes and y-intercepts were compared by calculating two two-tailed probability values (P-values), first testing the null hypothesis that the slopes are identical ('the lines are parallel'), and then testing the null hypothesis that the y-intercepts are identical ('there is no compelling evidence that the lines are different'). The method to compare the slopes and intercepts of two regression lines is discussed in detail in Chapter 17 of Biostatistical Analysis (Zar 1999).

Table 3.7 shows the results of the ANCOVA analysis. Based on the P-values shown in Table 3.7, the slopes and intercepts of the OBS and MOD regression lines for three of the subwatersheds (Mechums, North Fork Rivanna, and Rivanna) satisfy the null hypothesis and show that the regression lines are not statistically different with a $95 \%$ confidence level. However, for the Moormans subwatershed, the intercept values of the OBS and MOD regression lines are shown to be statistically different with a $99.9 \%$ confidence level. For a given level of estimated precipitation, the model consistently 
significantly underestimates stream flow in the Moormans subwatershed. This can be seen in Figure 3.2(b).

Table 3.7. Two-tailed probability values (P-values) for four Rivanna subwatersheds. Statistical difference with a 95\%-confidence level requires $P$-value $\leq .05$

\begin{tabular}{|l|c|c|c|}
\hline \multicolumn{1}{|c|}{ Subwatershed } & $\begin{array}{c}\text { Slope } \\
\text { P-value }\end{array}$ & $\begin{array}{c}\text { Intercept } \\
\text { P-value }\end{array}$ & $\begin{array}{c}\text { Statistically } \\
\text { different? }\end{array}$ \\
\hline Mechums & 0.1157 & 0.9752 & No \\
\hline Moormans & 0.1315 & 0.0004 & Yes \\
\hline North Fork Rivanna & 0.6604 & 0.9106 & No \\
\hline Rivanna & 0.0837 & 0.1591 & No \\
\hline
\end{tabular}

To compare precipitation fidelity to model performance at the annual scale, Figure 3.3 exhibits the relationship between the Annual PFI and annual model performance using the index values (OBS $\mathrm{r}^{2}$ values) from Table 3.6 and the MAAVE values from Table 3.1, respectively. There appears to be a consistent trend for the Mechums, North Fork Rivanna, and Rivanna subwatersheds, where model performance is directly related to the Annual PFI. However, the Moormans subwatershed, which exhibited significant differences between the OBS and MOD regressions in the ANCOVA analysis, is not consistent with the other subwatershed relationships. 


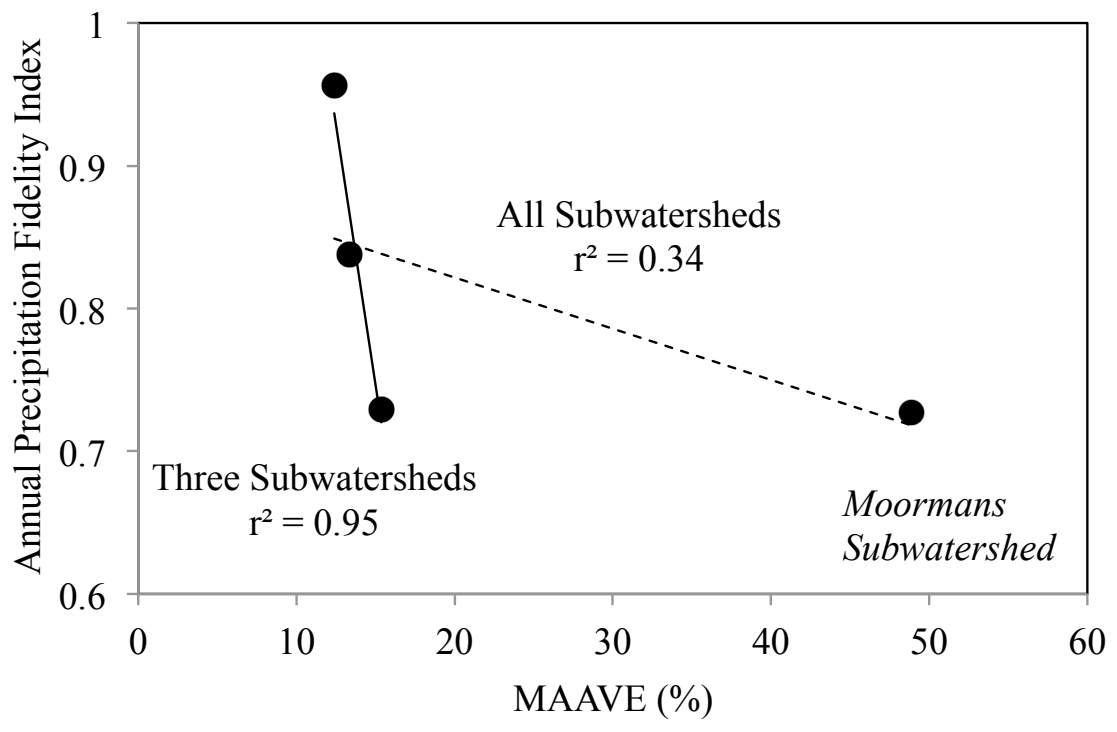

Fig. 3.3. Annual Precipitation Fidelity Index and model performance (MAAVE) for four Rivanna subwatersheds

The inconsistency with the Moormans subwatershed is due to a high annual mean error value. This result, coupled with the low MOD $r^{2}$ value and the statistical difference between the observed and modeled stream flow regressions for the Moormans subwatershed, suggests that there is either a problem with the subwatershed hydrology due to the lack of direct calibration, or there is a problem with the precipitation data itself. These results support the earlier conclusion that the high error values found for Moormans subwatershed in the Daily PFI results can be attributed to the fact that the Moormans subwatershed was the only one of the four case study subwatersheds that was not directly calibrated in the CBP5 hydrologic calibration. The inconsistency could be further compounded by the lower fidelity values observed in mountainous subwatersheds such as Moormans. 


\subsection{Conclusions}

Using only minimum data requirements (time series of estimated precipitation, observed stream flow, and modeled stream flow), the Daily and Annual Precipitation Fidelity Indices provide a useful way to analyze the correspondence between precipitation estimations and stream flow at both the daily and annual scales. The use of the indices in conjunction with model performance satisfy limitations seen in single 'goodness of fit' statistics such as the Nash-Sutcliffe Efficiency Index, namely by

categorizing model performance as a function of rainfall and stream flow events, implicitly incorporating rainfall into the measures of goodness of fit, and providing information about precipitation and model performance at different time scales. Furthermore, regression and ANCOVA analyses were shown to quantitatively describe the relationship between the fidelity measures and model performance.

While the lack of daily precipitation fidelity might not affect the long-term volumetric balances used in water quality analyses (as shown by the annual and entire period results shown in Table 3.1), the resulting daily error is important when using the model for water planning and permitting purposes. The low precipitation fidelity $(21 \%$ $25 \%$ days non-matching) in the headwater subwatersheds suggest that precipitation needs to be better represented in these headwater subwatersheds. Improved precipitation input should then reduce the number of $\mathrm{QP}_{01}$ days and their associated elevated model errors. Improved predictions in the headwater subwatersheds may also improve model performance in downstream subwatersheds.

Although making a generalization about regression trends cannot be validated with a small data set, these results appear to show that in cases where the annual 
regressions are found to be statistically similar, the model is a more accurate representation of the observed annual flows: the annual flow errors scale linearly with annual precipitation fidelity and have levels of model error below $20 \%$, which is considered in the acceptable range of annual model error for CBP5 subwatersheds (Apse et al. 2008). In contrast, significant difference in the annual regressions appears to lead to unsatisfactory model performance and a failure in linear scaling with precipitation fidelity. For the case study, lack of direct model calibration in the Moormans subwatershed may have led to the poor annual performance.

The inverse relationship between volumetric error and time scale length, as well as the model performance sensitivity at short time scales, presents a variety of future research possibilities. Further studies should examine a larger set of model data in order to make more generalized conclusions regarding the relationship between precipitation fidelity, model performance, and statistical similarities between modeled and observed data. Also, due to the importance of relatively short and "extreme" low flow events (e.g. droughts) in water resource planning, model accuracy during extreme low flow events should be carefully considered. 


\subsection{References}

Ahlburg, D. (1995). "Simple Versus Complex Models: Evaluation, Accuracy, and Combining." Mathematical Population Studies, 5, 281-90.

Andreassian, V., Perrin, C., Michel, C., Usart-Sanchez, I., and Lavabre, J. (2001). "Impact of imperfect rainfall knowledge on the efficiency and the parameters of watershed models." J. Hydrol., 250, 206-223.

Apse, C., DePhilip, M., Zimmerman, J. and Smith, M.P. (2008). 'Case Study 1: A model for water supply planning in Virginia', in "Developing instream flow criteria to support ecologically sustainable water resource planning and management", Final report to the Pennsylvania Instream Flow Technical Advisory Committee. 196 p., available at

http://www.depweb.state.pa.us/watershedmgmt/lib/watershedmgmt/water_allocati on/pa_instream_flow_report-_tnc_growing_greener-_final.pdf.

Ball, J.E. and Luk, K.C. (1998). "Modeling spatial variability of rainfall over a catchment." J. Hydrologic Engrg, 3(2),122-130.

Bardossy, A., and Das, T. (2008). "Influence of rainfall observation network on model calibration and application." Hydrol. Earth Syst. Sci., 12, 77-89.

Bastin, G., Lorent, B., Duque, C., and Gevers, M. (1984). "Optimal estimation of the average rainfall and optimal selection of rain gauge locations." Water Resour. Res., 20(4), 463-470.

Beven, K.J., and Hornberger, G.M. (1982). "Assessing the effect of spatial pattern of precipitation in modeling stream flow hydrographs." J. Am. Water Resour. Assoc., $18(5), 823-829$.

Bicknell, B.R., Imhoff, J.C., Kittle, J.L., Jr., Donigian, A.S., Jr., and Johanson, R.C. (1997). "Hydrological Simulation Program--Fortran, User's manual for version 11.” U.S. Environmental Protection Agency, National Exposure Research Laboratory, Athens, Ga., EPA/600/R-97/080, 755 p., available at http://water.usgs.gov/software/HSPF/.

Chaubey, I., Haan, C.T., Salisbury, J.M., and Grunwald, S. (1999). "Quantifying model output uncertainty due to spatial variability of rainfall." J. Am. Water Resour. Assoc., 35(5), 1113-1123.

Chesapeake Community Modeling Program. (2010). Chesapeake Bay Watershed Phase 5.3 Model, available at http://ches.communitymodeling.org/models.php

Chang, C-L, Lo, S-L, and Chen, M-Y. (2006). "Uncertainty in watershed response predictions induced by spatial variability of precipitation." Environmental Monitoring and Assessment, 127, 1-3, 147. 
Cole, S, and Moore, R. (2008). "Hydrological modelling using raingauge- and radarbased estimators of areal rainfall." J. Hydrol., 358, 159-181.

Doherty, J. (2004). "PEST: Model-independent parameter estimation, User manual," $5^{\text {th }}$ ed., Watermark Numer. Comput., Brisbane, Australia.

Fu, S., Sonnenborg, T.O., Jensen, K.H., and He, X. (2011). "Impact of precipitation spatial resolution on the hydrological response of an integrated distributed water resources model." Vadose Zone Journal, 10(1), 25-36.

Gupta, H. V., Sorooshian, S., and Yapo, P.O. (1998). "Toward improved calibration of hydrologic models: Multiple and noncommensurable measures of information." Water Resour. Res., 34(4), 751-763.

Hay, L.E., McCabe, Jr., G.J., Wolcok, D.M., and Ayers, M.A. (1991). "Simulation of precipitation by weather type analysis." Water Resour. Res., 27(4), 493-501.

Hay, L., Clark, M., and Leavesley, G. (2000a). "Use of atmospheric forecasts in hydrologic models - Part 2: Case Study" in Proceedings of the American Water Resources Association's Spring Specialty Conference on Water Resources in Extreme Environments, Anchorage, Alaska, April 2000, pp. 221-226.

Hay, L.E., Wilby, R.L., and Leavesley, G.H. (2000b). A comparison of delta change and downscale GCM scenarios for three mountainous basins in the United States. $J$. Am. Water Resour. Assoc., 36(2), 387-397.

Hay, L.E., Leavesley, G.H., Clark, M.P., Markstrom, S.L., Viger, R.J., and Umemoto, M. (2006). "Stepwise, multiple objective calibration of a hydrologic model for a snowmelt dominated basin." J. Am. Water Resour. Assoc., 42(4), 0877-0890.

Hirsch, R.M. (1979). “An evaluation of some record reconstruction techniques.” Water Resour. Res., 15(12), 1781-1790.

Hyndman, R. and Koehler, A. (2006). "Another Look at Measures of Forecast Accuracy." International Journal of Forecasting, 22, 679-688.

Jakeman, A., and Hornberger, G. (1993). "How much complexity is warranted in a rainfall-runoff model.” Water Resour. Res., 29(8), 2637-2649.

Kalinga, O.A., and Thian, Y.G. (2006). "Semi-distributed modelling of basin hydrology with radar and gauged precipitation.” Hydrol. Process., 20, 3725-3746.

Kim, U., and Kaluarachchi, J.J. (2009). "Hydrologic model calibration using discontinuous data: an example from the upper Blue Nile River Basin of Ethiopia." Hydrol. Process., 23, 3705-3717.

Lopes, V.L. (1996). " On the effect of uncertainty in spatial distribution of rainfall on catchment modelling." Catena, 28, 107-119. 
Lumb, A.M., McCammon, R.B., and Kittle, Jr., J.L. (1994). "Users manual for an expert system (HSPexp) for calibration of the Hydrologic Simulation ProgramFortran.” U.S. Geological Survey Water-Resources Investigations Report 944168, $102 \mathrm{p}$.

Nash, J.E., and Sutcliffe, J.V. (1970). "River flow forecasting through conceptual models. Part 1: A discussion of principles." J. Hydrol., 10(3), 282-290.

Nicotina, L., Alessi Celegon, E., Rinaldo, A., and Marani, M. (2008). "On the impact of rainfall patterns on the hydrologic response." Water Resour. Res., 44, W12401.

Obled, C., Wendling, J., and Beven, K. (1994). "The sensitivity of hydrological models to spatial rainfall patterns: an evaluation using observed data.' J. Hydrol., 159, 305333.

Oudin, L., Perrin, C., Mathevet, T., Andreassian, V., and Michel, C. (2006). "Impact of biased and randomly corrupted inputs on the efficiency and the parameters of watershed models." J. Hydrol., 320, 62-83.

Paturel, J.E., Servat, E., and Vassiliadis, A. (1995). "Sensitivity of conceptual rainfallrunoff algorithms to errors in input data - case of the GR2M model." J. Hydrol., $168,111-125$.

Pessoa, M.L., Bras, R.L., and Williams, E.R. (1993). "Use of weather radar for flood forecasting in the Sieve river basin: a sensitivity study." Journal of Applied Meteorology, 32, 462-474.

Rayer, S. (2007). "Population Forecast Accuracy: Does the Choice of Summary Measure of Error Matter?" Population Research and Policy Review, 26, 163-184.

Ruelland, D., Ardoin-Bardin, S., Billen, G., and Servat, E. (2008). "Sensitivity of a lumped and semi-distributed hydrological model to several methods of rainfall interpolation on a large basin in West Africa." J. Hydrol., 361, 96- 117.

Segond, M.L., Wheater, H.S., and Onof, C. (2007). "The significance of spatial rainfall representation for flood runoff estimation: A numerical evaluation based on the Lee catchment, UK." J. Hydrol., 347: 116-131.

Seo, D.J., Krajewski, W. F., and Bowles, D.S. (1990). "Stochastic interpolation of rainfall data from raingages and radar using cokriging: 1. Design of experiments." Water Resour. Res., 26, 469-477.

Servat, E. and Dezetter, A. (1991). "Selection of calibration objective functions in the context of rainfall-runoff modelling in a sudanese savannah area." Hydrol. Sci. J., 36(4), 307-330. 
Smith, M., Koren, V., Zhang, Z., Reed, S., Pan, J., and Moreda, F. (2004). "Runoff response to spatial variability in precipitation: an analysis of observed data." $J$. Hydrol., 298, 267-286.

Steenhuis, T. S., Winchell, M., Rossing, J., Zollweg, J. A., and Walter, M. F. (1995). "SCS runoff equation revisited for variable source runoff areas." J. Irrig. Drain. Eng., 121, 234-238.

Tabios, G. Q., and Salas, J.D. (1985). "A comparative analysis of techniques for spatial interpolation of precipitation." Water Resour. Bull., 21, 365-380.

Thiessen, A.H. (1911). "Precipitation for large areas.” Mon. Weather Rev., 39, 10821084.

Troutman, B.M. (1983). "Runoff prediction errors and bias in parameter estimation induced by spatial variability of precipitation." Water Resour. Res., 19(3), 791810 .

Umakhanthan, K., and Ball, J. (2003). "The Importance of Rainfall Models in Catchment Simulation." Modelling and Simulation Society of Australia and New Zealand Inc., Australia, 368-373.

United States Environmental Protection Agency (USEPA). (2010). "Chesapeake Bay Phase 5.3 Community Watershed Model.” EPA 903S10002 - CBP/TRS-303-10. U.S. Environmental Protection Agency, Chesapeake Bay Program Office, Annapolis MD. December 2010.

United States Geological Survey (USGS). (2011). "National Water Information System: USGS Surface-Water Data for the Nation," available at http://waterdata.usgs.gov/nwis/sw.

van der Heijden, S. and Haberlandt, U. (2010). "Influence of spatial interpolation methods for climate variables on the simulation of discharge and nitrate fate with SWAT." Adv. Geosci., 27, 91-98.

Wilson, C.B., Valdes, J.B., and Rodriguez-Iturbe, I. (1979). "On the influence of the spatial distribution of rainfall on storm runoff." Water Resour. Res., 15(2), 321328.

Zar, J. (1999). Biostatistical Analysis. 3rd edition, Prentice-Hall, Englewood Cliffs, NJ. 


\section{Chapter 4}

\section{Design of Outlet Control Structures for Ecological Detention Ponds}

\subsection{Introduction}

Development in the United States inevitably changes the hydrologic landscape of the country. In most cases, increased urbanization converts pervious areas, such as forest and pasture, into impervious areas, such as roofs, roads, and parking areas. One of the major effects of increased urbanization is the degradation of water resources and water quality (USEPA 2001). Increased imperviousness from urbanization in a watershed alters the natural hydrologic condition within a watershed, resulting in increased volume and rate of surface runoff, decreased ground water recharge and base flow, and frequent and severe incidents of local flooding (Carter 1961; Hall 1984; USEPA 1993; Tang et al. 2005). In addition, increased imperviousness often leads to decreased water quality in

receiving streams (Schueler 1995; Gove et al. 2001), which detrimentally affects the receiving aquatic systems. 
Current regulations, promulgated at the local and state levels, have focused on impacts of development, thereby limiting landscape alterations. For instance, Maryland (CWP and MDE 2009) and Virginia (VADCR 2010) are establishing a "Unified Sizing Criteria" for Best Management Practices (BMPs), geared to satisfy a continuum of management expectations. Each development site must meet various stormwater criteria, such as providing a water quality storage volume, a recharge volume, channel protection storage volumes, and flood protection. These storage volumes are typically defined with respect to addressing the flows from a limited number of storm events of various return periods, $\mathrm{T}_{\mathrm{R}}$ (such as the 2-yr, 10-yr and 100-yr storm events). Ecological protection is not an explicit criterion, and the hope is, at best, that the unified approach for BMP design will indirectly also preserve the downstream aquatic ecosystems.

Broadly defined, BMPs are techniques, measures, structural controls, or policies that are used to prevent or reduce the degradation of runoff water quantity and quality (USEPA 1991; Urbonas and Stahre 1993; USEPA 2004) and are often used to mimic natural hydrological processes of a stream network (Villarreal et al. 2004). BMPs are commonly incorporated into engineering design to lessen the impact of development in a watershed. Dry detention ponds (hereafter simply referred to as detention ponds) are one of the most commonly used BMPs (USEPA 2006). A detention pond is normally designed for two primary purposes: to attenuate specific return period discharges at a level below predevelopment conditions; and for suspended solids removal, especially due to the "first flush" phenomena (Sansalone and Cristina 2004).

Municipalities typically fashion peak flow release and water quality capture volume (WQCV) criteria to guide detention pond design. However, these criteria are 
oriented towards the volume and quality of discharged water and do not explicitly account for the health of in-stream ecosystems (Roesner et al. 2001). For example, detention ponds are effectively used to attenuate peak flows of large storms, but the slow release of stored water from multiple detention ponds distributed throughout a watershed may induce sustained high stream flow conditions which cause ecological damage (Reichold et al. 2010). Typical detention pond design criteria do not present an inclusive guide for accommodating the complete set of water quantity and quality needs of an ecosystem.

Alternatively, ecological functions can be more intimately integrated into the stormwater management by incorporating methods, such as flow frequency curves, that can be used to relate hydrological flows to ecological impact. Previous work has evaluated the performance, ecological impact (Nehrke and Roesner 2002; Nehrke and Roesner 2004), and erosion potential (Rohrer and Roesner 2006; Pomeroy et al. 2008) resulting from urban storm-water systems by comparing the post-development flow frequency curve to the pre-development curve; however, these studies were used for performance evaluation rather than design strategies. Flow frequency curves have also been suggested as a basis for the design of bioretention facilities (Palhegyi 2010a; Palhegyi 2010b), a Low-impact development BMP used to manage storm-water runoff. However, this author has found no specific strategy for designing ecologically sustainable detention pond outlet control structures using similar concepts.

This study proposes an alternative, ecological-flow-based design construct for stormwater management by introducing a detention pond outlet control structure design approach that attempts to minimize ecological impairment as defined by an innovative 
ecological flow paradigm based on flow frequency curves: the eco-flow statistics. The approach is then demonstrated for a case study to illustrate how detention ponds can be redesigned not only for the control of peak flows and water quality control volume release times $\left(\mathrm{T}_{\mathrm{WQ}}\right)$, but also to reduce downstream ecological impairment.

\subsection{Ecological Stream Flows}

Most river modeling texts still present minimum instream flows (Cavendish and Duncan 1986; Milhous et al. 1989) as the only ecological control (Vogel et al. 2007). However, recent studies have shown that a number of other flow parameters are also related to ecological attributes (Poff 1996; Puckridge et al. 1998; Bragg et al. 2005). These attributes are extremely diverse, such as temperature, water quality, and channel morphology, and are often difficult and expensive to measure. For these reasons, only limited historical data is available for most ecologically significant attributes. In contrast, a considerable amount of historical stream flow data has been gathered at local, state, and national levels. For instance, the USGS National Water Information System (NWIS 2010) supplies daily stream flow values from over 25,000 sites across the nation.

Given the limited available ecological data, yet extensive amount of stream flow data, research has aimed at identifying stream flow statistics or hydrologic indices that can be used as surrogates for identifying the impact of development and flow regulation on an ecosystem. Some methodologies that employ hydrological indices for understanding ecological health include: the Texas method (Matthews and Bao 1991), a planning method for estimating instream flow needs for protection of aquatic resources below potential reservoir sites; the Basic Flow methodology (Palau and Alcázar 2010), a 
management methodology which establishes the timing of instream flow requirements based on the biological functioning of a river; the Indicators of Hydrologic Alteration (IHA) methodology (Richter et al. 1996; Richter el al. 1997; Poff et al. 1997); and the ecodeficit and ecosurplus metrics (Vogel and Fennessey 1994; Vogel et al. 2007). These methodologies have been used in scientific studies across a variety of fields, including reservoir operations (Matthews and Bao 1991; Suen and Eheart 2006; Vogel et al. 2007; Shiau and Wu 2010), BMP placement (Edgerly 2006), optimized watershed development (Reichold et al. 2010), altered flow ecological assessments (Matthews and Bao 1991; Shiau and $\mathrm{Wu}$ 2004; Palau and Alcázar 2010), and ecological flow policy recommendations (Mathews and Richter 2007).

\subsection{Flow Duration Curves, Eco-Flow Statistics, and ecodifference Metric}

On the basis of over 100 literature references, five features of the natural flow regime (magnitude, duration, timing, frequency, and rate of change/flashiness) are considered essential for ecology (Bragg et al. 2005). The IHA methodology - a set of metrics used for quantifying the impact of regulation and development on flow regimes calculates 33 parameters within these five groups that are particularly relevant to ecological quality (Poff et al. 1997). Using the 33 parameters, a statistical signature of the health of the ecosystem is determined. IHA has been used extensively in a variety of ecological and engineering applications (see Shiau and Wu 2004; Richter et al. 2006; Shiau and Wu 2006; Suen and Eheart 2006; Mathews and Richter 2007; Shiau and Wu

2010; Reichold et al. 2010). However, many IHA parameters have been found to be inter- 
correlated (Olden and Poff 2003; Gao et al. 2009). This creates numerical redundancy that potentially complicates environmental flow assessments (Arthington et al. 2006).

In response, Gao et al. (2009) proposed a set of nine hydrological indices that have a strong relationship with the IHA parameters yet limits the numerical redundancy in employing all 33 IHA parameters. The nine hydrological indices are termed the ecoflow statistics. The nine eco-flow statistics are the annual ecodeficit, annual ecosurplus, winter ecodeficit, winter ecosurplus, spring ecodeficit, spring ecosurplus, summer ecodeficit, summer ecosurplus, and total seasonal ecochange.

The ecodeficit and ecosurplus are computed from median annual and median seasonal flow duration curves (FDCs). FDCs are flow frequency curves created by ranking average daily stream flows from highest to lowest over a period of interest, and then by plotting the ranked flow against each flow's exceedance probability (for further details, see Vogel and Fennessey 1994). FDCs calculated using hydrographs from before and after a hydrologic alteration, such as the construction of a dam and reservoir, give insight into the impact of a hydrologic alteration on downstream or receiving stream flow regimes. Similarly, comparison of pre- and post-development FDCs can give insight into the impact of a landscape alteration, such as a new land development, on the flow regimes.

An example set of FDCs is shown in Figure 4.1. The black line in Figure 4.1 is the median annual FDC for a receiving stream before development occurs and the dashed line is the median annual FDC for the same stream after development occurs. The area below the pre-development FDC and above the post-development FDC represents the amount of water now unavailable to the receiving stream due to flow alteration caused by 
the development. The ecodeficit of the period is the ratio of this area over the total area under the pre-development median annual FDC. Similarly, ecosurplus is the area above the pre-development FDC and below the post-development FDC divided by the total area under the pre-development median FDC. The ecosurplus represents the amount of water added to the receiving stream due to development. Thus, the ecodeficit and ecosurplus can be defined as dimensionless measures which represent the overall loss or gain, respectively, in stream flow due to flow regulation during a time period of interest (Vogel et al. 2007).

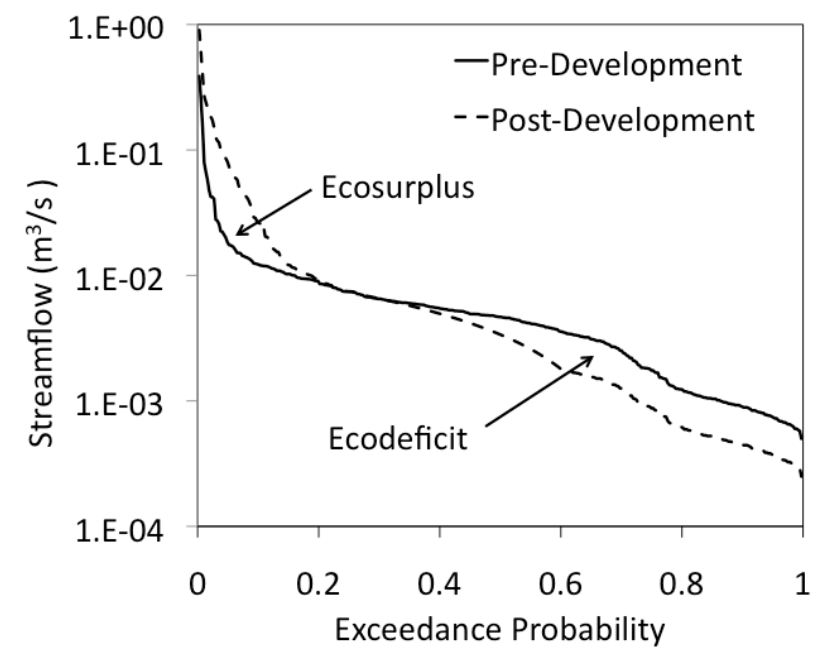

Fig.4.1. Areas of ecodeficit and ecosurplus between pre-development and postdevelopment median flow duration curves of a receiving stream

In addition to the annual ecodeficit and ecosurplus derived from median annual FDCs, ecodeficit and ecosurplus can be calculated for any time period of interest, such as months or seasons as well as years. Since FDCs do not explicitly incorporate the timing of stream flows, the use of seasonal ecodeficit and ecosurplus can be employed to capture some timing impacts (Vogel et al. 2007). As proposed by Gao (2009), the year can be 
divided into three seasons [winter (November - February), spring (March - June), and summer (July - October)] and seasonal ecodeficits and ecosurplus can be calculated for each of these three seasons. The ninth eco-flow statistic, the total seasonal ecochange, is the sum of all the median seasonal ecodeficits and ecosurplus.

Although more efficient than the use of 33 separate IHA statistics, the employment of nine different metrics for making ecologically sustainable BMP design decisions could be confusing, potentially redundant, and still difficult to implement. The use of a single metric of hydrologic alteration would reduce the difficulty in making design decisions. The simple sum of the nine eco-flow statistics is a good candidate for a single metric. However, depending on the characteristics of a region- specifically climate- as well as management and policy imperatives in that region, certain eco-flow statistics might necessitate greater influence on the BMP design than others. An assignment of specific weights to each of the eco-flow statistics provides the flexibility to incorporate case-specific preferences into the BMP design approach; the weighted statistics can then be summed to calculate a single value. In this study, the resulting weighted sum of the nine eco-flow statistics, termed the 'ecodifference,' will be used to specify ecological impact resulting from hydrologic alteration:

$$
\text { ecodifference }=\sum_{i=1}^{9} \mathrm{~W}_{\mathrm{i}} \mathrm{S}_{\mathrm{i}}
$$

where $\mathrm{S}_{i}$ is value of one of the nine eco-flow statistics and $\mathrm{W}_{i}$ is the weighting coefficient for that statistic; $S_{1}$ and $S_{2}$ are the annual ecodeficit and ecosurplus, $S_{3}$ through $S_{8}$ are the seasonal (winter, spring, summer) ecodeficits and ecosurplus, $\mathrm{S}_{9}$ is the total seasonal ecochange, and $\mathrm{W}_{1}-\mathrm{W}_{9}$ are weighting coefficients assigned to each of the nine eco-flow 
statistics. The values of the eco-flow statistics and the weighting coefficients are dimensionless, and thus the value of ecodifference is also dimensionless.

Various combinations of weighting coefficients can be used to calculate the ecodifference according to the needs and preferences of the designers or water managers. For this study, four combinations of weighting coefficients are presented (Table 4.1). Combination A provides equal weights for all nine eco-flow statistics. Three of the nine eco-flow statistics, the total seasonal ecochange, summer ecosurplus and winter ecosurplus, have been found to explain the most variability in the IHA statistics (Gao et al. 2009). A reduced statistical set containing only these three statistics further decreases the likelihood of intercorrelation amongst the statistics. Thus, Combination B represents the reduced statistical set by assigning a unit value to the total seasonal ecochange, summer ecosurplus and winter ecosurplus, and weights of zero to the other six statistics. Alternatively, Combination $\mathrm{C}$ gives some weight to all nine-flow statistics, yet gives greater weight to the three-member set. Finally, the timing impacts of flows can be the most important design variable in some cases. Therefore, Combination D emphasizes the effect of timing by highlighting the eco-flow statistic - the total seasonal ecochange - that incorporates the seasonal variability into the FDCs: namely, the winter, spring, and summer ecodeficits and ecosurplus. 
Table 4.1. Weighting coefficients and their values for the four combinations A, B, C, and D

\begin{tabular}{|l|c|c|c|c|c|}
\hline \multicolumn{1}{|c|}{ Eco-flow Statistic } & Weighting Coefficient & $\mathrm{A}$ & $\mathrm{B}$ & $\mathrm{C}$ & $\mathrm{D}$ \\
\hline Annual Ecodeficit & $\mathrm{W}_{1}$ & 1 & 0 & 1 & 0 \\
\hline Annual Ecosurplus & $\mathrm{W}_{2}$ & 1 & 0 & 1 & 0 \\
\hline Winter Ecodeficit & $\mathrm{W}_{3}$ & 1 & 0 & 1 & 0 \\
\hline Winter Ecosurplus & $\mathrm{W}_{4}$ & 1 & 1 & 2 & 0 \\
\hline Spring Ecodeficit & $\mathrm{W}_{5}$ & 1 & 0 & 1 & 0 \\
\hline Spring Ecosurplus & $\mathrm{W}_{6}$ & 1 & 0 & 1 & 0 \\
\hline Summer Ecodeficit & $\mathrm{W}_{7}$ & 1 & 0 & 1 & 0 \\
\hline Summer Ecosurplus & $\mathrm{W}_{8}$ & 1 & 1 & 2 & 0 \\
\hline Total Seasonal Ecochange & $\mathrm{W}_{9}$ & 1 & 1 & 2 & 1 \\
\hline
\end{tabular}

\subsection{Ecological Detention Pond Design Approach}

In many ways, detention ponds act as small reservoirs with simplified flow release controls. For example, detention ponds reduce alterations in runoff volumes and are typically designed based on a peak-flow value. This is analogous to flood control management in a reservoir system. Also, both impoundment types act as sediment 'stilling' basins for improving water quality in released water.

Although the reservoir-detention pond analogy works in many ways, there are also apparent differences between the two types of impoundments. Of particular interest in this study is the difference in the flow control options between a reservoir and a detention pond. A reservoir might have an extensive array of adjustable weirs, gates, and pipes for condition-sensitive releases, yet a standard detention pond outlet control structure (OCS) typically employs only a few types of control devices, such as weirs/spillways and riser pipes with orifices cut into the wall of the pipe. The placement of outlet controls (openings through which water can exit the pond) on the face of the OCS is the primary flow and storage regulation mechanism. The two most common kinds of outlet controls are a weir notch and an orifice. A weir is an overflow structure built 
perpendicular to the surface of the water, which can be used to measure and regulate the rate of flow, and a weir notch is an overflow section cut into the weir; an orifice is a welldefined, sharp-edged opening in a wall or bulkhead through which flow occurs (USBR 2001). Both weir notches and orifices are permanent flow release openings on the face of the structure and these outlet controls cannot be altered for condition-sensitive releases. A diagram of a detention pond and an OCS with a weir notch and multiple orifices is shown in Figure 4.2.

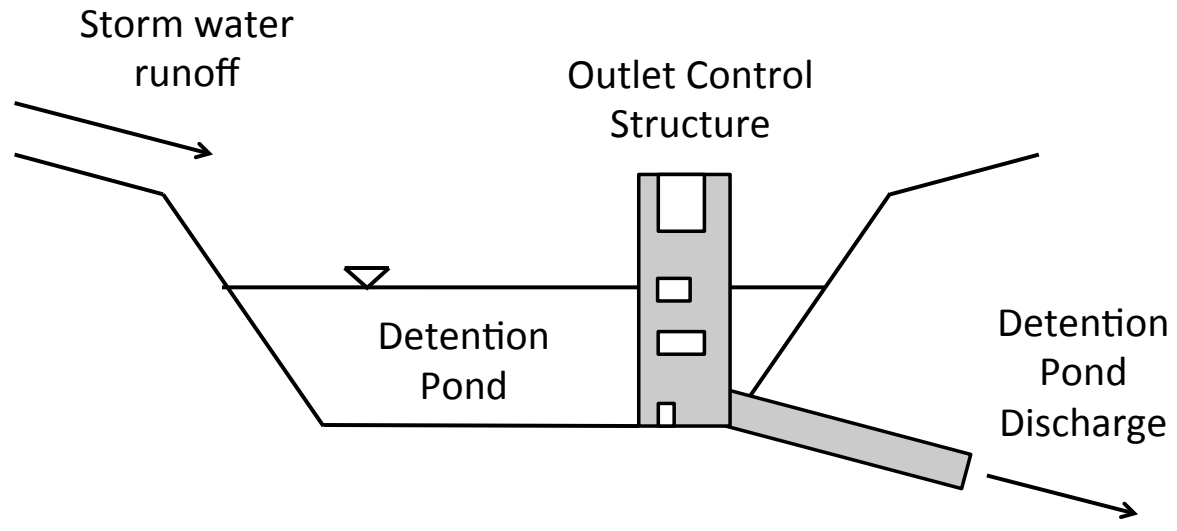

Fig.4.2. Storm water detention pond and outlet control structure

Since the outlet controls are stationary in time, release controls cannot be modified over time, such as has been done previously to create ecologically oriented reservoir outflows (Shiau and Wu 2010; Suen 2010). However, the reservoir-detention pond analogy can be used to motivate detention pond release operation policies for multiple downstream objectives using past and current research of ecologically oriented reservoir operations as an example. It seems plausible to extend the design of outlet control structures not only for the control of peak flows and sediment stilling, but also to 
reduce downstream ecological impairment through control of the detention pond discharge. To guide the "best" stationary OCS design for a range of storage and inflow conditions, an ecologically grounded approach must be used. One such approach is a design strategy that employs the ecodifference metric.

The proposed ecological detention pond design approach seeks to reduce ecological impairment in the receiving stream by decreasing the value of ecodifference. A reduction in ecodifference is accomplished by altering post-development outflows through the strategic sizing and placement of outlet controls (weirs and orifices) on the OCS wall. Furthermore, the traditional design criteria, such as controlling $\mathrm{T}_{\mathrm{WQ}}$ and peak flows for various $T_{R}$, must also be satisfied under the proposed design. A detention pond with this specially designed OCS can be termed an eco-detention pond.

The integration of three components is necessary to design an eco-detention pond: a hydrologic model, a detention pond model, and the ecodifference computations. The hydrologic model is used to simulate storm water runoff hydrographs for a number of short events, as well as for longer continuous simulations. The detention pond model is employed to route the storm water runoff through the detention pond and OCS, resulting in outflow hydrographs. The outflow hydrographs from the detention pond model are used to calculate the median annual and seasonal FDCs, which are needed to compute the eco-flow statistics and the ecodifference.

First, the hydrologic model is used to simulate event and continuous storm water runoff hydrographs for the pre-development scenario. The "pre-development" event storm water runoff hydrographs are used to determine the design criteria based on municipality regulations, and the pre-development continuous storm water runoff 
hydrograph is used to create the pre-development median annual and seasonal FDCs. Next, the hydrologic model is used to simulate event and continuous storm water runoff hydrographs for the uncontrolled post-development scenario. The continuous storm water runoff for the "uncontrolled post-development" case is routed through a detention pond model (with a specific combination of sizes and placements of outlet controls on the OCS) and a "controlled post-development" outflow hydrograph is created. The controlled post-development outflow values are then used to calculate the controlled postdevelopment median annual and seasonal FDCs.

From the pre-development and controlled post-development FDCs, the nine ecoflow statistics and the ecodifference are computed for the specific combination of outlet controls. Once a design that reduces ecodifference is determined, the controlled postdevelopment peak-flow values and $\mathrm{T}_{\mathrm{WQ}}$ are compared to the corresponding predevelopment values. If any of the values are unacceptable, the design is deemed unacceptable. A 'best trial' design is the trial design that has the lowest value of ecodifference while meeting each of the municipality design criteria.

The ecological benefits from the best trial design will be reported as a percentage difference in the value of ecodifference. The percentage reduction in ecodifference, termed the ecodifference Percent Reduction (EPR), is shown in (4.2):

$$
\mathrm{EPR}=100\left(\frac{\text { ecodifference }_{\text {eco }}-\text { ecodifference }_{\text {conv }}}{\text { ecodifference }_{\text {conv }}}\right)
$$

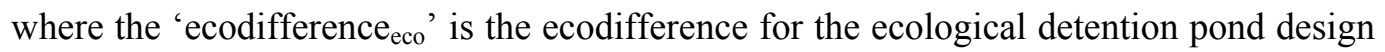
and 'ecodifference conv' ' is the ecodifference for the conventional detention pond design. 


\subsection{Case Study}

A 29-acre residential site development near Fort Collins, Colorado, was used as a case study site for demonstrating the use of the eco-detention pond design approach. The site was chosen because pre-development and post-development study site details and hydrologic input files for the study site are provided in the Storm Water Management Model Applications Manual (Gironas et al. 2010). This reduces the possibility of mistakes related to the hydrologic modeling portions of the methodology.

The case study site is being converted from pasture and forest into a residential development. The existing site is completely undeveloped with silt loam soil underlying mixed vegetation. The post-development scenario will consist of residential lots graded towards the streets with $2 \%$ slopes, and the streets and lots will follow the contours of the existing landscape. Runoff from the site will enter the storm water system through culverts located at various locations throughout the site and the water will be collected in a detention pond located at the outlet of the watershed. No areas outside of the 29-acre site will contribute water to the site or the detention pond. Displays of the predevelopment and post-development scenarios are shown in the Appendix (Figures A-1 and A-2, respectively). Further details regarding the case study site can be found in Chapter 1 of the Storm Water Management Model Applications Manual (Gironas et al. 2010).

The detention pond was designed with a length to width ratio of $2: 1$, a WQCV depth of 0.46 meters, a total depth of 1.83 meters, and a side slope of $4: 1(\mathrm{H}: \mathrm{V})$. The geometry of the detention pond was calculated using the methodology described in the

SWMM Applications Manual (Gironas et al. 2010), and thus, the geometry of the 
detention pond is the same as used in the Application Manual example. The OCS has a 1.83 meter height, corresponding to the total depth of the detention pond. The outlet controls on the OCS are one weir notch and three orifices. The orifices are assigned discharge coefficients of 0.65 and the weir is assigned a discharge coefficient of 3.3. Both the weir and the orifices are assumed to be rectangular in shape.

The detention pond design criteria are taken from SWMM User's Manual (Rossman 2009) and design guidelines published by the Denver Urban Drainage and Flood Control District (UDFCD 2001). The detention pond must reduce the postdevelopment peak release rates to their pre-development levels, as well as detain a water quality capture volume. Following most stormwater drainage manuals, the designers must demonstrate that the peak flows from the catchment are managed with respect to a series of synthetic design storms of different return periods (Gironas et al. 2010). The storms (2hour events with $T_{R}=2,10$, and 100 years) were selected by the City of Fort Collins to be used with SWMM (City of Fort Collins 1999). In addition to the peak flow criteria, the WQCV criterion requires release within 40 hours ( $\mathrm{T}_{\mathrm{WQ}}<40 \mathrm{hrs}$ ), during which a significant portion of particulate pollutants found in urban stormwater is removed (Akan and Houghtalen 2003; Gironas et al. 2010).

\subsection{Method}

In this research, the Storm Water Management Model (SWMM), Version 5.0 (Rossman 2009) was used as the hydrologic simulation model to generate outflow hydrographs from the contributing catchment that were then used as input into the detention pond model. SWMM is the most widely used storm water model (Obropta and 
Kardos 2007). SWMM can simulate overland flows, infiltration, groundwater interactions, and flow through BMPs for individual storm events or continuous (longterm) simulations. To facilitate multiple simulations, MATLAB (Mathworks 2011) was used to construct the detention pond model, as well as to calculate the FDCs, eco-flow statistics, and the ecodifference.

In addition to simulations of the three synthetic storms (events) used to calculate the peak flow and the $\mathrm{T}_{\mathrm{WQ}}$ for each design storm, a continuous simulation is required to calculate the FDCs for use in the eco-detention pond design approach. For the continuous simulation, continuous rainfall records from the city of Fort Collins were downloaded from the National Climatic Data Center (NCDC 2010) for a ten-year period (1968-1978). The reporting time step of the continuous rainfall record was 15 minutes (NCDC 2010). In order to reduce instabilities in the numerical simulations, the time step for the continuous simulation was set to one minute. Therefore, the precipitation value for each 15-minute interval was repeated 15 times, thus allowing the precipitation to be distributed over the smaller one-minute time steps. The simulation time step for the three synthetic storms was set to 15 seconds, corresponding to the time step length of the municipal design storm data (City of Fort Collins 1999).

Trial-and-error design was then used to determine the geometries of the outlet controls (one weir notch and three rectangular orifices) on the OCS. The sizing and placement of the outlet controls on the OCS are the only independent variables in this case study. The maximum width of all outlet controls is assumed to be 0.76 meters due to structural constraints. A conventional approach and an ecological approach were used to design the detention pond OCS. First, using the methodology described in the SWMM 
Applications Manual (Gironas et al. 2010), the conventional detention pond OCS was designed using only the peak flow and $\mathrm{T}_{\mathrm{WQ}}$ design criteria. In the conventional design methodology, each outlet device is designed to control one specific event criterion (for further details on the conventional design process, see Gironas et al. 2010). Next, a trialand-error process was used to modify the heights, widths, and elevations of the four outlet controls to find a design that results in the lowest value of ecodifference while meeting the peak flow and WQCV design criteria. This design can be termed the best trial ecological design.' The performance of the traditional and ecological detention ponds were then compared.

\subsection{Results}

The geometric details of the outlet controls on the OCS for the conventional detention pond and the best trial eco-detention pond are given in Tables 4.2 and 4.3, respectively. Table 4.4 summaries the results of the event simulations for the predevelopment and post-development scenarios. The first row of Table 4.4 shows the $\mathrm{T}_{\mathrm{WQ}}$ and peak discharges for the pre-development scenario. The pre-development peak discharge values were used as the post-development maximum peak flow criteria. The second and third rows show the event simulation results for the uncontrolled postdevelopment case and the post-development case with a conventional dry pond, respectively. The last row shows the post-development event results for the best trial ecological design. It can be seen that both the conventional and best trial ecological design meet the three peak flow criteria, as well as maintain $\mathrm{T}_{\mathrm{WQ}}$ less than 40 hours. 
Table 4.2. Characteristics of the conventional detention pond's Outlet Control Structure

\begin{tabular}{|c|c|c|c|c|}
\hline $\begin{array}{c}\text { Type of } \\
\text { Element }\end{array}$ & Shape & $\begin{array}{c}\text { Height } \\
(\mathrm{m})\end{array}$ & $\begin{array}{c}\text { Width } \\
(\mathrm{m})\end{array}$ & $\begin{array}{c}\text { Invert } \\
\text { Offset }(\mathrm{m})\end{array}$ \\
\hline Orifice & Rectangle & 0.07 & 0.08 & 0.00 \\
\hline Orifice & Rectangle & 0.15 & 0.45 & 0.46 \\
\hline Orifice & Rectangle & 0.08 & 0.55 & 0.68 \\
\hline Weir notch & Rectangle & 0.86 & 0.64 & 0.97 \\
\hline
\end{tabular}

Table 4.3. Characteristics of the eco-detention pond's Outlet Control Structure

\begin{tabular}{|c|c|c|c|c|}
\hline $\begin{array}{c}\text { Type of } \\
\text { Element }\end{array}$ & Shape & $\begin{array}{c}\text { Height } \\
(\mathrm{m})\end{array}$ & $\begin{array}{c}\text { Width } \\
(\mathrm{m})\end{array}$ & $\begin{array}{c}\text { Invert } \\
\text { Offset }(\mathrm{m})\end{array}$ \\
\hline Orifice & Rectangle & 0.37 & 0.09 & 0.00 \\
\hline Orifice & Rectangle & 0.26 & 0.05 & 0.37 \\
\hline Orifice & Rectangle & 0.22 & 0.03 & 0.68 \\
\hline Weir notch & Rectangle & 0.88 & 0.76 & 0.94 \\
\hline
\end{tabular}

Table 4.4. Event simulation results, including water quality release times, $T_{w a}$, and peak flows for each design storm

\begin{tabular}{|c|c|c|c|c|}
\hline \multirow[b]{2}{*}{ Simulation } & \multirow[b]{2}{*}{$\mathrm{T}_{\mathrm{wa}}$ (hrs) } & \multicolumn{3}{|c|}{ Peak Flows $\left(\mathrm{m}^{3} / \mathrm{s}\right)$} \\
\hline & & $2-y r$ & $10-y r$ & $100-y r$ \\
\hline Pre-Development & 4.90 & 0.12 & 0.21 & 0.89 \\
\hline Developed, No Control & 5.50 & 0.99 & 1.84 & 5.24 \\
\hline Developed, Conventional Pond & 38.78 & 0.12 & 0.21 & 0.88 \\
\hline Developed, Ecological Pond & 27.77 & 0.10 & 0.15 & 0.89 \\
\hline
\end{tabular}

Figure 4.3 exhibits the median annual and median seasonal flow duration curves constructed from the pre-development and post-development outflow hydrographs. In each frame of Figure 4.3, the black line is the FDC for the receiving stream before development occurs, the gray line is the FDC for the same stream after development occurs using a conventional OCS design, and the dotted line is the FDC for the receiving stream after development using the best trial ecological design. 

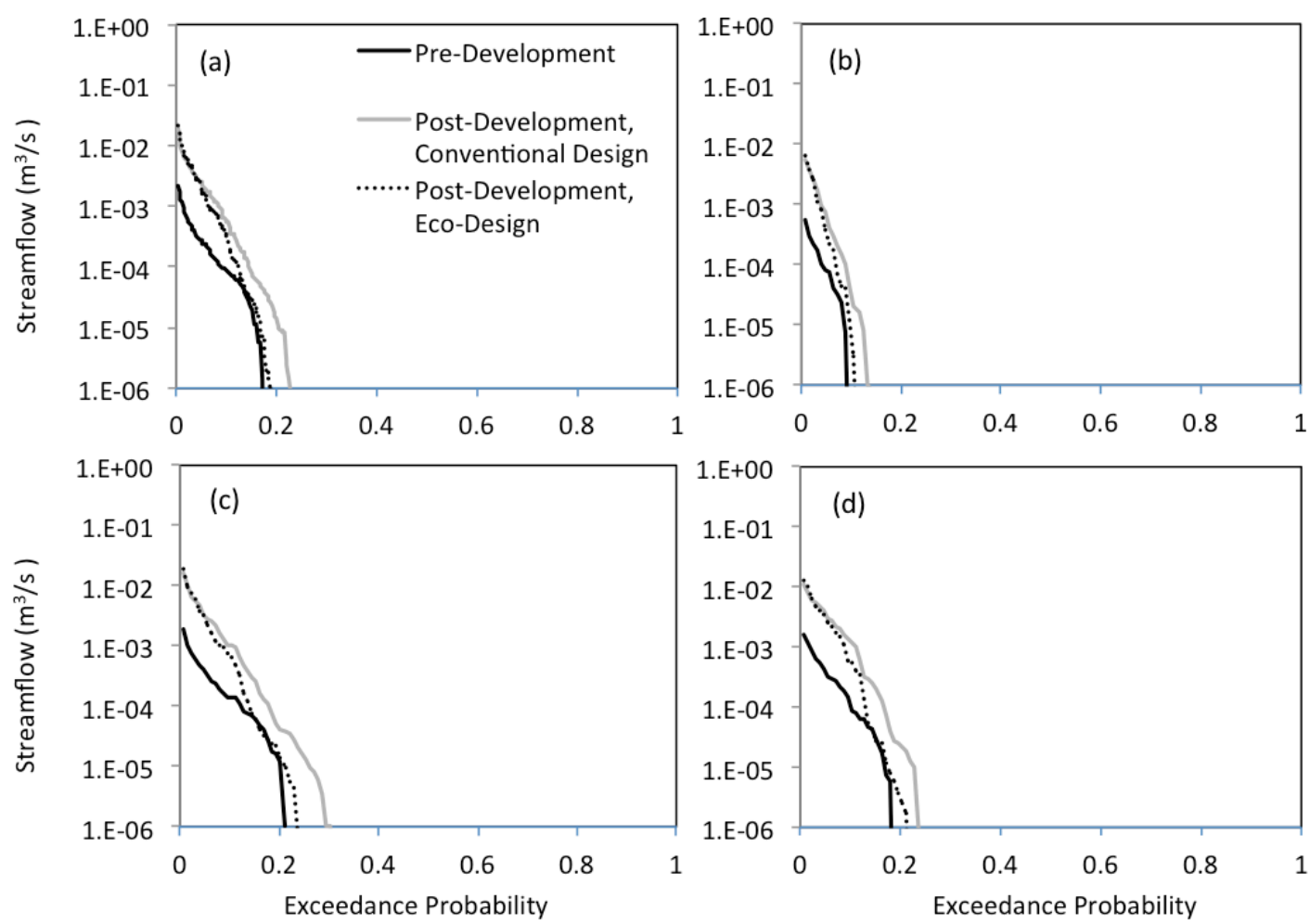

Fig. 4.3. Annual and Seasonal Flow Duration Curves for pre-development and postdevelopment scenarios: (a) Annual; (b) Winter; (c) Spring; (d) Summer

All three flow scenarios have zero values for exceedance probabilities greater than 0.25 , indicating that the site contributes no discharge to the receiving stream for more than $75 \%$ of the days. It can be seen that there is an abundance of ecosurplus, yet no ecodeficit, for both the conventional and ecological designs. This is to be expected, as increased imperviousness resulting from development decreases infiltration, reducing baseflow and increasing surface runoff, and thereby creating an ecosurplus. However, the ecological design has a smaller region between the pre-development and postdevelopment FDC curves as compared with the conventional design. Thus, for all four annual and seasonal results, the ecological design reduces the ecosurplus, thereby 
reducing the value of the ecodifference. The improvement is most prominent for the lower stream flow values.

Table 4.5 shows the values of nine eco-flow statistics for the conventional design and ecological design when a unit value is assigned for all nine weighting coefficients. Confirming the curves shown in Figure 4.3, there is no ecodeficit in either the annual or seasonal results. The greatest improvements are in the seasonal ecosurplus values, with the spring ecosurplus exhibiting the highest EPR of the nine statistics at 9.3\%.

Table 4.5. Values of nine eco-flow statistics using continuous simulation results

\begin{tabular}{|l|r|r|r|}
\hline & \multicolumn{2}{|c|}{ Design Type } & \\
\hline \multicolumn{1}{|c|}{ Eco-flow Statistic } & Conventional & Ecological & EPR (\%) \\
\hline Annual Ecodeficit & 0 & 0 & - \\
\hline Annual Ecosurplus & 0.20 & 0.20 & - \\
\hline Winter Ecodeficit & 0 & 0 & - \\
\hline Winter Ecosurplus & 0.26 & 0.24 & 6.4 \\
\hline Spring Ecodeficit & 0 & 0 & - \\
\hline Spring Ecosurplus & 0.22 & 0.19 & 9.3 \\
\hline Summer Ecodeficit & 0 & 0 & - \\
\hline Summer Ecosurplus & 0.20 & 0.19 & 6.2 \\
\hline Total Seasonal Ecochange & 0.67 & 0.62 & 7.9 \\
\hline
\end{tabular}

Finally, Table 4.6 shows the resulting ecodifference and EPR results for the four combinations of weighting coefficients given in Table 1. Using the trial-and-error method, the value of the ecodifference decreased from a score of 1.54 using the conventional design to a score of 1.44 using the best trial ecological design for weighting combination $\mathrm{A}$, a decrease from 1.13 to 1.05 for weighting combination $\mathrm{B}$, a decrease from 2.67 to 2.49 for weighting combination $\mathrm{C}$, and a decrease from 0.67 to 0.62 for weighting combination D. This translates to EPR scores of $6.3 \%, 6.9 \%, 6.6 \%$, and $7.3 \%$ 
for the four weighting combinations, respectively. Therefore, for all four weighting combinations, the ecological detention pond design is associated with decreased ecological impairment in the receiving stream, most prominently exhibited in seasonal ecosurplus and ecodeficit values (Combination D). It is also interesting to note that combinations $\mathrm{A}, \mathrm{B}$, and $\mathrm{C}$ produce similar ecodifference percentage reduction values. This result supports the assertion by Gao (2009) that the sub-set of three eco-flow statistics (total seasonal ecochange, summer ecosurplus, winter ecosurplus) explained the most variability in the IHA statistics and could possibly be used independently of the other six parameters to identify ecological impairment, and in this case, relative reductions in ecological impairment.

Table 4.6. Values of ecodifference for four weighting combinations

\begin{tabular}{|c|r|r|r|}
\hline \multirow{2}{*}{$\begin{array}{c}\text { Weighting Coefficient } \\
\text { Combination }\end{array}$} & \multicolumn{2}{|c|}{ ecodifference } & EPR (\%) \\
\cline { 2 - 4 } & Conventional Design & Ecological Design & \\
\hline A & 1.54 & 1.44 & 6.3 \\
\hline B & 1.13 & 1.05 & 6.9 \\
\hline C & 2.67 & 2.49 & 6.6 \\
\hline D & 0.67 & 0.62 & 7.3 \\
\hline
\end{tabular}

\subsection{Conclusions}

Use of the trial-and-error eco-detention pond design approach results in reductions in ecological impact without using additional outlet controls or violating either the maximum return period flows or maximum $\mathrm{T}_{\mathrm{WQ}}$. The constraint on the number of outlet controls in the ecological design was used to emphasize that reductions in ecologic impairment could be achieved by nothing more than adjusting the configuration of the existing outlet controls. It is anticipated that additional outlet controls could further reduce the ecodifference. An optimization routine to determine the design that minimizes 
the ecodifference can also be implemented into this approach and additional reduction resulting from the optimization would be expected. A simulation-optimization routine for optimal eco-detention pond design is explored in Chapter 5. 


\subsection{References}

Akan, A.O., and Houghtalen, R.J. (2003). Urban Hydrology, Hydraulics, and Stormwater Quality. John Wiley \& Sons, Inc, Hoboken, NJ.

Arthington, A.H., Bunn, S.E., Poff, N.L., and Naiman, R.J. (2006). "The challenge of providing environmental flow rules to sustain river ecosystems." Ecological Applications, 16(4), 1311-1318.

Bragg, O.M., Black, A.R., Duck, R. W., and Rowan, J. S. (2005). “Approaching the physical-biological interface in rivers: A review of methods for ecological evaluation of flow regimes." Prog. Phys. Geogr., 29, 506-531.

Carter, W.R. (1961). "Magnitude and frequency of floods in suburban areas." US Geological Survey Professional Paper 424-B: B9-11.

Cavendish, M.G., and Duncan M.I. (1986). "Use of the instream flow incremental methodology: a tool for negotiation." Environmental Impact Assessment Review, 6, 347-363.

Center for Watershed Protection (CWP) and Maryland Department of the Environment (MDE). (2009 revision, 2000 original). "Maryland Stormwater Management Design Manual (2009 revision).” Baltimore, Maryland.

(http://www.mde.maryland.gov/programs/water/stormwatermanagementprogram/ marylandstormwaterdesignmanual/pages/programs/waterprograms/sedimentandst ormwater/stormwater_design/index.aspx).

City of Fort Collins. (1999). "Memorandum: New Rainfall Criteria; Memorandum to Storm Drainage Design Criteria Users.” April 12, 1999, Utilities Department, Stormwater Division, Fort Collins, CO.

Edgerly, J.L. (2006). "Quantifying urban-induced flow regime alteration using mathematical models and hydrologic metrics." MS thesis, Colorado State University.

Gao, Y., Vogel, R.M., Kroll, C.N., Poff, N.L., and Olden, J.D. (2009). "Development of representative indicators of hydrologic alteration.” J. of Hydrology, 374, 136-147.

Gironas, J., Roesner, L.A., Rossman, L.A., and Davis, J. (2010). “A new applications manual for the Storm Water Management Model (SWMM)." Environmental Modelling \& Software, 25, 813-814.

Gove, N.E., Edwards, R.T., and Conquest, L.L. (2001). "Effects of scale on land use and water quality relationships." J. Am. Water Resour. Assoc., 37(6), 1721-1734.

Hall, M.J. (1984). Urban Hydrology. Elsevier applied science publishers, New York. 
Mathews, R., and Richter, B.D. (2007). "Application of the Indicators of Hydrologic Alteration Software in Environmental Flow Setting." J. Am. Water Resour. Assoc., 43(6), 1400-1413.

Matthews, R.C., Jr, and Bao, Y. (1991). "The Texas method of preliminary instream flow determination." Rivers, 2(4), 295-310.

Mathworks. (2011). MATLAB, version R2011b.

Milhous R.T., Updike, M.A., and Schneider, D.M. (1989). "Physical Habitat Simulation System Reference Manual-Version 2." Instream Flow Information Paper 26, USDOI Fish and Wildlife Services, Biology Report, 89(16).

National Climatic Data Center (NCDC). (2010). "Climate Data for the Nation", available at http://www.ncdc.noaa.gov/oa/ncdc.html

Nehrke, S.M., and Roesner, L.A. (2002). "Effect of detention and BMPs on flow frequency of runoff." Linking stormwater BMP designs and performance to receiving water impact mitigation, B. R. Urbonas, ed., ASCE, Reston, Va., 254265.

. (2004). "Effects of design practice for flood control and best management practices on the flow-frequency curve." J. Water Resour. Plann. Manage., 130(2): $131-139$.

National Water Information System (NWIS). (2010). USGS Surface-Water Data for the Nation, available at http://waterdata.usgs.gov/nwis/sw

Obropta, C.C., and Kardos, J. S. (2007). "Review of urban stormwater quality models: deterministic, stochastic, and hybrid approaches." J. Am. Water Res. Assoc., 43(6), 1508- 1523.

Olden, J.D., and Poff, N.L. (2003). "Redundancy and the choice of hydrologic indices for characterizing streamflow regimes." River Research and Applications, 19, 101121.

Palau, A., and Alcázar, J. (2010). "The basic flow method for incorporating flow variability in environmental flows." River Research and Applications. DOI: 10.1002/rra. 1439

Palhegyi, G. (2010a). "Designing stormwater controls to promote sustainable ecosystems: Science and application.” J. Hydrol. Eng., 15(6), 504-511.

Palhegyi, G. (2010b). "Modeling and Sizing Bioretention Using Flow Duration Control." J. Hydrol. Eng., 15(6), 417-425. 
Poff, N.L. (1996). "A hydrogeography of unregulated streams in the United States and an examination of scale-dependence in some hydrological descriptors." Freshwater Biology, 36, 71-91.

Poff, N.L., Allan, J.D., Bain, M.B., Karr, J.R., Prestegaard, K.L., Richter, B.D., Sparks, R.E., and Stromberg, J.C. (1997). "The natural flow regime." BioScience, 47(11), 769-784.

Pomeroy, C.A., Postel, N.A., O’Neill, P.A., and Roesner, L.A. (2008). "Development of storm-water management design criteria to maintain geomorphic stability in Kansas City metropolitan area streams.” J. Irrigat. Drain. Eng., 134(5), 562-566.

Puckridge, J.T., Sheldon, F., Walker, K.F. and Boulton, A.J. (1998). "Flow variability and the ecology of large rivers." Marine and Freshwater Research, 49, 55-72.

Reichold, L., Zechman, E.M., Brill, E.D., and Holmes, H. (2010). "SimulationOptimization Framework to Support Sustainable Watershed Development by Mimicking the Predevelopment Flow Regime." J. Water Resour. Plann. Manage., 136(3), 366-375.

Richter, B.D., Baumgartner, J., Powell, J., and Braun, D. (1996). "A method for assessing hydrologic alteration within ecosystems.' Conserv. Biol., 10, 1163-1174.

Richter, B.D., Baumgartner, J.V., Wigington, R., and Braun, D.P. (1997). "How much water does a river need?" Freshwater Biol., 37(1), 231-249.

Roesner, L.A., Bledsoe, B.P., and Brashear, R. W. (2001). "Are best-managementpractice criteria really environmentally friendly?" J. Water Resour. Plann. Manage., 127, 150-154.

Rohrer, C.A., and Roesner, L.A. (2006). "Matching the Critical Portion of the Flow Duration Curve to Minimize Changes in Modeled Excess Shear." Water Science and Technology, 54: 347-354.

Rossman, L.A. (2009). "Storm Water Management Model User's Manual Version 5.0." Rep. No. EPA/600/R-05/040.

Sansalone, J.J., and Cristina, C.M. (2004). "First flush concepts for suspended and dissolved solids in small impervious watersheds." J. Environ. Eng., 130(11), $1301-1314$.

Schueler, T. (1995). "Environmental Land Planning Series: Site Planning for Urban Streams Protection." Center for Watershed Protection Publication No. 95708, Metropolitan Washington Council of Governments, Washington, DC. 
Shiau, J., and Wu, F. (2004). "Assessment of hydrologic alterations caused by Chi-Chi diversion weir in Chou-Shui Creek, Taiwan: Opportunities for restoring natural flow conditions." River. Res. Appl., 20, 401-412.

. (2006). "Compromise programming methodology for determining instream flow under multiobjective water allocation criteria." J. Am. Water Resour. Assoc., 42(5), 1179-1191.

. (2010). "A dual active-restrictive approach to incorporating environmental flow targets into existing reservoir operation rules." Water Resour. Res., 46.

Suen, J.P., and Eheart, J.W. (2006). "Reservoir management to balance ecosystem and human needs: Incorporating the paradigm of the ecological flow regime." Water Resour. Res., 42(3), W03417.

Suen, J.P. (2010). "Determining the Ecological Flow Regime for Existing Reservoir Operation." Water Resources Management, 25(3), 817-825.

Tang, Z., Engel, B., Lim, K., Pijanowski, B., and Harbor, J. (2005). "Minimizing the impact of urbanization on long term runoff." J. Am. Water Resour. Assoc., 41, $1347-1359$.

U.S. Bureau of Reclamation (USBR). (2001). "Water Measurement Manual.” (http://www.usbr.gov/pmts/hydraulics_lab/pubs/wmm/index.htm).

United States Environmental Protection Agency (USEPA). (1991). "Construction site stormwater discharge control: an inventory of current practices." Rep. No. EPA/883/R-91/100.

. (1993). "Urban runoff pollution prevention and control planning." Rep. No. EPA/625/R-93/004.

. (2001). "Our Built and Natural Environments: A Technical Review of the Interactions between Land Use, Transportation, and Environmental Quality." Rep. No. EPA/231/R-01/002.

. (2004). "The Use of Best Management Practices (BMPs) in Urban Watersheds." Rep. No. EPA/600/R-04/184.

. (2006). "Dry Detention Ponds," Fact Sheet, National Menu of Best Management Practices, available at

http://cfpub.epa.gov/npdes/stormwater/menuofbmps/index.cfm

Urban Drainage and Flood Control District (UDFCD). (2001). “Urban Storm Drainage Criteria Manual, 2007 revision." Denver, CO. (http://www.udfcd.org/downloads/down_critmanual.htm). 
Urbonas, B., and Stahre, P. (1993). "Storm Water Best Management Practices and Detention for Water Quality, Drainage and CSO Management.” PTR Prentice Hall, New Jersey.

Villarreal, E.L., Semadeni-Davies, A., and Bengtsson, L. (2004). "Inner city stormwater control using a combination of best management practices." Ecological Engineering, 22(4-5), 279-298.

Virginia Department of Conservation and Recreation (VADCR). (2010). "Virginia Stormwater Handbook - Draft." Richmond, VA. (http://www.dcr.virginia.gov/lr2i.shtml).

Vogel, R.M., and Fennessey, N.M. (1994). "Flow duration curves I: a new interpretation and confidence intervals." J. Water Resour. Plann. Manage., 120(4).

Vogel, R.M., Sieber, J., Archfield, S.A., Smith, M. P., Apse, C.D., and Huber-Lee, A. (2007). "Relations among storage, yield, and instream flow." Water Resour. Res., $43(5)$. 


\section{Chapter 5}

\section{Simulation-Optimization Approach for the Design of Outlet Control Structures for Ecological Detention Ponds}

\subsection{Introduction}

Through the use of ecological flow methodologies, ecological functions can be more closely integrated into stormwater management, and into BMP design in particular. Ecological flow methodologies have been incorporated into a variety of ecological and water resources engineering applications (see Chapter 4 for details), yet only a few studies have coupled an ecological flow methodology, hydrologic simulation, and optimization for water resources engineering applications. The few that are available are directed at ecologically sustainable reservoir operations and land development. For example, reservoir operation models and ecological flow methodologies have been combined with an optimization routine to find reservoir operation policies that statistically reproduce the natural flow regime (Suen 2010; Shiau and $\mathrm{Wu} 2010$ ). Additionally, a simulation-optimization methodology has been used to identify the optimal development scenario in a watershed using hydrologic modeling and an 
ecological flow methodology (Reichold et al. 2010). However, this author has not found any studies that use ecological flow methodologies to guide ecologically optimal BMP design using a simulation-optimization construct.

This work develops a framework for the optimal design of a detention pond outlet control structure that attempts to minimize alteration to the natural flow regime - and thus ecological impairment - as defined by a contemporary ecological flow paradigm: the ecodifference metric, a weighted sum of the eco-flow statistics. This analysis merges modeling and optimization methods into a simulation-optimization methodology to find an outlet control structure design that minimizes the ecodifference. The methodology is demonstrated for a case study in order to illustrate the differences in ecosystem impacts between conventional and ecological detention pond designs and to demonstrate the advantages of employing this design construct. This work shows that an optimal design algorithm can be used to effectively and efficiently design outlet control structures for individual eco-detention ponds while meeting all existing municipality design criteria.

\subsection{Simulation-Optimization Methodology for OCS Design}

The weighted sum of the nine eco-flow statistics, termed the ecodifference, has been used to specify ecological impact resulting from hydrologic alteration; various combinations of weighting coefficients can be used to calculate the ecodifference according to the needs and preferences of the designers or water managers (Mobley and Culver, in review). In this study, an optimal design algorithm will be employed to minimize the ecodifference by strategic sizing and placement of outlet control openings on the OCS wall. 
The optimal design model to determine the size (height and width) and elevation of a series of rectangular outlet controls along the face of an eco-detention pond's OCS is formulated in equations (5.1) and (5.2):

$$
\begin{aligned}
& \text { minimize ecodifference }(\tilde{D})+\sum \mathrm{w}_{\mathrm{j}}\left(\mathrm{V}_{\mathrm{j}}\right) \\
& \text { subject to } \mathrm{L}_{\mathrm{k}}<\mathrm{D}_{\mathrm{k}}<\mathrm{U}_{\mathrm{k}} \quad \forall \quad \mathrm{k}
\end{aligned}
$$

where $\tilde{D}=$ is a matrix composed of vectors $D_{\mathrm{k}}$ which describe the opening characteristics for each rectangular outlet control device (k), consisting of height, width, and invert elevation; ecodifference $(\tilde{D})$ is the ecodifference, as defined by equation (4.1), resulting from an OCS with openings of characteristics $\tilde{D}$; j signifies the traditional design criteria based on municipality regulations, such as water quality control volumes and the control of peak flows of various return periods; $\mathrm{w}_{\mathrm{j}}\left(\mathrm{V}_{\mathrm{j}}\right)$ is the weighted violation of design criteria $\mathrm{j}$, where $\mathrm{V}_{\mathrm{j}}$ is a binary 'switch' that signifies adherence to (value 0 ) or violation of (value 1) design criteria $\mathrm{j}$, and $\mathrm{w}_{\mathrm{j}}$ is a 'weighted' penalty based on the percentage exceedance above the design criteria. For instance, a large penalty can be assigned if the violation is greater than $5 \%$ above the value of the design criteria, and a smaller penalty if the violation is less than $5 \%$ above the value of the design criteria. $L_{k}$ and $U_{k}$ are the lower and upper bounds, respectively, on the height, width, and invert elevation that can serve for outlet control $\mathrm{k}$.

A multi-step simulation-optimization methodology can be used to solve the formulation shown in equations $(5.1)-(5.2)$. A flowchart of the multi-step simulationoptimization methodology is given in Figure 5.1.

Step 1 (Simulation): A hydrologic model is used to simulate the daily runoff flow rates, hereafter called a 'flow series,' given precipitation input series for a series of 
synthetic storms (each related to a municipality design criteria), as well as for a continuous long-term (multi-year) period.

a) Pre-development continuous and synthetic storm flow series are first simulated given pre-development (and pre-detention pond) conditions.

b) The hydrologic model is then used to simulate continuous and synthetic storm flow series under post-development conditions that will be used as the daily pond inflow series in Step 4a.

Step 2 (Analysis): Median annual and seasonal flow duration curves (FDCs) are then derived from the continuous pre-development flow series from Step 1a.

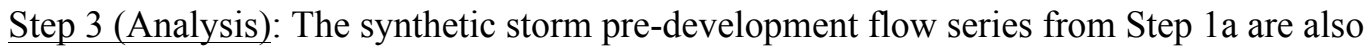
analyzed to quantify the site-specific BMP design criteria, such as maximum magnitudes of peak flows for design storms of particular return periods, required to satisfy regulatory standards.

Step 4 (Simulation-Optimization):

a) A reservoir (pond) routing model takes the continuous and synthetic storm post-development inflow series from Step $1 \mathrm{~b}$ and routes them through the ecodetention pond, given a potential OCS design.

b) Post-development median annual and seasonal FDCs are then derived from the resulting continuous outflow series in order to determine the nine eco-flow statistics for the eco-detention pond.

c) For each potential design, the nine eco-flow statistics - and then the ecodifference - are calculated by comparing the pre-development FDCs (Step 2) to that of the post-development FDCs (Step 4b). 
d) Peak flows and other values related to the municipality design criteria are calculated based on the synthetic storm outflow series.

e) Optimization systematically adjusts the locations and sizes of the outlet control devices on the OCS. The best OCS configuration is one that both minimizes the ecodifference while satisfying the requisite design criteria determined in Step 3. The ecological benefits from each design will be reported as a percentage difference in the value of ecodifference (EPR) as defined in equation (4.2). The optimal OCS design is the design with the lowest value of ecodifference, represented as ecodifference $\min _{\min }$

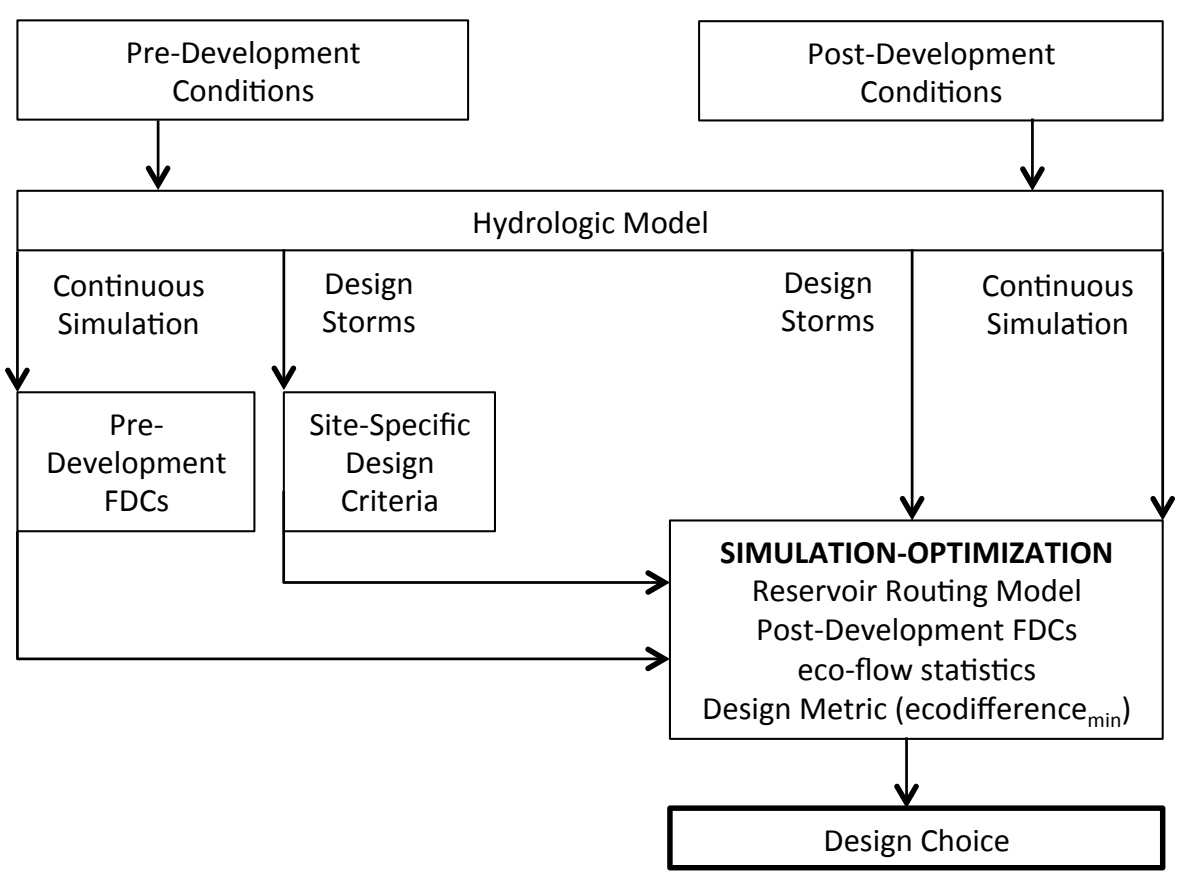

Fig. 5.1. Flowchart representing the simulation-optimization methodology 
The Storm Water Management Model (SWMM), Version 5.0, was used as the hydrologic simulation model. The simulation-optimization routine (in Step 4) was built using MATLAB and the MATLAB Global Optimization Toolbox (Mathworks 2011). The optimization method employed in this methodology is a form of Genetic Algorithm (GA) (Goldberg 1989). A GA is a probabilistic search method that uses techniques inspired by natural evolution, such as mutation, selection, and crossover, to generate solutions to optimization problems. In this analysis, the optimization utilizes the Augmented Lagrangian Genetic Algorithm (ALGA) to solve the nonlinear constraint problem (Conn et al 1991; Conn et al 1997). In the ALGA approach, bounds and linear constraints are handled separately from nonlinear constraints and the algorithm attempts to solve a nonlinear optimization problem with nonlinear constraints, linear constraints, and bounds. A subproblem is formulated by combining the fitness function and nonlinear constraint function using Lagrangian and penalty parameters, and a sequence of such optimization problems are approximately minimized using the GA such that the linear constraints and bounds are satisfied (Mathworks 2011).

\subsection{Illustrative Case Study}

The 29-acre residential site development near Fort Collins, Colorado, introduced in Chapter 4 is used to demonstrate the simulation-optimization design methodology. The same pre-development and post-development hydrologic conditions as those used in Chapter 4, including the design storms and continuous precipitation time series, were used in this work. The geometry of the detention pond also remained the same. Details regarding the case study site and precipitation input can be found in Chapter 4 of this 
thesis and Chapter 1 of the Storm Water Management Model Applications Manual (Gironas et al. 2010).

For use in the optimization problem, non-adherence to the municipality design criteria were incorporated into the fitness function as weighted violations (eq. 5.1). Penalties were added to the value of the design metric when the design storm outflow simulated using a potential OCS design exceeded the three peak flow criteria (peak flows resulting from synthetic design storms $T_{R}=2,10$, and 100 years) and/or the maximum Water Quality Capture Volume (WQCV) release criteria $\left(\mathrm{T}_{\mathrm{WQ}}\right)$ of 40 hours. A large penalty of 1.5 units was added to the ecodifference if the peak flow violation was greater than $5 \%$ above the value of the pre-development peak flow values or if the $\mathrm{T}_{\mathrm{WQ}}$ was above 41 hours, and a smaller penalty of 0.15 units was added if the peak flow violation was $0-5 \%$ above the value of the pre-development peak flow values or if the $\mathrm{T}_{\mathrm{WQ}}$ was between 40 and 41 hours. Additionally, a minimum WQCV release time was incorporated to assure removal of phosphorus from urban runoff, as well some settling of sediments in pond due to turbid inflow. A large penalty of 1.5 units was added when the $\mathrm{T}_{\mathrm{WQ}}$ was below 12 hours, since laboratory studies have confirmed that emptying times of dry detention ponds need to be greater than 12 hours for sufficient phosphorus removal (MWCOG 1987) and suspended sediment load removal ("Washington" 1983; Guo and Urbonas 1996). This penalty strategy strongly compelled the optimal design choice to adhere to the municipality design criteria.

Constraints on the optimization problem included upper and lower bounds on the height, width, and invert elevation that can serve for outlet control k (eq 5.2). Assuming that the structure is a rectangular hollow concrete box with dimensions 
$0.91 \mathrm{~m}$ (width):0.91m(depth): $1.83 \mathrm{~m}$ (height) - which is an appropriate conventional sizing of an OCS for the case study detention pond - the maximum width of all outlet controls was restricted to $0.76 \mathrm{~m}$ due to structural limitations. The invert elevation of any outlet control could be located anywhere along the height of the OCS face, and the height of each control was constrained to be no greater than the distance from the invert elevation to the top of the structure $(1.83 \mathrm{~m})$. Also, each outlet control design was permitted to have a height, width, and invert elevation of any value greater than or equal to zero. This allowed for the possibility of a zero solution for any outlet control. Additionally, only one overflow weir notch structure was permitted for each design. Finally, the design was constrained so that the outlet controls could not overlap in height. There was assumed to be no cost difference in the number and placement of the outlet controls during the structure construction phase, so all outlet control combinations were weighted as equally acceptable.

The conventional approach and the simulation-optimization methodology were used to determine the geometries of the outlet controls on the OCS. The sizing and placement of the outlet controls on the OCS are the only independent variables in this optimization problem. First, the conventional detention pond OCS was designed using only the peak flow and $\mathrm{T}_{\mathrm{WQ}}$ design criteria (see Chapter 4 for details). Next, the simulation-optimization methodology was used to determine the sizing and placement of the outlet controls for a variety of scenarios. The scenarios included variations on three design elements: (1) the total number of possible outlet controls; (2) weighting values for the nine eco-flow statistics used to calculate the ecodifference ( $\mathrm{W}_{\mathrm{i}}$, eq. 4.1$)$; and (3) weighted penalties for the violation of each of the design criteria based on the exceedance 
percentage $\left(\mathrm{w}_{\mathrm{j}}\right.$, eq. 5.1). Application of the simulation-optimization methodology produced an optimal solution (ecodifference ${ }_{\min }$ ) for each scenario. The performance of the conventional and optimized ecological detention ponds were then compared and discussed.

\subsection{Results}

For each of the scenarios explored, the genetic algorithm was performed five separate times using the settings shown in Table 5.1. A series of trials is necessary to represent the range of performance of the GA. On average, four out of the five trials produced the same solution; the scope of diversity in the trial solutions was small, with less than $1 \%$ difference between the minimum and maximum trial values of ecodifference in each of the scenarios explored.

Table 5.1. Parameter Settings for Genetic Algorithm

\begin{tabular}{lc}
\hline \multicolumn{1}{c}{ GA Parameter } & Setting \\
\hline \hline Population Size & 100 \\
Crossover & $80 \%$ \\
Mutation & Gaussian Distribution \\
Number of elite solutions & 2 \\
Function Tolerance & $1.00 \mathrm{E}-06$ \\
\hline
\end{tabular}

For each scenario, the design with the minimum optimal value of the five-trial series was chosen as the final 'best' solution for that scenario. Through initial testing of the GA for this problem, a population size of 100 individuals per generation was identified as sufficient to find an optimal solution. The GA uses the current population to create 'children' that make up the next generation through evolution rules such as 'elite' solutions, crossover, and mutation. The elite children were the two individuals with the 
best fitness values in the current generation that survived to the next generation. A crossover function, which combines two parents to form children for the next generation, was then used to determine $80 \%$ of the other 98 individuals.

The remaining nine individuals were determined using mutation. Mutations between generations were achieved by a Gaussian mutation function, which adds a random number taken from a Gaussian distribution to each entry of the parent vector. The Gaussian distribution was set with a mean value of 0 and a standard deviation of 1 . The algorithm was also set to shrink the standard deviation in each coordinate linearly until it reaches 0 (Mathworks 2011). The GA search was executed until the cumulative change in the fitness function value over 'stall' generations - defined as the number of generations since the last improvement of the fitness function - was below the function tolerance. The simulation-optimization routine typically required on the order of 5,200-5,600 solution evaluations and converged within 24 hours on a workstation with a dual-core 3GHz Intel dual-core Xeon cpu with 32GB of RAM. The convergence of one execution of the algorithm for an OCS with four openings and weighting combination A is shown in Fig. 5.2.

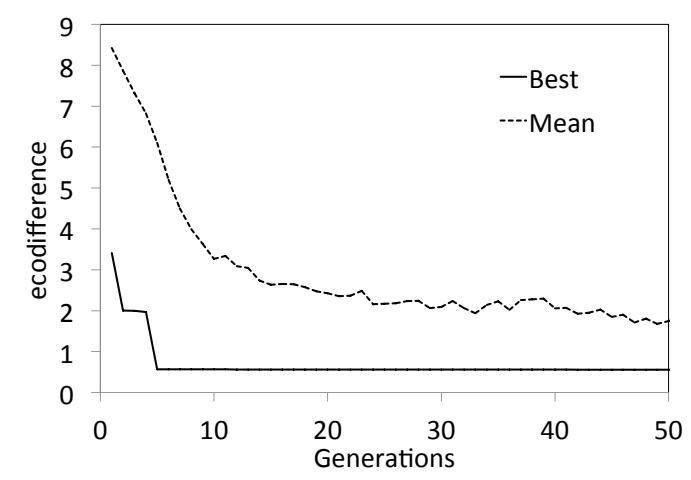

Fig. 5.2. Representative convergence of the genetic algorithm, showing the mean and best fitness value (ecodifference) identified per generation versus the number of generations. Results are for one trial with four openings and weighting combination A 
First, the simulation-optimization routine was used to identify which eco-flow statistics are most affected by the transition from a conventional design approach to an ecological simulation-optimization approach. This was accomplished by using the simulation-optimization methodology to identify the optimal value for each of the nine eco-flow statistics individually. For each of the nice eco-flow statistics, a series of trials was run where the eco-flow statistic of interest was assigned a weighting value of one and the other eight statistics a weighting value of zero. For a four-opening OCS, Table 5.2 shows the values of nine eco-flow statistics for the conventional design and 'best' optimal design, along with the corresponding EPR value. Note that all optimal designs referenced in Table 5.2 meet the three peak flow criteria, as well as maintain $\mathrm{T}_{\mathrm{WQ}}$ greater than 12 hours but less than 40 hours. Note that there are multiple designs that result in median annual or seasonal ecodeficits with a value of zero. The single eco-flow statistic that is most affected by the optimization is the spring ecosurplus, which exhibits the highest EPR of the nine statistics at $11.3 \%$. All three seasonal ecosurplus eco-flow statistics (and the total seasonal ecochange, the sum of the median seasonal ecosurpluses and ecodeficits) are prominently affected.

Table 5.2. Values of 9 eco-flow statistics when optimized individually; 4-opening OCS

\begin{tabular}{|l|r|r|r|}
\hline & \multicolumn{2}{|c|}{ Design Type } & \\
\hline \multicolumn{1}{|c|}{ Eco-flow Statistic } & \multicolumn{1}{c|}{ Conventional } & \multicolumn{1}{c|}{ Ecological } & EPR (\%) \\
\hline Annual Ecodeficit & 0 & 0 & - \\
\hline Annual Ecosurplus & 0.201 & 0.200 & 0.6 \\
\hline Winter Ecodeficit & 0 & 0 & - \\
\hline Winter Ecosurplus & 0.256 & 0.232 & 10.5 \\
\hline Spring Ecodeficit & 0 & 0 & - \\
\hline Spring Ecosurplus & 0.215 & 0.193 & 11.3 \\
\hline Summer Ecodeficit & 0 & 0 & - \\
\hline Summer Ecosurplus & 0.199 & 0.182 & 9.3 \\
\hline Total Seasonal Ecochange & 0.670 & 0.621 & 9.0 \\
\hline
\end{tabular}


Next, the conventional design was compared to optimal ecological designs for a variety of design scenarios. The geometric details of the outlet controls for the conventional detention pond are given in Table 4.2. The conventional design consists of four outlet controls (one weir and three orifices), each designed to regulate flows for a single design criteria. For comparison, the simulation-optimization methodology was used to design outlet control structures with different numbers of openings $(2,4,6$, and 8$)$ under the four weighting combinations. The values of minimum ecodifference and EPR for the best optimal design in each scenario are displayed in Table 5.3. The optimal ecodifference values can be compared against the ecodifference for the conventional design ('Conv') shown in the third column of the table. Again, the designs referenced in Table 5.3 meet the three peak flow criteria, as well as maintain $12<\mathrm{T}_{\mathrm{WQ}}<40$ hours.

Table 5.3. Minimum ecodifference and corresponding EPR values for four weighting combinations (A-D)

\begin{tabular}{|c|c|c|c|c|c|c|}
\hline & & \multicolumn{4}{|c|}{ Number of Openings } \\
\hline & & Conv & 2 & 4 & 6 & 8 \\
\hline \multirow{2}{*}{ A } & ecodifference $_{\min }$ & 1.542 & 1.444 & 1.442 & 1.436 & 1.436 \\
\hline & EPR (\%) & - & 6.4 & 6.5 & 6.8 & 6.8 \\
\hline \multirow{2}{*}{ B } & ecodifference $_{\min }$ & 1.126 & 1.048 & 1.047 & 1.046 & 1.038 \\
\hline & EPR (\%) & - & 6.9 & 7.0 & 7.1 & 7.8 \\
\hline \multirow{2}{*}{ C } & ecodifference $_{\min }$ & 2.668 & 2.491 & 2.490 & 2.491 & 2.483 \\
\hline & EPR (\%) & - & 6.6 & 6.7 & 6.6 & 6.9 \\
\hline \multirow{2}{*}{ D } & ecodifference $_{\min }$ & 0.670 & 0.621 & 0.621 & 0.621 & 0.616 \\
\hline & EPR (\%) & - & 7.3 & 7.4 & 7.4 & 8.2 \\
\hline
\end{tabular}

For each scenario shown in Table 5.3, the value of ecodifference was reduced from the conventional design scenario, which is seen as positive values of EPR. The 
results verify that the addition of more outlet controls results in an equal or greater value of EPR. However, the results indicate that there is actually little ecological flows benefit derived from the incorporation of additional outlet controls. Surprisingly, the results of the optimizations show that when properly sized and placed, only two outlet controls not four - are sufficient to not only meet the design criteria, but also to reduce the ecodifference (between $6.4 \%$ and $7.3 \%$, depending on the weighting combination). Figure 5.3 shows a representation of the conventional OCS design, and Figure 5.4 shows an ecological OCS Design optimized for two openings and weighting combination A. The ecological design in Figure 5.4 meets all design criteria and offers a $6.4 \%$ ecodifference reduction as compared with the conventional OCS design.

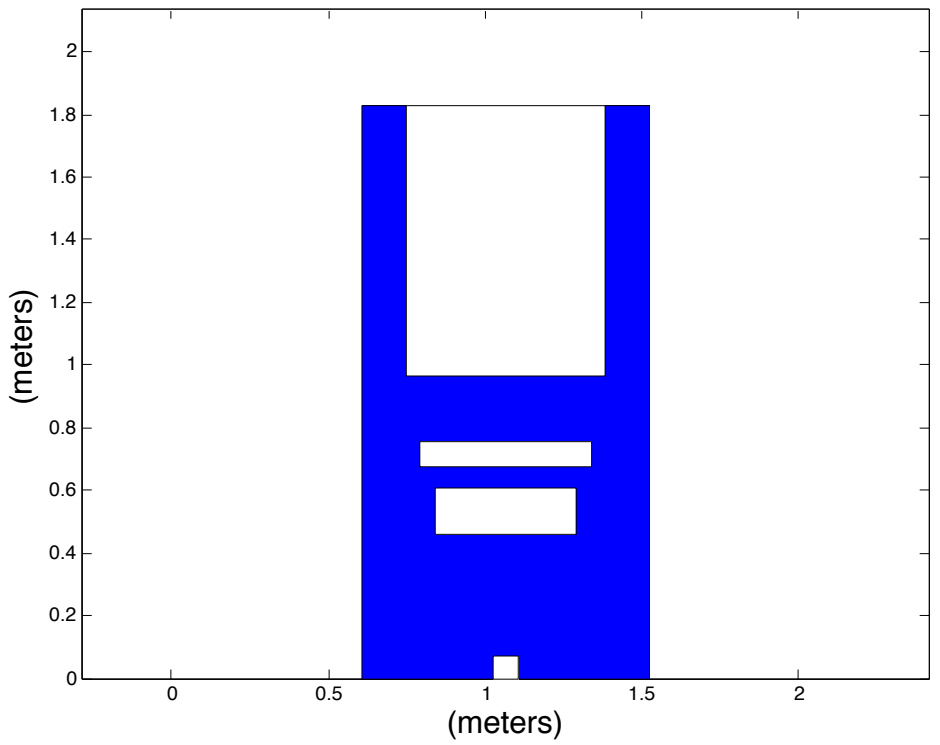

Fig. 5.3. Conventional OCS Design 


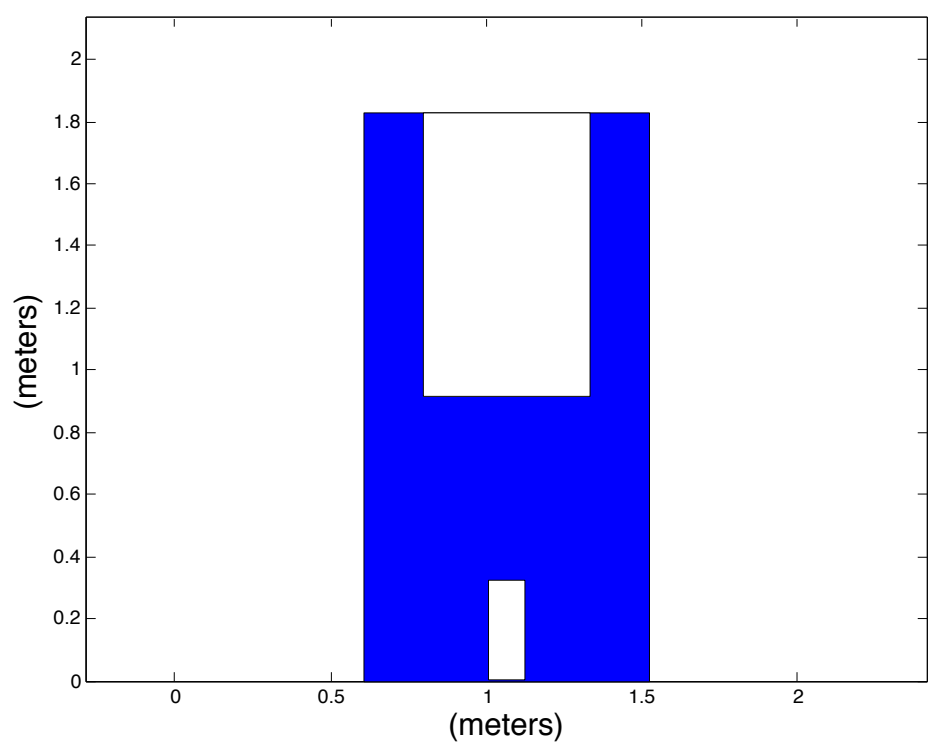

Fig. 5.4. Optimized Ecological OCS Design with two openings and under weighting combination A

Lastly, Table 5.4 shows the ecodifference ${ }_{\min }$ and corresponding EPR values for a four-outlet structure under four weighting combinations using three different design criteria violation conditions. The violation designation 'All' in Table 5.4 refers to the incorporation of all four design criteria in determination of the optimal solution. This is the design condition used in the earlier results. From a modeling perspective, the weighted violation for each design criteria is active, or "switched on," for those scenarios. The designation 'WQCV/100-yr' in Table 5.4 refers to the incorporation of only the two extreme design criteria (the water quality criteria and the overflow criteria) into the optimization, while 'None' means that none of the design criteria are incorporated. Thus, only the WQCV and 100-yr weighted violations were active in the optimization for the former scenarios, while no design criteria violations were active in the latter scenarios. In the 'WQCV/100-yr' scenarios, and particularly in the 'None' scenarios, the optimization 
could more freely seek a design that results in the closest match to the pre-development FDC without consideration of multiple discrete design limitations.

Table 5.4. Minimum ecodifference and corresponding EPR values for four weighting combinations under three violation conditions; four-opening OCS

\begin{tabular}{|c|c|c|r|}
\hline $\begin{array}{c}\text { Weighting } \\
\text { Combination }\end{array}$ & $\begin{array}{c}\text { Active Violation } \\
\text { Conditions }\end{array}$ & ecodifference $_{\min }$ & EPR (\%) \\
\hline \multirow{3}{*}{ A } & ALL & 1.442 & 6.5 \\
\cline { 2 - 4 } & WQCV/ 100-yr & 1.442 & 6.5 \\
\cline { 2 - 4 } & NONE & 1.442 & 6.5 \\
\hline \hline \multirow{3}{*}{ B } & ALL & 1.047 & 7.0 \\
\cline { 2 - 4 } & WOCV/ 100-yr & 1.038 & 7.8 \\
\cline { 2 - 4 } & NONE & 1.038 & 7.8 \\
\hline \hline \multirow{3}{*}{ C } & ALL & 2.490 & 6.7 \\
\cline { 2 - 4 } & WQCV/ 100-yr & 2.484 & 6.9 \\
\cline { 2 - 4 } & NONE & 2.484 & 6.9 \\
\hline \hline \multirow{3}{*}{ D } & ALL & 0.621 & 7.4 \\
\cline { 2 - 4 } & WOCV/ 100-yr & 0.619 & 7.7 \\
\cline { 2 - 4 } & NONE & 0.617 & 7.9 \\
\hline
\end{tabular}

In comparison to the other weighting combinations, the combination D scenarios show the largest ecodifference percent reductions, ranging from 7.4-7.9\%. This implies that optimization is most effective in detecting designs that reduce seasonal flow alterations. This finding supports the results of the individual eco-metric optimizations displayed in Table 5.2, where optimal winter, spring, and summer ecosurplus values ranged from $9.3-11.3 \%$.

As expected, there is some improvement for all weighting combinations when the number of design criteria is reduced. However, the reduction in EPR is not drastic. In this case study, the results suggest that the explicit design criteria assigned by the 
municipality do not significantly affect the optimal solution. Appendix B shows similar impacts of changes in the design criteria for outlet control structures with six or eight openings.

\subsection{Conclusions}

This work demonstrates the integration of the ecodifference metric within a simulation-optimization framework to identify outlet control structure designs that will reduce the alteration in the natural flow regime - and thus the ecological impairment - for a well-documented and realistic case study. The implementation of user-designated weights for design criteria violations, as well as for calculation of the design metric (ecodifference), allows for the exploration of potential solutions for different management options. This flexibility is important when applying this framework to a number of diverse sites with different municipality requirements and climate/terrain features.

The use of this simulation-optimization design approach results in reductions in ecological impairment for a variety of scenarios without violating either the maximum return period flows or minimum/maximum $\mathrm{T}_{\mathrm{WQ}}$. The results suggest that the design approach can be used to significantly reduce the values of the eco-flow statistics individually or when summed as a weighted ecodifference. In this case study, the explicit design criteria assigned by the municipality do not significantly affect the optimal solution. Also, additional outlet controls do not substantially reduce the ecological impairment to the receiving stream. In fact, the results of the optimization indicate that when properly sized and placed, only two outlet control devices - rather than the four 
proscribed by the conventional design approach - will be sufficient to both meet the design criteria and reduce the downstream ecological impairment. Finally, and possibly most importantly, this framework presents a fully automated way to design an outlet control structure without necessitating the conventional step-by-step design process for each outlet control on the OCS, which is time-consuming and has the potential for human error.

Although the focus for this work was to develop an ecologically sustainable design methodology for dry detention ponds, the ecological-flow-based optimal design construct could also be applied to other BMPs that store water and have control release features, such as bioretention systems, bioinfiltration systems, and wet ponds. Overflow outlets for large events could be designed directly analogous to the multiple outlet approach described above for a dry pond. Furthermore, other design features of these facilities, such as the number, type, and sizing of soil layers in a bioretention facility, could be designed to attenuate outflows in a way that reduces the ecological impact, as measured by the ecodifference, to the lowest possible extent.

The optimal eco-detention pond design found using the simulation-optimization approach provides significant improvement for the lower stream flow values, though less improvement at the higher stream flow values. The dry detention pond and corresponding outlet control structures are limited in this regard. However, other BMPs could be used to attenuate the high stream flow values at pre-development levels, and a series of BMPs each focused on one part of the FDC (e.g. low or high stream flows) - could be used to reduce the ecodifference more than a single BMP alone. Future explorations should consider this possibility. Thus, the flexibility and generality of this concept has far- 
reaching potential for a variety of ecologically sustainable BMP design techniques and for systems of sustainable BMPs. 


\subsection{References}

Conn, A. R., Gould, N.I.M., and Toint, P.L. (1991). "A Globally Convergent Augmented Lagrangian Algorithm for Optimization with General Constraints and Simple Bounds." SIAM Journal on Numerical Analysis, 28(2), 545-572.

Conn, A. R., Gould, N.I.M., and Toint, P.L. (1997). "A Globally Convergent Augmented Lagrangian Barrier Algorithm for Optimization with General Inequality Constraints and Simple Bounds." Mathematics of Computation, 66(217), 261288.

Gironas, J., Roesner, L.A., Rossman, L.A., and Davis, J. (2010). "A new applications manual for the Storm Water Management Model (SWMM)." Environmental Modelling \& Software, 25, 813-814.

Goldberg, D. E. (1989). Genetic algorithms in search, optimization, and machine learning. Addison-Wesley, Reading, Mass.

Guo, J. C. Y., and Urbonas, R. B. (1996). "Maximized detention volume determined by runoff capture ratio." J. Water Resour. Plann. Manage., 122(1), 33-39.

Mathworks. (2011). "Description of the Nonlinear Constraint Solver, Mathworks R2011b Documentation: Global Optimization Toolbox", as found on February 5, 2012, at http://www.mathworks.com/help/toolbox/gads/bqf8bdd.html

Mobley, J.T., and Culver, T.B. (in review). "Design of Outlet Control Structures for Ecological Detention Ponds.” J. Water Resour. Plann. Manage.

Metropolitan Washington Council of Governments (MWCOG). (1987). "Controlling Urban Runoff: A Practical Manual for Planning and Designing Urban BMPs."

Reichold, L., Zechman, E.M., Brill, E.D., and Holmes, H. (2010). "SimulationOptimization Framework to Support Sustainable Watershed Development by Mimicking the Predevelopment Flow Regime." J. Water Resour. Plann. Manage., 136(3), 366-375.

Shiau, J., and Wu, F. (2010). "A dual active-restrictive approach to incorporating environmental flow targets into existing reservoir operation rules." Water Resour. Res., 46.

Suen, J.P. (2010). Determining the Ecological Flow Regime for Existing Reservoir Operation. Water Resources Management, 25(3), 817-835.

"Washington Area NURP Project." (1983). Rep., Prepared for Metropolitan Washington Council of Governments, Occoquan Watershed Monitoring Laboratory, Manassas, Va. 


\section{Chapter 6}

\section{General Conclusions and Recommendations for Future Work}

\subsection{Conclusions}

This dissertation introduces new analysis and design techniques that will benefit comprehensive water resource management and modeling at both regional/state and local/neighborhood scales. This work is important to assist managers and designers in understanding the advantages, limitations, and possibilities of comprehensive hydrologic models so that they can be employed in the most effective ways.

Chapter two of this dissertation explored the novel use of seven IHA statistics for performance evaluation of a hydrologic simulation model under low flow conditions. For a case study in the CBP5 model domain, the results showed that the use of the CBP5 model for simulating low flow and extreme low flow events resulted in high volumetric error during those simulated events. The errors are most likely attributable to the limitations of "lumping" precipitation input, the omission of hydraulically relevant local structures, or insufficient emphasis on low flows in the current calibration. 
Recommendations before implementing the model for local scale water planning and management include: improved weather input and development of a 'nested' modeling capability that would allow community modelers to run a subwatershed of the Chesapeake Bay independently with locally updated information; incorporation of a flow routing model for complex discharge, transfer, and withdrawal simulations; and recalibration of the hydrologic model using a combination of statistics that will preserve predictions of contaminant loads to the Chesapeake Bay while also reproducing low flow events accurately.

Chapter 3 introduced a new concept called 'precipitation fidelity' to specifically assess the inter-relationships between estimated precipitation, observed stream flow, and model performance in a hydrologic model. Using two novel precipitation fidelity metrics, the Daily Precipitation Fidelity Index and the Annual Precipitation Fidelity Index, the results indicate that calibration of the model is directly linked to model performance, and that direct calibration of each subwatershed is necessary before implementing as a localscale water supply planning and permitting tool. The need for further calibration and implementation of new calibration measures for the hydrologic portions of the model is an important recommendation discussed in both Chapters 2 and 3 of this thesis.

Chapter 4 introduced a new design approach for the design of ecological detention ponds, and Chapter 5 incorporated an optimization routine into the design approach, resulting in a comprehensive simulation-optimization methodology for designing the BMPs. The results show that reductions in ecological impairment can be achieved for a variety of scenarios without violating municipality design criteria. The results further suggest that this methodology presents designers with an automated approach to 
identifying OCS designs that meet municipality design criteria while both decreasing the downstream ecological impairment and reducing the necessary number of outlet controls on the structure.

\subsection{On-going and Future Research}

Utilization of CBP5 as a water supply planning and management model. In order to alleviate model errors resulting from oversimplification of complex discharge, transfer, and withdrawal simulations in the CBP5-HSPF model, the VaDEQ is currently developing and testing a new state-wide surface water modeling platform to evaluate the impacts of surface water withdrawal and discharge permits on water resources throughout the Commonwealth of Virginia. The framework, called WOOOMM (Web Online ObjectOriented Meta-Model framework), incorporates a flow routing model that can be used in conjunction with CBP5-HSPF, where the surface runoff and groundwater (hydrology) portion of the CBP5-HSPF model is integrated with the reservoir operation and flow routing simulation provided by WOOOMM. The framework couples storage-discharge with Manning's equation and incorporates the ability to integrate a complex reservoir management rule-based system. Since only larger reservoirs were incorporated into the CBP5-HSPF model, initial results show that the integration of this framework with the CBP5 model is effective in reducing stream flow model error in areas where small upstream reservoirs were not modeled in CBP5 (e.g. areas downstream of Sugar Hollow Reservoir in the Mechums River watershed).

Simulation-Optimization Methodology for Eco-BMPs. The ecological simulation

- optimization design approach presented in Chapters 4 and 5 lays the groundwork for 
improving contemporary stormwater management design practice. Considering the novelty and initial success of this approach, there are many future research possibilities. The ecological focus and simulation-optimization approach outlined in this thesis can be extended to other BMPs, such as infiltration trenches and bioretention systems. Additionally, it would also be useful to explore a watershed composed of multiple subcatchments being prepared for future development. The ecological simulationoptimization framework could be utilized for the design of a BMP individually, as well as for a series of BMPs discharging to the outlet of the watershed, introducing a variety of research questions, such as: (1) How different are the designs of the individual structures when optimizing individually versus optimizing for a series of BMPs?; (2) How does the ecodifference at each subcatchment discharge location change between individual and watershed optimizations? What are the ecological implications of this?; and (3) What is more important to optimize: releases from individual subcatchments or release from the entire watershed? How can the trade-offs between the two strategies be quantitatively evaluated? 


\section{Appendix A}

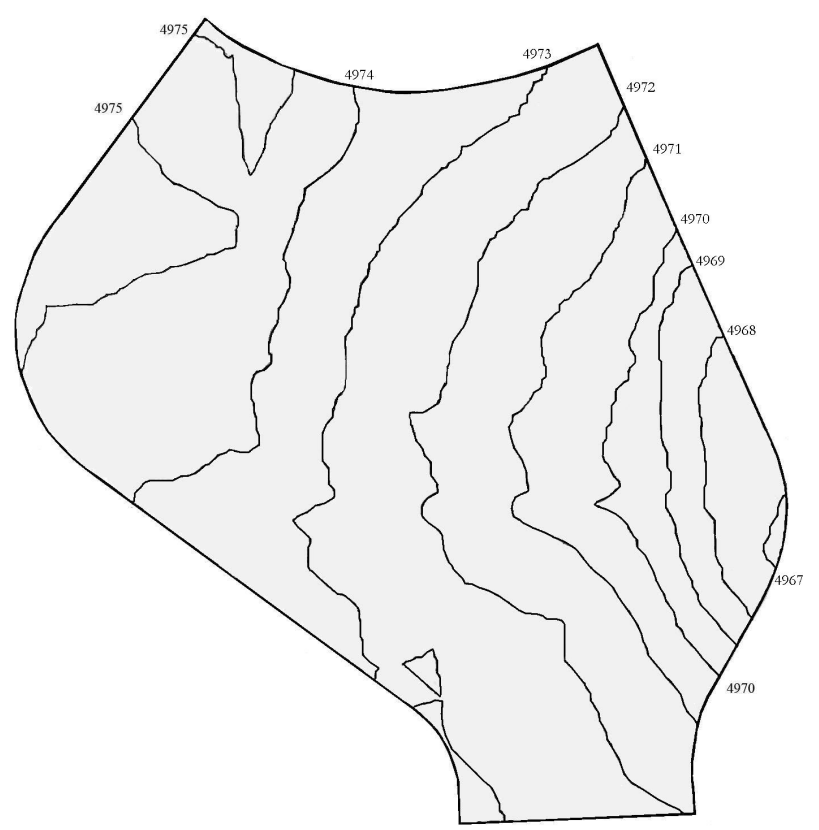

Fig.A-1. Pre-Development conditions (from Gironas et al. 2010)

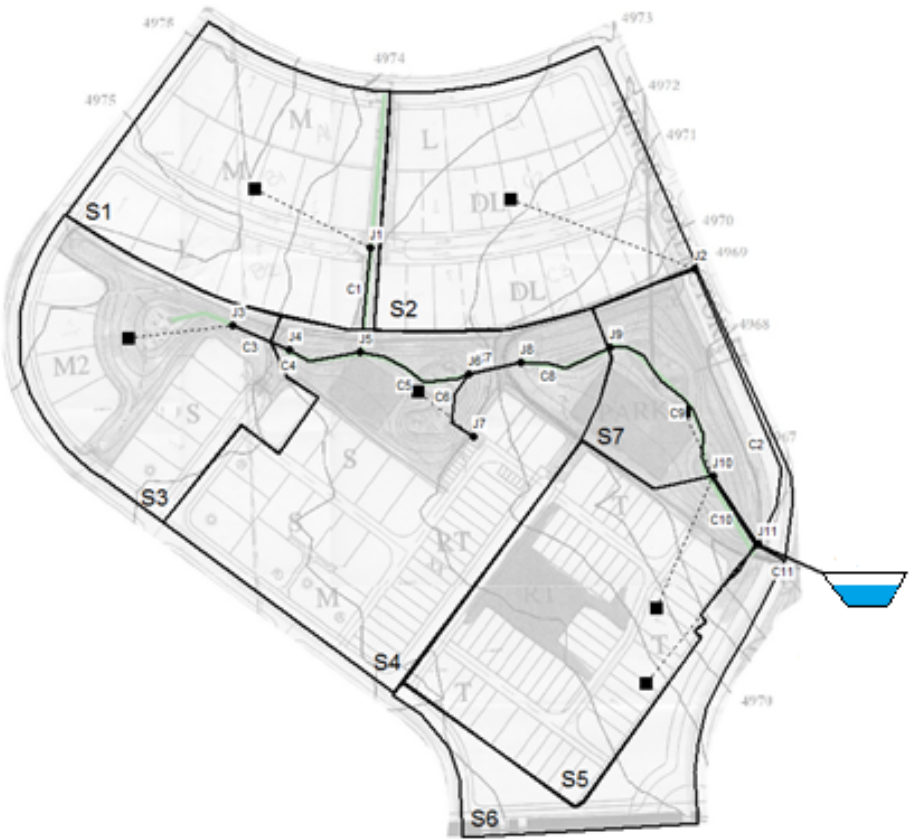

Fig.A-2. Post-Development conditions and location of detention pond (adapted from Gironas et al. 2010) 


\section{Appendix B}

Table B-1. Minimum ecodifference and corresponding EPR values for four weighting combinations under three constraint conditions; six-opening OCS

\begin{tabular}{|c|c|c|r|}
\hline $\begin{array}{c}\text { Weighting } \\
\text { Combination }\end{array}$ & Active Constraints & ecodifference $_{\text {min }}$ & EPR (\%) \\
\hline \multirow{3}{*}{ A } & ALL & 1.436 & 6.8 \\
\cline { 2 - 4 } & WQCV/ 100-yr & 1.436 & 6.8 \\
\cline { 2 - 4 } & NONE & 1.436 & 6.9 \\
\hline \hline \multirow{3}{*}{ B } & ALL & 1.046 & 7.1 \\
\cline { 2 - 4 } & WQCV/ 100-yr & 1.039 & 7.7 \\
\cline { 2 - 4 } & NONE & 1.039 & 7.7 \\
\hline \hline \multirow{3}{*}{ C } & ALL & 2.491 & 6.6 \\
\cline { 2 - 4 } & WQCV/ 100-yr & 2.476 & 7.2 \\
\cline { 2 - 4 } & NONE & 2.476 & 7.2 \\
\hline \hline \multirow{3}{*}{ D } & ALL & 0.621 & 7.4 \\
\cline { 2 - 4 } & WQCV/ 100-yr & 0.620 & 7.5 \\
\cline { 2 - 4 } & NONE & 0.618 & 7.8 \\
\hline
\end{tabular}

Table B-2. Minimum ecodifference and corresponding EPR values for four weighting combinations under three constraint conditions; eight-opening OCS

\begin{tabular}{|c|c|c|r|}
\hline $\begin{array}{c}\text { Weighting } \\
\text { Combination }\end{array}$ & Active Constraints & ecodifference $_{\min }$ & EPR (\%) \\
\hline \multirow{3}{*}{ A } & ALL & 1.436 & 6.8 \\
\cline { 2 - 4 } & WQCV/ 100-yr & 1.436 & 6.8 \\
\cline { 2 - 4 } & NONE & 1.436 & 6.9 \\
\hline \hline \multirow{3}{*}{ B } & ALL & 1.038 & 7.8 \\
\cline { 2 - 4 } & WQCV/ 100-yr & 1.038 & 7.8 \\
\cline { 2 - 4 } & NONE & 1.040 & 7.6 \\
\hline \hline \multirow{3}{*}{ C } & ALL & 2.483 & 6.9 \\
\cline { 2 - 4 } & WOCV/ 100-yr & 2.476 & 7.2 \\
\cline { 2 - 4 } & NONE & 2.475 & 7.2 \\
\hline \hline \multirow{3}{*}{ D } & ALL & 0.616 & 8.2 \\
\cline { 2 - 4 } & WOCV/ 100-yr & 0.616 & 8.2 \\
\cline { 2 - 4 } & NONE & 0.616 & 8.2 \\
\hline
\end{tabular}

